\title{
Proceso de Identificación de Comportamiento de Comunidades Educativas Basado en Resultados Académicos
}

\author{
Pablo Cigliuti ${ }^{1,2,3}$ \\ Maestría en Tecnología Informática Aplicada en Educación. Universidad Nacional de La Plata. Argentina \\ 2. Grupo de Investigación en Sistemas de Información. Universidad Nacional de Lanús. Remedios de Escalada, Argentina \\ 3. Departamento de Ingeniería en Sistemas de Información. Universidad Tecnológica Nacional (FRBA). Argentina \\ pabcig@gmail.com
}

\begin{abstract}
Resumen-Los procesos de explotación de información se incorporan al ámbito educativo para ayudar a entender y mejorar tanto la enseñanza de los docentes como el aprendizaje de los alumnos. Entre estas cuestiones se destaca el análisis del comportamiento de comunidades educativas de forma tal de proveer al docente herramientas que ayuden a mejorar la enseñanza/aprendizaje. En este contexto, el presente trabajo tiene como objetivo proponer, estudiar y validar un proceso de explotación de información que permita identificar el comportamiento de comunidades educativas basado en resultados académicos.
\end{abstract}

Palabras Clave-Procesos de explotación de información, educación, análisis del comportamiento, comunidades educativas.

\section{INTRODUCCIÓN}

En esta sección se presenta el contexto general de este trabajo (sección A), luego se expone la síntesis del trabajo realizado (sección B), y se aborda la estructura del trabajo (sección C).

\section{A. Contexto General del Trabajo}

En esta sección se presentan las generalidades propias de la educación a distancia (sección A1), luego se aborda el contexto general de la explotación de información (sección A2), y finalmente se exponen las generalidades propias de la explotación de información educativa (sección A3).

\section{A1. Educación a Distancia}

[1] sostienen que tradicionalmente, nunca se había concebido una fórmula de enseñanza que no contemplara lo presencial, es decir, la coincidencia física en espacio y tiempo del maestro y el alumno. Así, a lo largo de la historia, los procesos educativos se basaban en la idea de que el contacto educador-educado era la actividad básica que posibilitaba una formación esencialmente oral, ayudada por un soporte escrito que podía presentar ciertas limitaciones.

A partir de la invención de la imprenta, la relación educativa, tradicionalmente considerada un asunto exclusivo entre maestro y alumno, incorporó un tercer elemento: los libros. La creación de los grandes sistemas escolares públicos, significó la generalización y la expansión de unas formas de enseñanza y aprendizaje basadas, lógicamente, en la acción de un maestro o maestros sobre un grupo de alumnos más o menos numeroso, en un espacio y en un tiempo concreto (la clase) y con el soporte de libros de texto. En tanto, la enseñanza universitaria no fue ajena a esta evolución.
A finales del siglo XIX, a causa de la disminución progresiva del precio del papel y la creación de los grandes servicios públicos de correos, aparecen las primeras fórmulas alternativas de enseñanza no presencial, concebidas entonces como enseñanza por correspondencia [2]. Todas ellas se basan en la concepción de que aquello que el maestro enseña oralmente (la lección magistral) puede ser sustituido por aquello que puede ser explicado sobre un soporte de papel impreso, pues al fin y al cabo, según esta visión prototípica y tradicional de la enseñanza a distancia, se trata de transmitir contenidos desde la mente del profesor hasta la del estudiante.

A medida que la tecnología fue evolucionando, fueron cambiando las modalidades de la educación a distancia utilizando diferentes soportes para lograr el objetivo: radiodifusión, televisión, videos, informática y telemática fueron algunas de ellas, hasta llegar a la actualidad con internet. Pues ahora la educación a distancia utiliza mayormente plataformas virtuales especialmente preparadas para la ocasión.

La educación a distancia y presencial tienen diferencias tangibles. En la educación a distancia el alumno y el profesor se encuentran separados físicamente y carecen de una interacción cara a cara. La educación a distancia es un sistema de enseñanza mediado por tecnología, donde el profesor y al alumno no comparten un espacio físico en común para llevar a cabo este proceso. Como principales características podemos mencionar [3]: (a) la separación alumno-profesor, (b) la utilización sistemáticas de medios y recursos tecnológicos, (c) el aprendizaje individual, (d) el apoyo de una organización de carácter tutorial y (e) la comunicación bidireccional.

En la educación a distancia la interacción alumno-profesor, en general, se hace por intermedio de recursos tecnológicos [4], donde la posibilidad de comunicarse con lenguaje gestual, corporal y oral, está dificultada. Estos recursos tecnológicos son diversos y han ido cambiando a lo largo del tiempo: correo postal, cassette y teléfono son alguno de los ejemplos. Con la aparición de la computadora personal, y mucho más adelante de internet, la tecnología utilizada como soporte para la educación a distancia ha ido evolucionando rápidamente. Actualmente los cursos de educación dictados a distancia se apoyan, en su mayoría, en Entornos Virtuales de Enseñanza y Aprendizaje (EVEAs). Estas plataformas, además de contener información de los participantes, cuentan también con herramientas que dan soporte a la comunicación entre alumnos (foros, mensajes, chats, repositorios de materiales de lectura, entre otros). Estos instrumentos generan gran cantidad de información [5]. 
Para [6] el aprendizaje es definido como un cambio estable en la conducta. Antes de aprender, un alumno no es capaz de lograr un objetivo y, luego del aprendizaje, será capaz de alcanzarlo. En este contexto, la evaluación es la herramienta que utilizan los docentes que les permite observar los avances en el desarrollo de las habilidades de conducta, los objetivos del programa y detectar los errores frecuentes evaluando la eficacia del programa de la materia propuesto. Sin embargo, las evaluaciones por sí mismas no permiten al docente diagnosticar las dificultades de aprendizaje de los alumnos y sus causas.

\section{A2. Explotación de Información}

En [7] se define el término explotación de información como el proceso de descubrir nuevas correlaciones, patrones y tendencias utilizando grandes cantidades de datos almacenados en repositorios, utilizando tecnologías de reconocimiento de patrones así como herramientas matemáticas y de estadística.

La Explotación de Información es una subdisciplina de los Sistemas de Información [8] que provee herramientas de análisis y síntesis para extraer conocimiento no trivial el cual se encuentra (implícito) en los datos disponibles en diferentes fuentes de información [9].

Un Proceso de Explotación de Información, puede ser definido como un conjunto de tareas relacionadas lógicamente [10] que son ejecutadas para lograr, desde un conjunto de información con un grado de valor para la organización, otro conjunto de información con un grado mayor de valor que el primero [11];[12].

En [13] se proponen los siguientes procesos de explotación de información: descubrimiento de reglas de comportamiento, descubrimiento de grupos, descubrimiento de atributos significativos, descubrimiento de reglas de pertenencia a grupos y ponderación de reglas de comportamiento o de pertenencia. El proceso de descubrimiento de reglas de comportamiento aplica cuando se requiere identificar cuáles son las condiciones para obtener determinado resultado en el dominio del problema. El proceso de descubrimiento de grupos aplica cuando se requiere identificar una partición en la masa de información disponible sobre el dominio de problema. El proceso de ponderación de interdependencia de atributos aplica cuando se requiere identificar cuáles son los factores con mayor incidencia (o frecuencia de ocurrencia) sobre un determinado resultado del problema. El proceso de descubrimiento de reglas de pertenencia a grupos aplica cuando se requiere identificar cuáles son las condiciones de pertenencia a cada una de las clases en una partición desconocida "a priori", pero presente en la masa de información disponible sobre el dominio de problema. El proceso de ponderación de reglas de comportamiento o de la pertenencia a grupos aplica cuando se requiere identificar cuáles son las condiciones con mayor incidencia (o frecuencia de ocurrencia) sobre la obtención de un determinado resultado en el dominio del problema, sean éstas las que en mayor medida inciden sobre un comportamiento o las que mejor definen la pertenencia a un grupo.

Cada proceso de explotación de información tiene asociado una familia de técnicas de minería de datos [14] que son útiles para descubrir los patrones de conocimiento que están siendo buscados. Varias de estas técnicas vienen del campo del Aprendizaje Automático [14].

Una vez que el problema de explotación de información es identificado, el Ingeniero de Explotación de Información selecciona la secuencia de procesos de explotación de información a ser ejecutados para resolver el problema de descubrimiento de patrones de conocimiento.

\section{A3. Explotación de Información Educativa}

La Explotación de Información Educativa (EIE) consiste en aplicar técnicas de minería de datos a los datos generados a partir de los procesos de enseñanza y aprendizaje. El objetivo es poder analizar este tipo de datos con el propósito de ayudar a resolver problemas de investigación educativa [15]. La EIE está relacionada con el desarrollo de métodos para explorar tipos únicos de datos en entornos educativos, utilizando estos métodos para comprender mejor a los estudiantes y los entornos en los que aprenden [16]. Por un lado el crecimiento tanto en software educativo como en bases de datos con información de los estudiantes, han creado un gran repositorio de datos, reflejando la forma en que los estudiantes aprenden [17]. Por otro lado, el uso de internet en la educación ha creado un nuevo contexto conocido como e-learning o educación basada en la web, en la cual se genera gran cantidad de información sobre la interacción enseñanza-aprendizaje [18]. La EIE busca usar estos repositorios de datos para comprender mejor a los estudiantes y profesores, y desarrollar aproximaciones computacionales que combinen datos y teoría para mejorar la forma en que se realiza la práctica.

La EIE se ha convertido en un área de investigación en los últimos años para los investigadores de todo el mundo abarcando temáticas como [19]:

- Educación Presencial: en este ámbito se transmiten conocimientos y habilidades basadas en el contacto cara a cara y también se estudia psicológicamente cómo el humano aprende (se han aplicado técnicas psicométricas y estadísticas a datos obtenidos desde los EVEAs, relacionados con el comportamiento y rendimiento de los estudiantes).

- Educación a Distancia y EVEAs: la educación a distancia soportada por EVEAs además de brindar aprendizaje en línea provee herramientas de comunicación, colaboración y administración (se han aplicado técnicas de minería web a los datos que estos sistemas guardan en archivos logs y base de datos sobre las actividades realizadas por los estudiantes).

- Tutoría Inteligente: consiste en sistemas que adaptan el aprendizaje a las necesidades de cada estudiante en particular (la explotación de información ha sido aplicada a los datos generados por estos sistemas, como los archivos de logs, modelos de usuarios, etc.).

Avalando el uso de explotación de información en el campo de la educación se han desarrollado experiencias tanto a [a] nivel internacional como a $[\mathrm{b}]$ nivel nacional:

[a] Desde una visión de marco teórico, en [20]; [21] se revisa la historia y las tendencias en el campo de la Explotación de Información Educativa. Se formulan reflexiones sobre el perfil metodológico de la investigación en EIE; y se discuten los cambios y tendencias llevadas por la comunidad. En particular, se discute el mayor énfasis en la predicción y el surgimiento de trabajo utilizando los modelos existentes para hacer descubrimiento de conocimiento en el ámbito educativo. Por otra parte, en [22] analizan la aplicación de explotación de información en los sistemas de enseñanza tradicionales. Se realiza una comparación de la explotación de información aplicadas a sistemas de e-learning con los de ecommerce. En un trabajo posterior [19] formulan una revisión bibliográfica sobre estudios relevantes realizados en EIE. Allí se describen los diferentes grupos de usuarios, tipos de entornos educativos y los datos que estos entornos generan. También se enumeran aplicaciones típicas de la explotación de 
información en el ámbito educativo mencionando las técnicas de minería de datos utilizadas. En [23] se describe un proceso para explotación de información de datos de e-learning, así como la forma de aplicar las técnicas de minería de datos a la obtención de reglas de comportamiento en el espacio virtual provisto por la plataforma Moodle.

Desde una visión de aplicativa, en [24] se clasifican a los estudiantes prediciendo su calificación final basándose en características extraídas de los logs de acceso al EVEA. Se diseñan una serie de patrones de clasificación y se comparan entre sí. En [25] se evalúan aplicaciones de e-learning a través de los datos generados por los estudiantes, proponiendo un acercamiento para detectar potenciales síntomas de baja performance en cursos de e-learning utilizando el proceso de descubrimiento de reglas. En [26] se presenta un caso de estudio en el cual, se utilizan procesos de explotación de información para predecir el abandono de estudiantes de una carrera de ingeniería luego del primer semestre de sus estudios, o antes de entrar a la carrera, e identifica los factores de éxito para esta carrera.

[b] En [27][28] se utilizan procesos de explotación de información para ayudar a los docentes a diagnosticar las dificultades de aprendizaje de los alumnos (y sus causas) relacionadas a sus errores en programación con base en un proceso de descubrimiento del conocimiento de tres pasos. En [28] se presenta una solución al problema de la selección del estilo de enseñanza utilizando el proceso de explotación de información de descubrimiento de grupos, para encontrar los patrones de estudiantes con características comunes partiendo de los datos de estilos de aprendizaje y personales, todos ellos relevados sobre cada individuo. Estos patrones de conocimiento descubiertos son utilizados para determinar el protocolo pedagógico, conforme a los descriptos por la Teoría Uno [29], que mejor aplica a cada estudiante. En [30][31] se aborda el estudio del abandono de los estudios universitarios en el nivel de pregrado buscando posibles causas de deserción, utilizando los procesos de explotación de información: descubrimiento de reglas y descubrimiento de atributos significativos para caracterizar el abandono e identificar las variables con mayor incidencia en la deserción, a partir de la información disponible en el Sistema SIU-Guarani [32]. En [33] se define una metodología basada en procesos de explotación de información: descubrimiento de reglas y descubrimiento de atributos significativos, que permiten al docente: (1) identificar los errores de aprendizaje de los alumnos en instancias evaluativas y (2) diagramar los conceptos enseñados en pos de minimizar, en tanto sea posible, dichos errores.

\section{B. Sintesis del Trabajo Realizado}

Durante el desarrollo de este trabajo se abordará la investigación de temas tales como los patrones de comportamiento de comunidades educativas, los procesos de explotación de información, la creación de procesos de explotación de información aplicables a la identificación de comportamientos sociales y la propuesta de procesos de identificación de patrones de comportamientos de poblaciones educativas utilizando explotación de información.

De este modo, y a partir de lo expresado, se espera arribar a la definición de procesos de explotación de información que permitan estudiar el comportamiento de los estudiantes a lo largo de un curso o una carrera. Y así, identificar y resolver distintos problemas asociados a la apropiación de los conceptos $\mathrm{y}$ al favorable desarrollo de la materia, brindando una herramienta que favorezca la comprensión del curso y la posibilidad de implementar medidas que permitan detectar alumnos con dificultades en el curso e intervenir de manera temprana, pudiendo corregir factores que impacten en el resultado de la cursada.

\section{Estructura del Trabajo}

En la sección "Estado de la Cuestión" se presenta una introducción general a la explotación de información, luego se abordan los diferentes procesos de explotación de información, se presentan los antecedentes de la explotación de información en el ámbito educativo, y se exponen diferentes casos de estudio.

En la sección "Problema" se abordan los problemas comunes relacionados con el rendimiento de los estudiantes tanto en la educación presencial como a distancia, luego se proponen las líneas de investigación con el objetivo de ayudar a resolver los problemas mencionados los diferentes procesos de explotación de información.

En la sección "Solución" se presentan los marcos de la solución propuesta y luego se plantea la solución a los problemas desarrollados en la sección anterior.

En la sección "Validación" se describen tres casos; el primero de ellos de Procesos de Identificación de Comportamiento de Recursantes Utilizando EVEAs, el segundo consiste en Identificación Conceptos Críticos de una Cursada, y por último Identificación de Contenidos Débilmente Apropiados por Estudiantes.

En la sección "Conclusiones" se exponen los aportes realizados por este trabajo y se presentan las futuras líneas de investigación.

\section{ESTADO DE LA CUESTIÓN}

En esta sección se presenta una introducción general a la explotación de información (sección A), luego se abordan los diferentes procesos de explotación de información (sección B), se presentan los antecedentes de la explotación de información en el ámbito educativo (sección C), y se exponen diferentes casos de estudio (sección D).

\section{A. Introducción General a la Explotación de Información}

Se denomina inteligencia de negocio al conjunto de estrategias y herramientas [34] enfocadas a la administración y creación de conocimiento mediante el análisis de datos existentes en una organización [35]. Involucra el uso de los datos de una organización para facilitarle a las personas que realizan la toma de decisiones estratégicas del negocio, la comprensión del funcionamiento actual y la anticipación de acciones para dar una dirección bien informada a la organización [36].

La explotación de información se ha definido como la búsqueda de patrones interesantes y de regularidades importantes en grandes masas de información [37]. Al hablar de explotación de información basada en sistemas inteligentes [38] se refiere específicamente a la aplicación de métodos de sistemas inteligentes, para descubrir y enumerar patrones presentes en la información. Los métodos basados en sistemas inteligentes [39], permiten obtener resultados de análisis de la masa de información que los métodos convencionales [40] no logran tales como: los algoritmos TDIDT (Top Down Induction Decision Trees), los mapas auto organizados (SOM) y las redes bayesianas. Se ha señalado la necesidad de disponer de procesos [41] que permitan obtener conocimiento [42] a 
partir de las grandes masas de información disponible [43], su caracterización [44] y tecnologías involucradas [45].

\section{B. Procesos de Explotación de Información}

Un proceso de explotación de información [10], puede definirse como un conjunto de tareas relacionadas lógicamente, que se ejecutan para lograr a partir de un conjunto de información con un grado de valor para la organización, otro conjunto de información con un grado de valor mayor que el inicial [11].

Cada proceso de explotación de información define un conjunto de información de entrada, un conjunto de transformaciones y un conjunto de información de salida. Un proceso de explotación de información puede ser parte de un proceso mayor que lo abarque o bien puede incluir otros procesos de explotación de información que deban ser incluidos en él, admitiendo una visión desde varios niveles de granularidad [12].

Identificado el problema de inteligencia de negocio y las técnicas de explotación de información, un proceso de explotación de información describe cuáles son las tareas que hay que desarrollar para que aplicando las técnicas de explotación a la información que se tenga vinculada al negocio se obtenga una solución al problema de inteligencia de negocio [46].

En este contexto [47] proponen la siguiente caracterización de los problemas de explotación de información asociados a los problemas de inteligencia de negocios:

[a] Descubrimiento de Reglas de Comportamiento: el proceso de descubrimiento de reglas de comportamiento (Fig. 1) aplica cuando se requiere identificar cuáles son las condiciones para obtener determinado resultado en el dominio del problema. Para el descubrimiento de reglas de comportamiento definidos a partir de atributos clases en un dominio de problema que representa la masa de información disponible, se propone la utilización de algoritmos de inducción TDIDT [28] para descubrir las reglas de comportamiento de cada atributo clase.

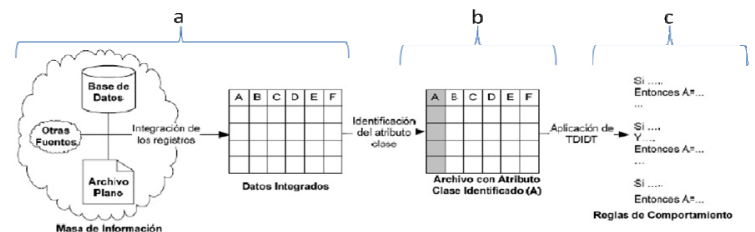

Fig. 1. Proceso de Descubrimiento de Reglas de Comportamiento.

Los pasos a seguir para este proceso consisten en:

a) Identificar todas las fuentes de información (bases de datos, archivos planos, entre otras), e integrarlas entre sí formando una sola fuente de información a la que se llamará datos integrados.

b) Seleccionar un atributo clase con base en los datos integrados.

c) Aplicar el algoritmo de inducción TDIDT al atributo clase. A partir de esto se obtiene un conjunto de reglas que definen el comportamiento de dicha clase.

[b] Descubrimiento de Grupos: se aplica cuando se requiere identificar una partición en la masa de información disponible sobre el dominio de problema. Para el descubrimiento de grupos, a partir de masas de información del dominio de problema sobre las que no se dispone ningún criterio de agrupamiento "a priori", se propone la utilización de Mapas Auto Organizados de Kohonen. El uso de esta tecnología busca descubrir si existen grupos que permitan una partición representativa del dominio de problema que la masa de información disponible representa. Este proceso y sus subproductos pueden ser visualizados gráficamente en la Figura 2 y consiste en:

a) Identificar todas las fuentes de información (bases de datos, archivos planos, entre otras), e integrarlas entre sí formando una sola fuente de información a la que se llamará datos integrados.

b) Aplicar mapas auto-organizados con base en los datos integrados. Como resultado de la aplicación de SOM se obtiene una partición del conjunto de registros en distintos grupos a los que se llamará grupos identificados.

c) Generar el archivo correspondiente para cada grupo identificado.

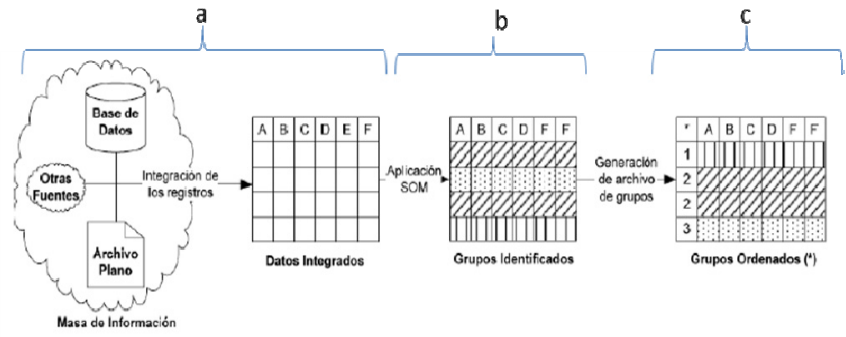

Fig. 2. Proceso de Descubrimiento de Grupos

[c] Ponderación de Interdependencia de Atributos: este proceso (Fig. 3) se aplica cuando se requieren identificar cuáles son los factores con mayor incidencia sobre un determinado resultado o problema. Los pasos de este proceso son los siguientes:

a) Identificar todas las fuentes de información (bases de datos, archivos planos, entre otras), e integrarlas entre sí formando una sola fuente de información a la que se llamará datos integrados.

b) Seleccionar el atributo clase con base en los datos integrados.

c) Aplicar Redes Bayesianas al archivo con el atributo clase identificado. A partir de esto se obtiene el árbol de aprendizaje.

d) Aplicar el aprendizaje predictivo al árbol de aprendizaje obtenido en c). Así, se obtiene el árbol de ponderación de interdependencias que tiene como raíz al atributo clase y como hojas a los otros atributos con la frecuencia (incidencia) sobre el atributo clase.

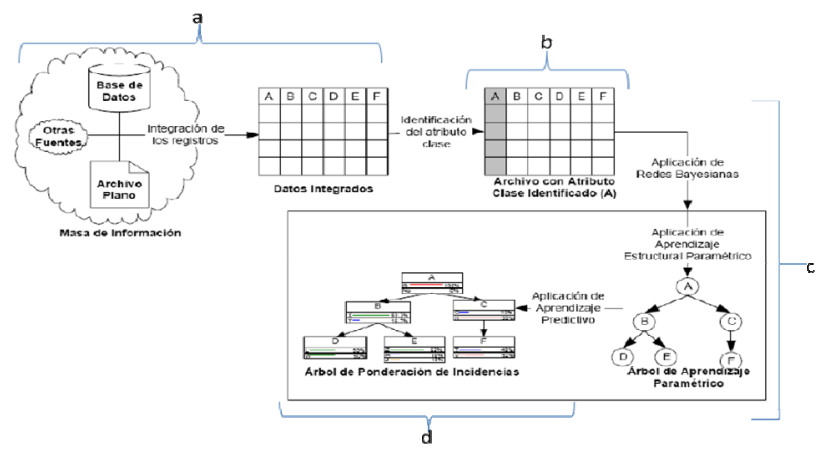

Fig. 3. Proceso de Ponderación de Interdependencia de Atributos.

[d] Descubrimiento de Reglas de Pertenencia a Grupos: este proceso (Fig. 4) aplica cuando se requiere identificar cuáles son las condiciones de pertenencia a cada una de las clases en una partición desconocida "a priori", pero presente en la masa de información disponible sobre el dominio de problema. Para el descubrimiento de reglas de pertenencia a 
grupos se propone la utilización de mapas auto-organizados para el hallazgo de los mismos y; una vez identificados los grupos, la utilización de algoritmos de inducción para establecer las reglas de pertenencia a cada uno [48]. Los pasos para realizar este proceso son:

a) Identificar todas las fuentes de información (bases de datos, archivos planos, entre otras), e integrarlas entre sí formando una sola fuente de información a la que se llamará datos integrados.

b) Aplicar mapas auto-organizados con base en los datos integrados. A partir de esto se obtiene una partición del conjunto de registro en distintos grupos. A estos grupos se los llama grupos identificados.

c) Generar los archivos asociados a cada grupo identificado. A este conjunto de archivos se lo llama grupos ordenados. El atributo "grupo" de cada grupo ordenado se identifica como el atributo clase de dicho grupo, constituyéndose este en un archivo con atributo clase identificado (GR).

d) Aplicar el algoritmo de inducción TDIDT al atributo clase de cada grupo GR. De esta manera, se obtiene un conjunto de reglas que definen el comportamiento de cada grupo.

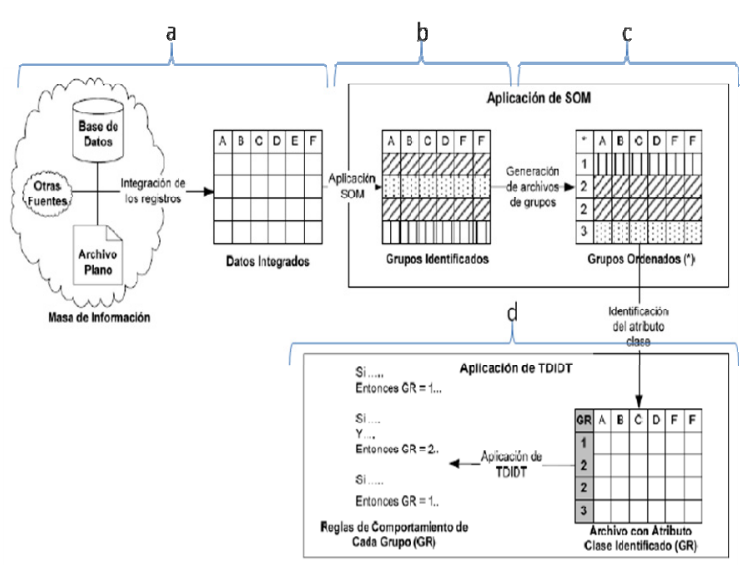

Fig. 4. Proceso de Descubrimiento de Reglas Pertenecientes a Grupos.

[e] Ponderación de Reglas de Comportamiento o de Pertenencia a Grupos: el proceso de ponderación de reglas de comportamiento (Fig. 5.) se aplica cuando se requiere identificar cuáles son las condiciones con mayor incidencia (o frecuencia de ocurrencia) sobre la obtención de un determinado resultado en el dominio del problema, sean estas las que en mayor medida inciden sobre un comportamiento o las que mejor definen la pertenencia a un grupo. Para la ponderación de reglas de comportamiento o de pertenencia a grupos se propone la utilización de redes bayesianas [48]. Esto puede hacerse a partir de dos procedimientos dependiendo de las características del problema a resolver: cuando no hay clases/grupos identificados; o cuando hay clases/grupos identificados. El procedimiento a aplicar cuando hay clases/grupos identificados consiste en la utilización de algoritmos de inducción TDIDT [28] para descubrir las reglas de comportamiento de cada atributo clase y posteriormente se utiliza redes bayesianas para descubrir cuál de los atributos establecidos como antecedentes de las reglas tiene mayor incidencia sobre el atributo establecido como consecuente. Los pasos para aplicar este proceso son los siguientes:

a) Identificar todas las fuentes de información (bases de datos, archivos planos, entre otras), e integrarlas entre sí formando una sola fuente de información a la que se llamará datos integrados. Con base en los datos integrados se puede aplicar dos procedimientos posibles: 1) cuando hay clases/grupos identificados, y 2) cuando no hay clases/grupos identificados.

1) Clases o grupos identificados:

1.a) Aplicar el algoritmo de inducción TDIDT al atributo clase, de manera de obtener un conjunto de reglas que definen el comportamiento de dicha clase.

1.b) Construir un archivo con los atributos antecedentes y consecuentes identificados por la aplicación del algoritmo TDIDT.

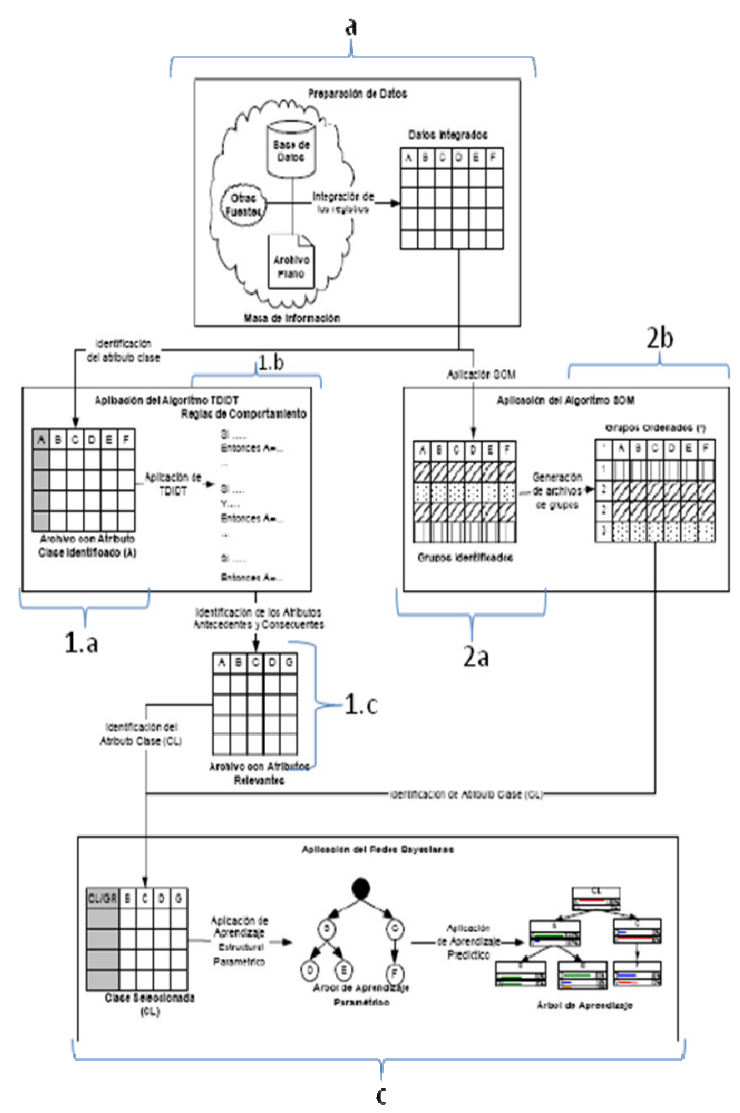

Fig. 5. Proceso de Ponderación de Reglas de Comportamiento o de Pertenencia a Grupos.

2) Clases o grupos no identificados:

2.a) Aplicar la técnica de mapas auto organizados. Como resultado de la aplicación de SOM se obtiene una partición del conjunto de registros en distintos grupos a los que se llamará grupos identificados.

2.b) Generar para cada grupo identificado el archivo correspondiente. A este conjunto de archivos se lo llama grupos ordenados. El atributo "grupo" de cada grupo ordenado se identifica como el atributo clase de dicho grupo, constituyéndose este en un archivo con atributo clase identificado (GR).

b) Aplicar el aprendizaje estructural a los archivos generados en 1.b) o 2.b) según corresponda, para de esta forma obtener el árbol de aprendizajes.

c) Aplicar el aprendizaje predictivo al árbol de aprendizajes. De este modo, se obtiene el árbol de ponderación de interdependencias que tiene como raíz al atributo clase (en este caso el atributo consecuente) y como nodos hojas a los atributos antecedentes con la frecuencia (incidencia) sobre el atributo consecuente. 


\section{Explotación de Información en el Ámbito Educativo}

Con el objetivo de proveer un ambiente de aprendizaje más efectivo se pueden utilizar procesos de explotación de información sobre la información generada por los EVEAs. El proceso de explotación de información aplicado a la educación involucra diferentes grupos de usuarios o participantes. Los diferentes grupos analizan la información relacionada con la educación desde diferentes ángulos de acuerdo a la misión, visión y objetivos de cada uno en cuanto a la utilización de los procesos de explotación de información [49]. En la Tabla I se clasifican posibles grupos a los cuales se les puede aplicar explotación de información [50].

La explotación de información ha sido aplicada al comercio electrónico en forma exitosa [51] y ha comenzado a utilizarse en la educación a distancia con resultados prometedores. [49] sostiene que, si bien los métodos utilizados en el comercio electrónico y en la educación mediada por EVEAs son similares, existen algunas diferencias importantes a resaltar:

[a] Dominio: el propósito del comercio electrónico es guiar a los clientes en las compras, mientras el propósito del aprendizaje mediados por EVEAs es guiar a los estudiantes en el aprendizaje [52].

[b] Datos: en el comercio electrónico la utilización de los datos por lo general es simplemente acceder al log de acceso, pero en el aprendizaje a través de entornos virtuales hay más volumen de información sobre las interacciones del estudiante [53].

[c] Objetivo: el objetivo de la explotación de información en el comercio electrónico es el de incrementar las ganancias, una ganancia tangible y medible en términos de dinero, número de clientes, fidelidad del cliente, y demás. Mientras que el objetivo de la explotación de información aplicada a la educación tiene como objetivo, entre otras cosas, mejorar el aprendizaje. Por supuesto que, en materia de educación, es mucho más subjetivo y difícil de medir.

[d] Técnicas: los EVEAs tienen características especiales que requieren de diferentes tratamientos. Como consecuencia de esto, algunos procesos de explotación de información hay que adaptarlos a necesidades particulares del proceso de aprendizaje [54][53]. Así, algunos pueden ser adaptados mientras que otros no.

TABLA I. GRUPOS DE APLICACIÓN DE PROCESOS DE EXPLOTACIÓN DE INFORMACIÓN

\begin{tabular}{|l|l|}
\hline \multicolumn{1}{|c|}{ Usuario / Rol } & \multicolumn{1}{|c|}{$\begin{array}{c}\text { Objetivo en la utilización de procesos de } \\
\text { explotación }\end{array}$} \\
\hline Estudiantes & $\begin{array}{l}\text { Personalización del aprendizaje; para recomendar } \\
\text { actividades, recursos y tareas de aprendizaje que } \\
\text { puedan mejorar su aprendizaje; para sugerir } \\
\text { experiencias interesantes de aprendizaje; para } \\
\text { recomendar cursos; discusiones relevantes; libros, } \\
\text { etc. }\end{array}$ \\
\hline $\begin{array}{l}\text { Profesores } \\
\text { Educadores }\end{array}$ & $\begin{array}{l}\text { Para recibir retroalimentación objetiva sobre el } \\
\text { instructor; para analizar el aprendizaje y } \\
\text { comportamiento de los estudiantes; para detectar } \\
\text { que estudiantes requieren soporte; para agrupar } \\
\text { estudiantes en distintos grupos; para encontrar los } \\
\text { errores cometidos con más frecuencia, etc }\end{array}$ \\
\hline $\begin{array}{l}\text { Desarrolladores de } \\
\text { cursos / Investigadores } \\
\text { de la educación }\end{array}$ & $\begin{array}{l}\text { Para evaluar y mantener los cursos; para mejorar el } \\
\text { aprendizaje de los estudiantes; para evaluar la } \\
\text { estructura de los contenidos del curso y su } \\
\text { efectividad en el proceso de aprendizaje; para } \\
\text { construir automáticamente modelos de estudiantes y } \\
\text { de tutores; para comparar técnicas de minería de } \\
\text { datos con el objetivo de recomendar la más } \\
\text { adecuada para cada tarea, etc. }\end{array}$ \\
\hline $\begin{array}{l}\text { Organizaciones } \\
\text { Universidades }\end{array}$ & $\begin{array}{l}\text { Para mejorar el proceso de decisiones en la escuela } \\
\text { superior; para lograr objetivos específicos; para }\end{array}$ \\
\hline
\end{tabular}

\begin{tabular}{|c|c|}
\hline Empresas de cursos & $\begin{array}{l}\text { recomendar ciertos cursos que pueden ser mejores } \\
\text { para cierta clase de estudiantes; para encontrar el } \\
\text { costo más efectivo para retener alumnos y } \\
\text { graduarlos, etc. }\end{array}$ \\
\hline $\begin{array}{l}\text { Administradores / } \\
\text { Directores de colegios } \\
\text { / } \\
\text { Administradores de } \\
\text { redes / } \\
\text { Administradores de } \\
\text { Sistemas } \\
\end{array}$ & $\begin{array}{l}\text { Para desarrollar la mejor forma de organizar los } \\
\text { recursos institucionales (humanos y materiales) y su } \\
\text { oferta educativa; para utilizar los recursos } \\
\text { disponibles de forma más efectiva; para evaluar a } \\
\text { los profesores y los planes de estudio, para } \\
\text { configurar parámetros para mejorar la eficiencia de } \\
\text { los sitios y adaptarlos a los usuarios, etc }\end{array}$ \\
\hline
\end{tabular}

La aplicación de la extracción de conocimiento en sistemas educativos con el objetivo de mejorar el aprendizaje puede ser vista como una técnica de evaluación formativa. Una técnica de evaluación formativa es la evaluación de un programa de educación mientras está en desarrollo [55], y tiene el propósito de una mejora continua.

En la Figura 6 se puede observar a los profesores y responsables académicos que están encargados de diseñar, planificar, construir, y mantener los sistemas educativos. Los estudiantes utilizan e interactúan con estos sistemas. A partir de la información disponible en los cursos, y la interacción y uso de la misma por parte de los alumnos, se utilizan diferentes procesos de explotación de información para descubrir conocimiento el cual puede ayudar no solo a los educadores, sino también a los estudiantes [56].

[22] sostienen que la minería de datos aplicada a la educación se puedo aplicar en el ámbito de [a] la clase presencial y en $[\mathrm{b}]$ educación a distancia.

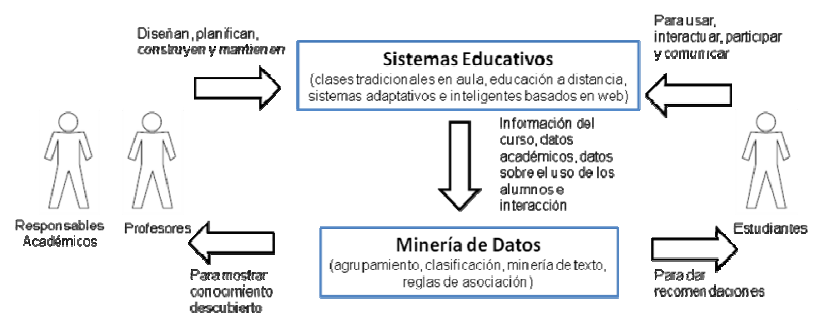

Fig. 6. El Ciclo de la Aplicación de la Minería de Datos en los Sistemas Educativos

[a] Las clases en modalidad presencial son las más utilizadas actualmente en el sistema educativo y están basadas en un contacto cara a cara entre alumnos y docentes. Hay varios subtipos de educación presencial: privada, pública, primaria, secundaria, terciaria, universitaria, etc. Este tipo de educación ha sido muy criticada porque fomenta el aprendizaje pasivo, pasa por alto las diferencias individuales y necesidades de los diferentes estudiantes, y no presta atención a la resolución de problemas, pensamiento crítico $\mathrm{u}$ otras habilidades de pensamiento de orden superior [57].

En la clase presencial los docentes intentan mejorar sus clases a través de la visualización del rendimiento de los estudiantes por medio de la observación y los registros escritos, como exámenes y ejercicios prácticos. También utilizan información de asistencia, información sobre el curso, objetivos de la materia, etc. Una institución educativa posee diversas $y$ variadas fuentes de información [58]: bases de datos tradicionales (con información de los estudiantes, de los docentes, de las clases, y de la planificación de estas), información en línea (páginas web y cuenta de twitter de las institución, contenido de la materia), base de datos multimedia, etc.

La explotación de información puede ayudar a cualquier actor del proceso de aprendizaje (profesores, estudiantes, responsables académicos, entre otros). Las instituciones se 
interesan por saber qué estudiante se podría anotar a qué curso, y qué estudiante necesita ayuda para poder graduarse. Al administrador le podrían interesar predecir los cantidad de estudiantes que se van a anotar a un curso. El alumno podría querer saber cuál es el mejor curso para anotarse de acuerdo a su perfil e incluso predecir su rendimiento. Los docentes podrían querer saber cuáles son las experiencias que más contribuyen a resultados generales de aprendizaje, por qué una clase supera a otra, grupos de estudiantes similares, etc.

[b] La educación a distancia consiste en proveer acceso a programas de educación para estudiantes que están separados por tiempo y espacio del docente. Existen varias formas de implementar la educación a distancia, pero hoy en día una de las más difundidas es mediante Entornos Virtuales de Educación y Aprendizajes (EVEAs). En su mayoría estos entornos pueden por lo general grabar los accesos de los estudiantes, los cuales proveen por donde fue navegando estudiante. Si bien los logs pueden registrar las actividades de los estudiantes, también poseen varias limitaciones, como por ejemplo: se conoce desde qué máquina se conecta el usuario pero no se sabe qué usuario lo hizo, se registran los clics que realiza cada uno pero no hay información sobre la actividad a la que estaban relacionados, además tampoco capturan información del contexto. Por este motivo varios autores plantean otras soluciones. Así, [59] propone otra forma de almacenar las actividades de los estudiantes. La misma incluye el camino de aprendizaje, los cursos preferidos, el tiempo de aprendizaje, y demás. Por otro lado [54] utiliza más canales de comunicación para modelar el comportamiento de navegación de los usuarios: logs de acceso, estructura de los sitios web visitados y sus contenidos. En cambio, [60] combina los datos con otros métodos de investigación, tales como charlas informales con los estudiantes, encuestas, o devolución escrita sobre el sitio web.

En el ámbito de educación a distancia, la explotación de información puede ser utilizada, por ejemplo, para saber cómo los estudiantes hacen uso del curso, cómo una estrategia pedagógica impacta en los diferentes estudiantes, en qué orden los estudiantes estudian las diferentes unidades de las materias, cuánto tiempo el estudiante permanece en una página.

La explotación de información en el ámbito educativo se clasifica en diferentes grupos según el objetivo que ésta persiga. En [50] se propone la siguiente clasificación:

[a] Análisis y visualización de datos: se resalta la información útil y se da soporte a la toma de decisiones mediante técnicas gráficas que ayudan a las personas a analizar y entender los datos. En ambientes educativos, por ejemplo, podría ser de gran ayuda a los docentes para analizar las actividades realizadas en un curso y la información utilizada para tener una vista general del aprendizaje del estudiante.

[b] Proveer conocimiento para dar soporte a los instructores: se genera retroalimentación de las actividades que realizan los estudiantes para que esto ayude a los profesores en la toma de decisiones (sobre mejorar el aprendizaje de los estudiantes y organizar el material de enseñanza de manera más eficiente, entre otras cosas) y en la realización de acciones proactivas y/o correctivas.

[c] Recomendaciones para estudiantes: se hacen recomendaciones a los estudiantes, en forma personalizada, sobre sus actividades, enlaces a visitar, el próximo problema a realizar, etc. También se pueden adaptar contenidos a cada estudiante en particular.

[d] Predecir el rendimiento de los estudiantes: se estima el valor desconocido de las variables que describen al alumno.
En educación a distancia por lo general estos valores se utilizan para predecir el desempeño, conocimiento, y notas de los estudiantes.

[e] Modelado del estudiante: se desarrollan modelos cognitivos para los estudiantes, incluyendo el modelado de sus habilidades y conocimiento declarativo. Se utiliza la explotación de información para examinar de forma automática características del estudiante y su comportamiento de aprendizaje con el objetivo de poder generar modelos de estudiantes en forma automática [61].

[f] Detectar comportamientos no deseados de los estudiantes: se descubren aquellos estudiantes que tienen algún tipo de problema o comportamiento inusual tales como: acciones erróneas, baja motivación, abandono, etc.

[g] Agrupamiento de estudiantes: se crean grupos de estudiantes de acuerdo características particulares, funciones personalizadas, etc. Cada uno de estos grupos puede ser utilizado luego por los docentes para construir un sistema de aprendizaje personalizado, para promover aprendizaje efectivo al grupo, para adaptar contenidos, etc.

[h] Análisis de redes sociales: se busca el estudio de las relaciones entre individuos, en lugar de atributos o propiedades individuales. Una red social es un grupo de personas que están conectados por relaciones sociales, ya sean de amistad, de cooperación o de intercambio de información [62].

[i] Desarrollo de mapas conceptuales: se ayuda a los profesores a la construcción automática de mapas conceptuales. Un mapa conceptual es un gráfico que muestra relaciones entre conceptos y expresa una estructura jerárquica del conocimiento [63].

[j] Construcción de cursos: se ayuda a los instructores y desarrolladores de cursos a distancia a llevar adelante el proceso de construcción y desarrollo del curso y de los contendidos de aprendizaje de forma automática. Por otro lado, también intenta promover la reutilización / intercambio de recursos de aprendizaje existentes entre los diferentes usuarios y sistemas.

[k] Planificación y organización: se mejora el proceso tradicional de educación a través de la planificación de cursos, ayudando con la organización de los estudiantes, planificando la asignación de recursos, colaborando en la admisión y desarrollando planes de estudio, entre otras cosas.

A diferencia de Romero y Ventura, [21] proponen clasificar la explotación de información en el ámbito educativo de la siguiente forma:

[a] Mejoramiento de los modelos de estudiantes: un modelo de estudiante representa información sobre las características o estado del estudiante, tales como el conocimiento actual del mismo, motivación, y actitudes. Modelar las diferencias individuales de los estudiante sobre estas características permite responder a estas diferencias en forma individual, mejorando notablemente el aprendizaje del estudiante [64].

[b] Estudio del apoyo pedagógico: se busca conocer qué tipo de apoyo pedagógico es más efectivo, ya sea en general, o para diferentes grupos de estudiantes, o en distintas situaciones.

[c] Evidencias empíricas: se buscan evidencias en base a las experiencias para refinar y ampliar las teorías de la educación y los fenómenos educativos ya conocidos, a través de la obtención de un conocimiento más profundo de los factores claves que impactan en la educación, siempre teniendo en vista el mejoramiento de los sistemas de aprendizaje.

Así, luego del análisis de ambas clasificaciones en el presente trabajo se tomará una posición más cercana a los 
grupos definidos por [50] y se hará foco en la identificación del comportamiento de las comunidades educativas a través de la explotación de información aplicada a la educación, pudiendo ayudar a actividades como:

[a] Evaluación del rendimiento del estudiante.

[b] Mejoramiento del proceso de aprendizaje.

Modificación sobre el diseño de los cursos.

Para las diferentes aplicaciones mencionadas anteriormente, los distintos autores proponen la utilización de diversas técnicas de minería de datos, así [65] utiliza las siguientes técnicas:

[a] Estadísticas y Visualización: si bien las estadística es a menudo la herramienta utilizada como punto de partida para el análisis de los datos generados por los sistemas de educación a distancia, no es considerada una técnica de minería de datos [66]. Algunos ejemplos de estadísticas pueden ser indicadores tan simples como el número total de ingresos al EVEA, la cantidad de visitas por páginas, o la distribución a través del tiempo de cómo se fueron conectando los estudiantes a los entornos de aprendizaje. La visualización es una técnica que facilita el análisis de grandes volúmenes de información a través de gráficos (gráficos de línea, de dispersión, gráficos en tres dimensiones, etc.). Muchas veces, con esta técnica se representan los resultados de encuestas de admisión a las universidades, resultados de exámenes de los alumnos, etc [67].

[b] Web Mining: la Minería Web [51] es la aplicación de técnicas de minería de datos para extraer conocimiento a partir de los datos de la web. Hay dos tipos de minería web aplicadas a la educación [54]:

- Minería Web Off Line: se utiliza para descubrir patrones u otra información útil para ayudar a los educadores para validar los modelos de aprendizaje y reestructurar los EVEAs.

- Minería Web On Line: los patrones automáticamente descubiertos son introducidos en un sistema de software inteligente el cual podría ayudar a los estudiantes a llevar adelante sus tareas.

Se utilizan diferentes técnicas de datos para la minería web en sistemas educativos, pero casi todas ellas se pueden agrupar en:

- Agrupación, clasificación y detección de outliers: se trata de un proceso de agrupamiento físico o abstracto de objetos en clases de objetos similares.

- Reglas de asociación y patrones secuenciales: se trata de uno de los métodos de minería más estudiados en donde las normas se asocian con uno o más atributos de un conjunto de datos con otro atributo, produciendo una declaración sobre los valores de los atributos.

- Minería de texto: los métodos de minería de texto pueden ser vistos como una extensión de la minería de datos en datos de texto. Se trata de un área interdisciplinaria que involucra aprendizaje automático y minería de datos, estadísticas, información recuperación y procesamiento de lenguaje natural [68]. La minería de textos puede trabajar con conjuntos de datos no estructurados o semi-estructurados (documentos, archivos HTML, correos electrónicos, etc.)

[21] clasifican las diferentes técnicas de minería de datos para la explotación de información aplicada a la educación en cinco grupos:

[a] Predicción: se utilizan técnicas de minería de datos como clasificación, regresión, y estimación de densidad.

[b] Agrupamiento: se utilizan técnicas de clustering las cuales consisten en algoritmos de agrupamiento. [c] Minería de relación: se utilizan reglas de asociación, correlación, y patrones secuenciales.

[d] Destilación de los datos para el juicio humano.

[e] Descubrimiento con Modelos.

Las técnicas $[\mathrm{a}],[\mathrm{b}]$, y [c] son las más conocidas y utilizadas por la mayoría de los investigadores. La técnica [d], puede ser comparada con las estadísticas y la técnica de visualización propuesta por [65]. La técnica [e] es, quizás, en el ámbito de la explotación de información la menos común. En esta técnica se desarrolla el modelo de algún evento o hecho específico a través de algún tipo de proceso el cual puede ser validado de alguna forma (por lo general con predicción o ingeniería del conocimiento). Este modelo es luego utilizado como componente para otros análisis, como predicción o minería de relación. El descubrimiento con modelos soporta análisis sofisticados pudiendo responder a preguntas como: qué sub categoría del material de aprendizaje beneficiará mejor al estudiante [69], cómo los diferentes tipos de comportamiento de los estudiantes impacta en la forma de aprender de los estudiantes [70], y cómo las variaciones en el diseño de un tutor inteligente impacta en el comportamiento de los estudiantes a través del tiempo [71].

Las técnicas de minería de relación ha sido una de las técnicas más destacadas en lo concerniente a minería de datos aplicada a la educación. En la encuesta que realiza Romero y Ventura entre 1995 y 2005, de un total de 60 trabajos reportados, en el $43 \%$ estaba involucrada la minería de relación, mientras que un $28 \%$ utilizaba métodos de predicción. En la Figura 7 se puede observar la distribución de los diferentes métodos utilizados en los trabajos mencionados.

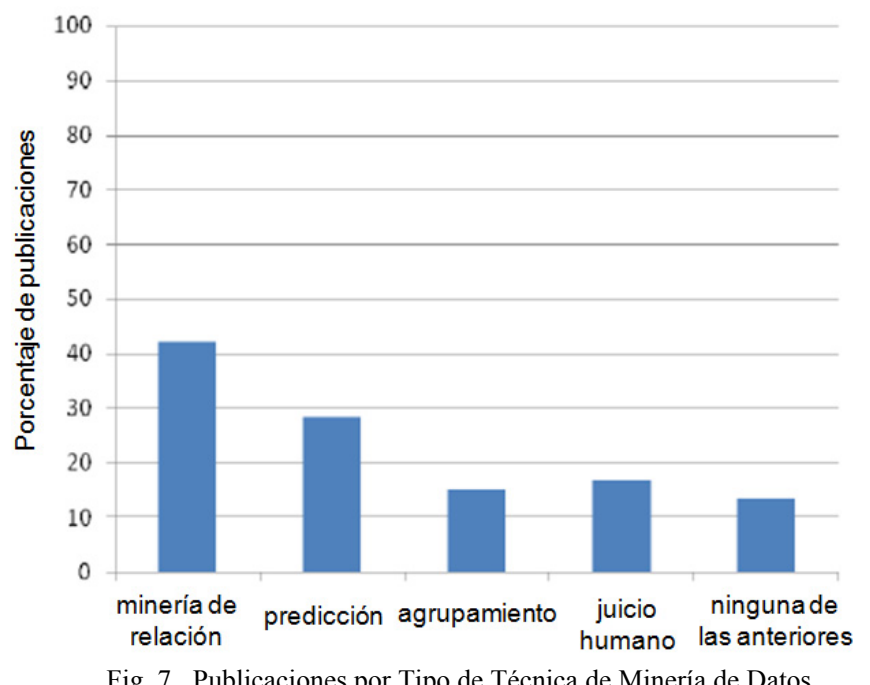

Fig. 7. Publicaciones por Tipo de Técnica de Minería de Datos Utilizadas [22]

Las técnicas mencionadas anteriormente son propias de la minería de datos. En este trabajo se propone utilizar los procesos de explotación de información definidos por [72]. En la Tabla 2 se realiza el mapeo de las diferentes técnicas con los procesos de explotación de información.

\section{Casos de Estudio}

En esta sección se presenta los distintos casos de estudio de ámbito internacional (sección D1), y de ámbito nacional (sección D2).

\section{D1. Ámbito Internacional}

A nivel internacional, los procesos de explotación de información aplicados a temáticas relacionadas con la 
educación llevan unos cuantos años. La cantidad de trabajos publicados sobre explotación de información aplicada a la educación ha incrementado notablemente año a año. En la Figura 8 se puede apreciar la cantidad de publicaciones que ha realizado el grupo de investigación Working Group in EDM (Educational Data Mining) a lo largo de los años [50].

Si bien se trata de las publicaciones de un solo grupo de investigación, esto puede tomarse como una muestra para apreciar la tendencia de crecimiento en cantidad de publicaciones.

TABLA II. MAPEO DE PROCESOS DE EXPlotación DE INFORMACIÓN CON TÉCNICAS DE MINERÍA DE DATOS.

\begin{tabular}{|c|c|}
\hline $\begin{array}{l}\text { Proceso de explotación de } \\
\text { información }\end{array}$ & $\begin{array}{c}\text { Técnicas de minería de datos / } \\
\text { Algorítmos }\end{array}$ \\
\hline Descubrimientos de Grupos & $\begin{array}{ll}- & \text { Agrupación } \\
\text { - } & \text { Estimación de densidad } \\
\text { - } & \text { Detección de Outliers }\end{array}$ \\
\hline $\begin{array}{l}\text { Descubrimiento de Reglas de } \\
\text { Comportamiento }\end{array}$ & $\begin{array}{l}\text { - } \quad \text { Clasificación } \\
\text { - } \quad \text { Minería de Texto } \\
\text { - } \quad \text { Árboles de decisión }\end{array}$ \\
\hline $\begin{array}{l}\text { Ponderación de Interdependencia de } \\
\text { Atributos }\end{array}$ & - $\quad$ Reglas de Asociación \\
\hline
\end{tabular}

Si bien se trata de las publicaciones de un solo grupo de investigación, esto puede tomarse como una muestra para apreciar la tendencia de crecimiento en cantidad de publicaciones.

En [20] se propone monitorear y predecir la transferencia de estudiantes entre colegios a través de procesos de explotación de información. El modelo realizado ayuda a predecir la transferencia de cada estudiante inscripto y tiene como objetivo proveer el perfil de los estudiantes transferidos y predecir qué estudiantes anotados en el colegio solicitarán una transferencia para, de esta forma, poder personalizar y planificar sus iteraciones e intervenciones con estos estudiantes, quienes probablemente necesiten de asistencia para realizar estos trámites. Se utilizaron datos de tres universidades diferentes sumando un total de treinta y dos mil estudiantes. Los datos utilizados incluyen algunas de las siguientes características: demográficas, ayuda financiera, estado de la transferencia, cantidad de transferencias, total de unidades ganadas y calificaciones por tipo de curso.

Para preparar los datos se proponen cuatro pasos basados en la metodología CRISP-DM:

[a] Investigar la posibilidad de aplicar procesos de explotación de información directamente desde el Data Warehouse. Esto evita posibles errores en nombre de campos, cambios inesperados en los tipos de datos, esfuerzo extra en llenar diferentes repositorios de datos.

[b] Seleccionar una sólida herramienta de consulta para poder dar forma a los archivos sobre los cuales se trabajarán.

[c] Visualización y validación de información. Esto significa examinar la distribución de esta información a través de histogramas, gráficos y otros tipos de herramientas. Este paso da a los investigadores una primera impresión del contenido de los datos y cómo aprovecharlos en el análisis. [d] Explotar los datos. Se utilizaron redes neuronales, y algoritmos de inducción C5.0 y CR\&T para comparar ambos modelos y complementar los resultados.

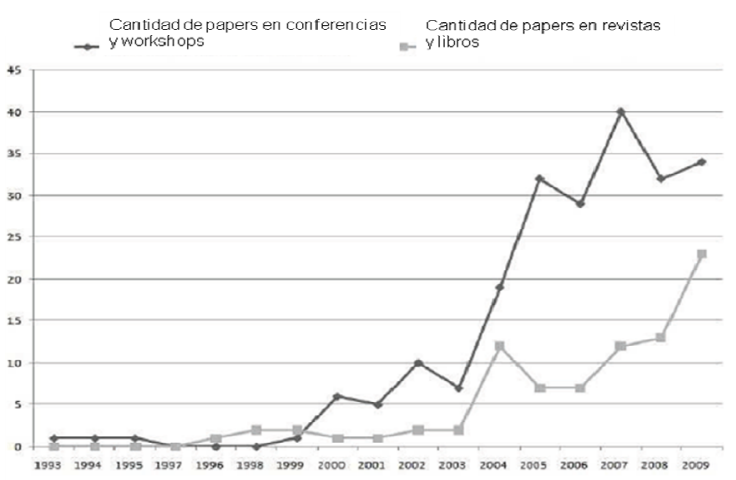

Fig. 8. Cantidad de Papers publicados hasta el 2009 agrupados por año [50]

Una vez obtenidos los resultados se concluye:

[a] La utilización de explotación de información para la investigación en los colegios secundarios en un gran desafío.

[b] A través de la utilización de algoritmos como la máquina de aprendizaje y la inteligencia artificial para discernir reglas, asociaciones y la probabilidad de eventos, la explotación de información tiene un profundo significado de aplicación.

[c] A través del uso de explotación de información se pudo convertir una base de datos poco manejable y caótica en una base para planificar el programa y para resolver cuestiones operativas.

[d] La potencialidad de la explotación de información radica en el hecho que simultáneamente mejora las salidas y reduce costos. La doctrina del 1\% [20] dice que un cambio del $1 \%$ significa una unidad de ganancia y una unidad de ahorro.

[e] La posibilidad de intervenir en aquellos estudiantes que van a abandonar o a cambiarse de colegio genera un valor agregado que va más allá de los costos y ahorro que se puedan generar.

[f] La explotación de información ayuda a predecir la probabilidad de personas interesadas en inscribirse a un colegio. Esto permite a los colegios anticiparse y enviarle al potencial estudiante material para que se asesore antes del ingreso.

[23] proponen aplicar explotación de información sobre datos generados por un EVEA implementado sobre Moodle.

Moodle guarda en forma detallada todas las acciones que realizan los estudiantes [Rice, 2006]. En base a esas acciones guardadas en tablas de la base de datos del EVEAs se propone aplicar los siguientes procesos:

La aplicación de los procesos de información en EVEAs es un proceso iterativo [73]. Se define un proceso de cuatro pasos que consiste en:

[a] Recolectar datos del EVEA,

[b] Procesar los datos,

[c] Aplicar procesos de explotación de información, e

[d] Interpretar y evaluar los resultados e implementarlos en el EVEA (Fig. 9)

La aplicación de la explotación de información en la educación no dista mucho de su aplicación en otras áreas, aunque hay algunas características importantes que le son propias [74]:

[a] Datos: en otros sistemas basados en web los datos utilizados para analizar, por lo general son sacados de un log 
de acceso, pero en los sistemas EVEAs hay mucha más información disponible sobre la interacción de los estudiantes. Los EVEAs pueden registrar cualquier actividad que el estudiante realice (leer, escribir, realizar exámenes, realizar diferentes tareas, e incluso comunicarse con sus compañeros). Normalmente este tipo de sistemas proveen una base de datos que almacena toda la información del sistema con la información personal de los usuarios y los datos de interacción de los usuarios.

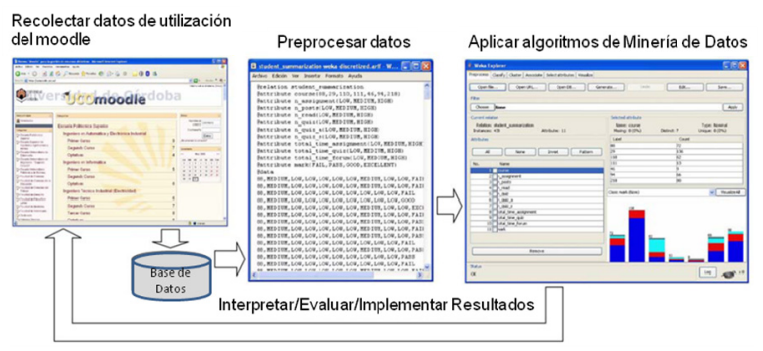

Fig. 9. Minería de Datos sobre Moodle [23]

[b] Objetivo: el objetivo de la explotación de información en cada área es diferente y puede ser más o menos objetiva. Por ejemplo, en comercio electrónico el objetivo es incrementar la rentabilidad, lo cual es tangible y puede ser medido en término de cantidades de dinero, números de clientes, y fidelidad de los clientes. Sin embargo, los objetivos de la explotación de información son los de mejorar el proceso de aprendizaje y guiar a los estudiantes en ese proceso. Este objetivo es más subjetivo y más delicado de medir.

[c] Técnicas: los EVEAs tienen características especiales que requieren un tratamiento diferente de los problemas de minería. Algunas técnicas tradicionales pueden ser aplicadas directamente, pero otras no, y tienen que ser adaptadas a un problema de educación específico.

Esta actividad se ha realizado sobre una base de 438 alumnos donde los profesores utilizan actividades del EVEA como tareas, mensajes, foros y encuestas. A continuación se mencionan los pasos utilizados para la preparación de datos:

[a] Se creó una tabla de sumarización donde se puede almacenar la información al nivel requerido para el análisis, en este caso a nivel alumno. Esta tabla tendrá la suma por fila del total de cada actividad que ha realizado cada estudiante.

[b] Se pasaron los datos continuos a discretos para poder mejorar la interpretación y comprensión.

[c] Se transformaron los datos al formato necesario para poder aplicar las técnicas de minería de datos

Una vez preparados los datos y aplicadas diferentes técnicas de explotación de información se concluye que:

[a] Se puede observar cómo diferentes técnicas de explotación de información pueden ser utilizadas para mejorar el curso y el aprendizaje de los estudiantes.

[b] Estas técnicas pueden ser aplicadas por separado en un mismo sistema o todas juntas en un sistema híbrido.

[c] Si bien se describieron las técnicas más comunes utilizadas en la explotación de información aplicada a la educación, existen otras técnicas también aplicables.

[d] En el futuro será muy útil tener herramientas de explotación de información enfocadas en la educación. Actualmente, éstas son diseñadas pensando en potencia y flexibilidad, más que en simplicidad. Las mismas son demasiado complejas de utilizar para los educadores, entonces, deben tener una interfaz de usuario más amigable. También es necesario que las herramientas de explotación de información sean integradas en los EVEAs y que éstas sean una herramienta más que el docente pueda utilizar para obtener resultados del curso y de los alumnos.

[24] se propone utilizar la explotación de información para predecir la performance de los estudiantes, buscando responder las siguientes preguntas:

[a] ¿Se pueden detectar diferentes clases de estudiantes? Es decir, existen grupos de estudiantes que utilizan los recursos del EVEA en forma similares. ¿Se pueden identificar esas clases en cada estudiante? Contestando estas preguntas se podrá lograr que los estudiantes utilicen mejor los recursos, basado en el uso de los recursos por los otros estudiantes de la misma clase.

[b] ¿Se pueden clasificar los problemas que han resuelto los alumnos? En caso de poder, se podrá ver cómo diferentes tipos de problemas impactan en el logro de cada alumno y permitirá ayudar a los profesores a realizar los ejercicios de tarea de forma más efectiva y eficiente.

Este trabajo se realiza sobre el EVEA de la Universidad del Estado de Michigan (MSU) [75]. Se utilizan los datos de un curso introductorio de física, compuesto por 12 tareas con un total de 184 problemas por resolver, donde se matricularon 261 alumnos y terminaron 221. El EVEA almacena diferentes características de las actividades que realiza el alumno de las cuales se utilizarán las siguientes:

[a] Número total de respuestas correctas

[b] Resolución del problema en la primera oportunidad en contraposición a la resolución del problema en un número alto de oportunidades.

[c] Total de intentos para realizar el problema en forma correcta.

[d] El tiempo total desde que se empezó a resolver el problema, hasta que se lo resolvió correctamente.

[e] El tiempo que se tardó en abordar por primera vez el ejercicio, más allá de que se haya resuelto o no.

[f] Resolución del problema tras la participación en el mecanismo de comunicación en contraposición a la resolución del problema en forma aislada.

Para este problema se utiliza el proceso de descubrimiento de reglas de comportamiento y se concluye que:

La optimización exitosa de la clasificación de estudiantes demostró los méritos de utilizar los datos del EVEA para predecir las notas finales de los estudiantes basadas en sus características extraídas de las tareas.

La explotación de información puede ser aplicada en forma exitosa por los docentes para incrementar el aprendizaje de los estudiantes.

[25] sostienen que la tecnología ha ayudado a la adopción de la educación a distancia mediante EVEAs. A través de estas plataformas podemos obtener, entre otros beneficios, mayor interacción con el alumno, enriquecer la experiencia de aprendizaje, flexibilidad de acceso, etc. Sin embargo el diseño y la evaluación de la educación a distancia mediada por sistemas EVEAs aún es una tarea compleja que requiere tiempo y experiencia que muchos docentes todavía no poseen, $\mathrm{y}$ quienes por lo general necesitan ayuda de expertos para poder diseñar sus cursos. Por lo tanto, se propone evaluar los sistemas EVEA's en base al análisis de los datos que los mismos registran en su log. Uno de los desafíos para un instructor que evalúa los EVEAs es la falta de evidencia de los estudiantes, ya que los mismos tienen solo acceso a las interacciones con el material de estudio y no se puede observar su comportamiento o recibir feedback de ellos en el momento. Dado que el comportamiento de los estudiantes está oculto dentro de sus interacciones, los instructores deberían 
analizarlos para evaluar performance de los estudiantes y evaluar el software de e-learning. Lo que es más, los sistemas EVEAs generan gran cantidad de datos en sus logs. Se considera que la explotación de información es lo más adecuado para realizar esta tarea, ya que es una tecnología que combina métodos de análisis de datos tradicionales con algoritmos complejos para procesar grandes volúmenes de datos con el objetivo de descubrir información útil [76]. El objetivo de este trabajo es encontrar patrones o síntomas que puedan indicar la baja performance de los estudiantes, para esto se analizan los logs generados por los EVEAs. Entonces, por ejemplo, se podrían detectar a aquellos estudiantes que en un ejercicio superan la cantidad de errores que se comenten en promedio.

Es difícil para los instructores detectar este tipo de síntomas sin la ayuda de la explotación de información. Al mismo tiempo, es beneficioso para el profesor poder ser advertido de ciertos problemas que están teniendo los estudiantes con un conjunto de ejercicios en particular y, por lo tanto, poder tomar una acción a tiempo. ¿Cómo ocurren estos síntomas? ¿Qué factores los disparan? Este trabajo propone responder a todas esas preguntas proveyendo un método para detectar síntomas de baja performance de los estudiantes en un curso.

Naturalmente, cada síntoma observado en los datos, significa una variación de performance en el curso. Es útil identificar aquellos patrones que puedan causar caídas en el rendimiento, como así también identificar cuáles son los más importantes. Para esto se propone un método que ayuda a filtrar y armar un ranking de los síntomas detectados basado en Descubrimiento de Reglas de Comportamiento.

[25] trabaja sobre datos por la Escuela de Ciencias de la Información de la Universidad de Pittsburgh (Pittsburgh, EEUU) los cuales fueron recolectados durante el año 2007 del EVEAs de la materia Introducción a la Programación en C, generando un registro de análisis de 55 alumnos, con un total de 52734 interacciones. Las actividades desarrolladas para esta materia en el sistema EVEA se basan en cuestionarios. Cuando un estudiante responde una pregunta del cuestionario se genera un nuevo registro en la tabla de log del sistema. Para el análisis se realizan cinco pasos:

[a] Se selecciona el algoritmo a utilizar. Se eligen árboles de decisión, en especial el algoritmo C4.5 dado los buenos resultados que ha arrojado en trabajos previos [25].

[b] Se definen los atributos del archivo de log a ser analizado, y cuál de ellos se utilizará como clase.

[c] Se aplica el algoritmo para poder obtener los resultados e interpretarlos.

[d] Se analizan los resultados y se deja la rama del árbol donde están todos los casos en los cuales los alumnos fallaron al responder la encuesta.

[e] Se filtran las reglas con el objetivo de solo quedarse con aquellas reglas relevantes. Para esto se calcula la banda inferior como el $10 \%$ de los casos utilizados en las reglas.

Luego de aplicados los pasos mencionados se concluye que:

Se detectaron tres reglas que indican la caída de rendimiento para varios estudiantes.

[a] Esta información puede ser relevante para el instructor o diseñador del curso ya que puede realizar mejoras generando nuevas actividades o modificando las existentes o, incluso, modificando la estructura del curso.

[b] Los árboles de decisión muestran cierta debilidad, sus resultados están fuertemente relacionados con la distribución de los datos y la proporción de las clases. En consecuencia, para futuros trabajos aplicarán reglas de asociación.

[c] Por último, se resalta la importancia de probar y verificar, con otros tipos de datos, el análisis propuesto. En este contexto, en futuros trabajos se procurará utilizar datos de otros EVEAs con el objetivo de mejorar el método de detección.

[77] propone la utilización de la explotación de información para predecir el abandono de estudiantes. El monitoreo y apoyo a los estudiantes de primer año es un tema que se considera sumamente importante en varias instituciones de educación. En algunas facultades la inscripción de los estudiantes recién graduados del bachillerato puede ser menor a lo deseado $\mathrm{y}$, cuando se combina con un alto ratio de abandono, ponen de manifiesto la necesidad de dar forma a enfoques efectivos para predecir el abandono de los estudiantes, así como la identificación de los factores que afectan a todo ello. Entonces, se propone utilizar la explotación de información para predecir el abandono de los estudiantes. En el departamento de ingeniería eléctrica de la Universidad de Tecnología de Eindhoven el porcentaje de abandono de los nuevos estudiantes es de un $40 \%$ [77]. Aparte de que el departamento intenta disminuir este porcentaje, existe otra razón para identificar el éxito o fracaso de un estudiante en la etapa temprana (antes del primer semestre): la carrera de Ingeniería Eléctrica de la universidad vecina acepta alumnos provenientes de otra universidad antes del mes de enero. Por otro lado, existe siempre un grupo de estudiantes que el departamento lo considera un grupo de riesgo como, por ejemplo, estudiantes que necesitan atención extra o algún cuidado especial que los ayude a aprobar la materia. Detectar estos grupos en una etapa temprana le permite al departamento de ingeniería eléctrica enfocar sus recursos hacia los estudiantes que más lo necesitan y de esta forma poder evitar el abandono de la materia.

\section{D2. Ámbito Nacional}

La aplicación de procesos de explotación de información aplicados a la educación, a nivel nacional, es algo reciente. Se han realizado algunas experiencias en temas tales como: identificación de errores de apropiación [78], detección de problemas de aprendizaje [79], e identificación de comportamiento en comunidades educativas [80].

En [27] se propone la utilización de herramientas de explotación de información como ayuda a los docentes para diagnosticar las dificultades de aprendizaje de los alumnos (y sus causas) relacionadas con la programación, para el cual se utilizan herramientas de bases de datos de sistemas inteligentes: inducción de reglas por algoritmos TDIDT y redes bayesianas, con base en un descubrimiento del conocimiento de tres pasos:

Construir una base de datos sobre una caracterización estándar de cada estudiante y conceptos mal aprendidos de programación. Esta caracterización se focaliza en aspectos de: metodología de desarrollo del programa escrito por el estudiante, funcionalidad del programa desarrollado por el estudiante y calidad del diseño del programa creado por el estudiante.

Proceder al descubrimiento de reglas (mediante algoritmos TDIDT) las cuales establecen una relación entre conceptos no comprendidos de programación y sus posibles causas. Las reglas obtenidas son aplicadas para revisar la estructura propuesta para el curso y la hipótesis de los profesores. Los resultados experimentales indican que aplicando este paso, el 
profesor puede descubrir posibles causas de los conceptos mal aprendidos por los estudiantes.

Descubrir el peso que cada una tiene sobre cada concepto mal aprendido (mediante redes bayesianas). Esto permite establecer el rango de importancia de las causas de conceptos no comprendidos para proponer estrategias de enseñanzas remediales.

[78] proponen la utilización de procesos de explotación de información para la identificación de errores de apropiación de conceptos. El proyecto busca la obtención de una metodología que le permita al docente:

[a] Identificar los errores de aprendizaje de los alumnos en instancias educativas y;

[b] Diagramar los conceptos enseñados en pos de minimizar, en tanto sea posible, dichos errores.

Para esto, se utilizan los procesos de explotación de información [13][72]: descubrimiento de reglas de comportamiento y ponderación de interdependencia de atributos. Se tuvieron en cuenta dos casos de estudio, uno con la asignatura Análisis de Sistemas correspondiente a la carrera de Ingeniería en Sistemas de Información de la Universidad Tecnológica Nacional Facultad Regional Buenos Aires (UTNFRBA) y otro con la asignatura Sistemas y Organizaciones de la misma casa de altos estudios. Para ambos se utilizó el siguiente proceso de cinco pasos para identificar errores de apropiación de conceptos:

Paso 1: conceptualización del dominio

[a] Seleccionar los conceptos enseñados que se consideran importantes para la determinación del aprendizaje del individuo.

[b] Construir un glosario de términos

[c] Construir el mapa de dependencia o precedencia conceptual

Paso 2: identificación de Subdominio de Análisis

[a] Identificar el submapa candidato para el análisis

[b] Refinar los conceptos del submapa candidato en subconceptos.

[c] Identificar los atributos de evaluación vinculados al submapa candidato.

Paso 3: preparación de datos

[a] Identificar los valores de los atributos de evaluación, vinculados a los subconceptos del submapa candidato en las instancias de evaluación individual.

[b] Construir la Base de Datos usando como campos los atributos de evaluación y, como instancias, los valores de estos atributos para cada sujeto de la población en estudio.

Paso 4: Explotación de Información

[a] Aplicar el Descubrimiento de Reglas de Comportamiento [13], tomando como clase el atributo que se encuentra en la raíz del subárbol asociado al submapa candidato.

[b] Aplicar el proceso Ponderación de Interdependencia de Atributos [13], tomando a los atributos hoja de las reglas obtenidas en el Subpaso $4.1 \mathrm{y}$ atributo clase.

Paso 5: interpretar los resultados

[a] Interpretar los resultados generados a partir de los procesos de explotación de información del Paso 4.

Luego de realizada las pruebas de concepto con las materias mencionadas anteriormente se concluye que [78]:

[a] La apropiación de conceptos por parte del alumno no es un proceso unidireccional. Si bien requiere un esfuerzo del alumno, es fundamental la participación del docente no solo en la transmisión pura del conocimiento sino en el proceso que esa transmisión implica.

[b] Para el docente es de gran ayuda contar con una metodología o proceso que le permita determinar qué errores en la apropiación de conceptos de los alumnos provienen de la implementación del proceso de transmisión mencionado. Entonces, se plantea una metodología que le permita a un docente revisar, en caso de ser necesario, el proceso utilizado en el dictado de sus clases para intentar minimizar los errores de apropiación de conceptos detectados en los alumnos.

[c] El proceso propuesto constituye una nueva herramienta de diagnóstico en el área; y si bien los resultados obtenidos en este estadio del proyecto son prometedores, no son concluyentes.

[80] sostienen que los procesos de explotación de información pueden ser utilizados también, para identificar el comportamiento de comunidades educativas, en este caso, las centradas en entornos virtuales de enseñanza.

Para cumplir con los objetivos de este estudio se llevan a cabo los siguientes pasos:

[a] Realizar una Investigación documental, estudio y síntesis de los marcos teóricos de:

1. Educación mediada por EVEAs,

2. Explotación de información y

3. Comportamientos de poblacionales con comunicación mediada por tecnología.

[b] Identificar las variables utilizadas para el modelado de comportamientos poblacionales con comunicación mediada por EVEAs.

[c] Crear y validar los procesos de explotación de información que identifiquen comportamientos de poblaciones con comunicación mediadas por EVEA.

[d] Realizar una prueba de concepto de los procesos de explotación creados utilizando datos reales de poblaciones con comunicación mediadas por EVEA.

A través de los pasos mencionados el proyecto busca:

[a] La comprensión de comportamientos de comunidades mediada por tecnología con énfasis en comunidades educativas; $y$

[b] La formulación de una propuesta de identificación de patrones de comportamientos poblacionales en comunidades educativas mediadas por EVEAs utilizando procesos de explotación de información.

[81] proponen utilizar la explotación de información para la mejora de la asignatura de grado de Inteligencia Artificial de la Universidad Tecnológica Nacional. Dicha materia es aprobada por el $65 \%$ de los alumnos que la cursan. Si bien actualmente la mayoría de los alumnos aprueba el parcial, desde el 2011 se observa una tendencia negativa que proyectada al año 2013 bajaría a menos del 50\%. Entonces, se estudian alternativas en el desarrollo de la clase con el objetivo de aumentar el porcentaje de aprobación.

Los temas que forman parte de la asignatura son los siguientes:

- Teoría (TEORIA), donde se incluyen preguntas teóricas de todos los conceptos de la asignatura.

- Modelos de Arquitecturas de Sistemas Inteligentes (ARQ) que incluye preguntas teóricas sobre conceptos y tipos de sistemas inteligentes (Redes Neuronales, Sistemas Expertos y Algoritmos Genéticos).

- Métodos de Búsqueda (BUSQ), Emparrillado (EMP), Análisis de Protocolos (AP), Deducción Natural (DEDNAT) y Traducción Lógica (TRAD), que engloban ejercicios prácticos para cada tema. 
Se propone como solución la aplicación de un proceso de explotación de información aplicándolo sobre la información proveniente de exámenes parciales ya evaluados de la asignatura en cuestión, para así estudiar los temas relevantes para la evaluación de los exámenes parciales. El proceso de explotación utilizado es el de Descubrimiento de Reglas de Comportamiento [72] a través de los siguientes pasos:

- Se prepara la base de datos con un total de 229 registros (cada uno representado por un parcial realizado por un alumno) los cuales están formados por 25 atributos y una clase.

- Se aplica el algoritmo de inducción C4.5 de la familia TDIDT [82] y como resultado se obtienen 11 reglas.

- Se interpretan los resultados

Realizados estos pasos se concluye que:

- La solución propuesta un ejemplo de herramienta de diagnóstico en el área satisfactorio.

- Se pudo observar en detalle el grado de importancia de los resultados finales permitiendo al docente mejorar el dictado de la asignatura haciendo hincapié en aquellos temas críticos para su aprobación.

- Estos resultados con concluyentes y prometedores para ser analizados en un futuro y evaluar su incidencia en la fase de aprobación de los alumnos.

\section{PROBLEMA}

En esta sección se abordan los problemas comunes relacionados con el rendimiento de los estudiantes tanto en la educación presencial como a distancia (sección A), luego se proponen las líneas de investigación con el objetivo de ayudar a resolver los problemas mencionados los diferentes procesos de explotación de información (sección B).

\section{A. Generalidades del Problema}

La institución u organización es la que enseña (organización que ayuda la llama [83] y organización de apoyo lo denomina [84]), no el profesor. En la enseñanza presencial es el docente el que habitualmente diseña, produce, distribuye, desarrolla y evalúa el proceso de enseñanza-aprendizaje, por lo que el aprendizaje del alumno suele estar en función de que le haya correspondido un buen o un mal docente. En la enseñanza a distancia, sin embargo, el docente nunca es uno, son multitud los agentes que intervienen en el proceso de enseñar y aprender, hasta tal punto que solemos reconocer a la institución como la portadora de la responsabilidad de enseñar. Por tanto, es la institución, más que el profesor, la que diseña, produce, distribuye, desarrolla o tutela el proceso de aprendizaje de los estudiantes. Pero este aprendizaje ha de permitir al estudiante ser protagonista en cuanto al tiempo, espacio y ritmo de aprender, es decir, el proceso de enseñanza diseñado por la institución propicia el aprendizaje flexible del estudiante. Y esa flexibilidad es facilitada a través de la comunicación o diálogo didáctico mediado entre institución y estudiante. Son, en efecto, los medios los que permiten la flexibilidad antes referida [3].

Al tratar el caso de un nuevo paradigma de enseñanza basado en los entornos de aprendizaje virtual, existe la tendencia a centrarse en las posibilidades positivas. Sin embargo, hay otra cara de esta visión. [85] en su investigación, tienen que enfrentarse a problemas causados por las diferencias horarias y de cultura que son inherentes a la interacción entre países. Algunos de los problemas que han encontrado eran predecibles, como el hecho de que algunos profesores se sintieran amenazados por la tecnología y el hecho de que los estudiantes quisieran tener contacto real unos con otros. Otras dificultades resultaron más inesperadas Se produjeron problemas de intransigencia de la propia tecnología y modelos de conducta inesperados, como una exagerada comunicación por correo electrónico.

[3] sostiene que uno de los problemas que más acusan los alumnos de esta modalidad de enseñanza es el de la soledad y alejamiento del profesor y de los compañeros de estudio. La necesidad de relacionarse con los otros se convierte a veces en determinante para el logro de resultados de aprendizaje. Entonces, el reto de la educación a distancia consiste en mantener un sistema comunicacional no presencial ya que se prescinde de la habitual presencia cara a cara entre profesores $y$ alumnos. Si se logra una buena comunicación el alumno no se sentirá tan solo y contará con la orientación y motivación del profesor y de sus propios compañeros.

Uno de los principales escollos con los que topa el desarrollo de nuevos sistemas de enseñanza a distancia basados en internet es la ausencia de un marco teórico adecuado. En efecto, por una parte, las instituciones dedicadas tradicionalmente a la enseñanza a distancia encuentran dificultades para cambiar, rápidamente, sus métodos y procedimientos por causa de resistencias en parte internas de la propia institución y en parte en la mentalidad de sus usuarios, sean éstos docentes o estudiantes. Por otra parte, las instituciones que nacen asentadas sobre una base tecnológica innovadora tienen el riesgo de comprometerse excesivamente con una determinada tecnología, hasta el punto de verse en dificultades en el momento en que dicha tecnología pase a ser obsoleta [1].

Lo que distingue la enseñanza a distancia del resto es el carácter diferido en el tiempo de buena parte de las ayudas pedagógicas, contenidas ya en los materiales didácticos [84]. Quienes participan en la elaboración de dichos materiales acostumbran a preocuparse no sólo del contenido sino también, de la disposición de las actividades que deben ayudar al estudiante a relacionar los con sus conocimientos previos. Así, a diferencia de otros procesos de enseñanza en que toda interacción se da en una coincidencia espacio-temporal, aquí se parte del convencimiento que esa coincidencia o no es posible o bien debe reducirse al mínimo imprescindible. Las nuevas tecnologías ayudan decididamente a que los materiales didácticos sean más ricos en las posibilidades de diferir las ayudas pedagógicas y, por supuesto, de diversificarlas de forma individualizada [86].

La función docente, en este contexto, debe considerarse como la organización de las ayudas pedagógicas y la gestión de los ajustes derivados de la individualización del proceso [87]. Por consiguiente, la gestión del aprendizaje debe ser considerada el resultado de un proceso en el que participan tanto el docente como el estudiante.

El desarrollo tradicional de los cursos de e-learning es una actividad laboriosa [88] en el que el promotor (por lo general el profesor del curso) tiene que elegir los contenidos que se mostrarán, decidir sobre la estructura de los contenidos, y determinar los elementos de contenido más adecuadas para cada tipo de usuario potencial del curso. Debido a la complejidad de estas decisiones, un diseño de una sola vez es poco factible, incluso cuando se hace con cuidado. En su lugar, será necesario en la mayoría de los casos para evaluar y posiblemente modificar los contenidos del curso, la estructura y la navegación basada en la información de uso de los estudiantes, de preferencia, incluso siguiendo un enfoque continuo de evaluación empírica [89]. Para facilitar esto, se 
necesitan métodos y herramientas de análisis de datos para observar el comportamiento de los estudiantes y para ayudar a los maestros en la detección de posibles errores, deficiencias y posibles mejoras. Análisis de datos tradicional en e-learning es hipótesis o suposición conducido [90] en el sentido de que el usuario comienza a partir de una pregunta y explora los datos para confirmar la intuición. Mientras que esto puede ser útil cuando un número moderado de factores $\mathrm{y}$ datos están involucrados, puede ser muy difícil para el usuario encontrar patrones más complejos que se relacionan diferentes aspectos de los datos. Una alternativa al análisis de datos tradicional es utilizar la minería de datos como un enfoque inductivo para descubrir automáticamente información oculta presente en los datos. La minería de datos, en contraste, es el descubrimiento impulsado en el sentido de que la hipótesis se extrae automáticamente de los datos y por lo tanto es impulsado por los datos en lugar de basados en la investigación o inducido por el hombre [66]. La minería de datos se construye modelos analíticos que descubren patrones y tendencias interesantes de la información de uso de los estudiantes que pueden ser utilizados por el profesor para mejorar el aprendizaje y por supuesto el mantenimiento del estudiante.

La utilización de EVEAs ha crecido exponencialmente en los últimos años, estimulado por el hecho de que ni los estudiantes ni los profesores están obligados a una ubicación específica y que esta forma de educación basada en la computadora es prácticamente independiente de cualquier plataforma de hardware específicos [91]. Las herramientas de colaboración y comunicación se están utilizado cada vez más en contextos educativos así, como resultado, los Entornos de Aprendizaje y Enseñanza Virtuales se instalan cada vez más por las universidades, colegios comunitarios, escuelas, empresas e incluso también son utilizados por instructores individuales con el fin de agregar tecnología web para sus cursos y para complementar los cursos tradicionales cara a cara [92]. Estos sistemas pueden ofrecer una gran variedad de canales y espacios de trabajo para facilitar el intercambio de información y la comunicación entre los participantes en un curso, para permitir que los educadores de distribuir información a los estudiantes, producir material de contenido, preparar las tareas y exámenes, participar en debates, gestionar las clases a distancia y permitir la colaboración aprendizaje con foros, chats, áreas de almacenamiento de archivos, servicios de noticias, etc. Estos entornos de aprendizaje acumulan una gran cantidad de información que es muy valiosa para el análisis del comportamiento de los estudiantes y podrían crear una mina de oro de datos educativos [93]. Se puede grabar cualquier actividad en la que los estudiantes están involucrados, tales como leer, escribir, realizar exámenes, la realización de diversas tareas, e incluso comunicarse con los compañeros [94].Por lo general, estas plataformas no proporcionan a los educadores las herramientas específicas que les permitan realizar un seguimiento a fondo, la posibilidad de evaluar todas las actividades realizadas por sus alumnos, ni tampoco cuentan con un mecanismo para evaluar la estructura, el contenido del curso, y su eficacia en el proceso de aprendizaje. Aunque algunas plataformas ofrecen herramientas como reportes de gestión, cuando existe un gran número de estudiantes, la tarea de extraer información útil se vuelve difícil [56]. Entonces, un área muy prometedora para el logro de este objetivo, es el uso de minería de datos [95].

El EVEA registra todas las instancias de comunicación interpersonales. Tales registros podrían utilizarse como base para modelar el comportamiento de los alumnos de educación a distancia.

En la educación presencial los docentes intentan mejorar sus clases a través de la visualización del rendimiento de los estudiantes por medio de la observación. Dicho método puede ser muchas veces subjetivo e incompleto. También existen registros escritos, como exámenes y ejercicios prácticos en los cuales los docentes se pueden apoyar para mejorar sus clases. También utilizan información de asistencia, información sobre el curso, objetivos de la materia, etc. Una institución educativa posee diversas fuentes de información y variadas [58]: bases de datos tradicionales (con información de los estudiantes y de los docentes, de las clases, y la programación de las mismas).

\section{B. Pregunta de Investigación}

La explotación de información permite identificar conocimiento oculto en los datos registrados. El proceso de aprendizaje está compuesto por una serie de hitos que permiten al docente identificar puntos críticos para favorecer la comprensión de los temas expuestos. En [80] se plantea la línea de investigación cuyos objetivos son:

[a] La comprensión de comportamientos de comunidades mediadas por tecnología con énfasis en comunidades educativas.

[b] La formulación de una propuesta de identificación de patrones de comportamientos poblacionales en comunidades educativas mediadas por EVEAs utilizando procesos de explotación de información.

En este contexto, se plantea la siguiente pregunta de investigación:

¿Se puede desarrollar un proceso de explotación de información que ayude a la comprensión del comportamiento de comunidades educativas a partir de los resultados académicos?

\section{SOLUCIÓN}

En la presente sección se abordan los marcos de la solución propuesta (sección A), y luego se presenta la solución a los problemas planteados en la sección anterior (sección B).

\section{A. Marco de la Solución}

Un Proceso de Explotación de Información se define como un grupo de tareas relacionadas lógicamente [10] que, a partir de un conjunto de información con un cierto grado de valor para la organización, se ejecuta para lograr otro, con un grado de valor mayor que el inicial. Adicionalmente, existe una variedad de técnicas de minería de datos, en su mayoría provenientes del campo del aprendizaje automático [14], susceptibles de utilizar en cada uno de estos procesos.

[13] propone los siguientes procesos de explotación de información: descubrimiento de reglas de comportamiento, descubrimiento de grupos, descubrimiento de atributos significativos, descubrimiento de reglas de pertenencia a grupos y ponderación de reglas de comportamiento o de pertenencia. El proceso de descubrimiento de reglas de comportamiento aplica cuando se requiere identificar cuáles son las condiciones para obtener determinado resultado en el dominio del problema. El proceso de descubrimiento de grupos aplica cuando se requiere identificar una partición en la masa de información disponible sobre el dominio de problema. El proceso de ponderación de interdependencia de atributos aplica cuando se requiere identificar cuáles son los factores con mayor incidencia (o frecuencia de ocurrencia) sobre un determinado resultado del problema. El proceso de 
descubrimiento de reglas de pertenencia a grupos aplica cuando se requiere identificar cuáles son las condiciones de pertenencia a cada una de las clases en una partición desconocida "a priori", pero presente en la masa de información disponible sobre el dominio de problema. El proceso de ponderación de reglas de comportamiento o de la pertenencia a grupos aplica cuando se requiere identificar cuáles son las condiciones con mayor incidencia (o frecuencia de ocurrencia) sobre la obtención de un determinado resultado en el dominio del problema, sean estas las que en mayor medida inciden sobre un comportamiento o las que mejor definen la pertenencia a un grupo.

En particular, las metodologías de explotación de información destacan la importancia de la comprensión del negocio y la vinculación entre el problema de negocio con el patrón o regularidad a descubrir en la información a partir del proceso de explotación de información a utilizar. Sin embargo, es un problema abierto determinar de manera sistemática cual es el proceso de explotación de información que se debe aplicar para resolver el problema de negocio.

\section{B. Solución Propuesta}

Como respuesta al problema planteado [96] se propone un procedimiento que permite derivar del proceso de explotación de información a partir del modelado del dominio de negocio (Tabla 4.1).

Los formalismos de ingeniería de conocimiento que se utilizan para modelar el dominio de negocio y de explotación de información son las redes semánticas [97] y las tablas concepto - atributo - valor [98].

Con base en los formalismos señalados, se proponen doce formalismos para el modelado del dominio:

- Tabla concepto - atributo - valor del dominio (CAVD): se utiliza para la representación sistemática de los conceptos del dominio, con detalles de los atributos y valores.

- Tabla concepto - relación del dominio (CRD): se utiliza para modelar las relaciones entre los conceptos del dominio.

- Red semántica del modelo de negocio (RSMN): modela el dominio del negocio.

- Tabla concepto - atributo - valor del problema de explotación de información (CAVPEI): es una representación sistemática de los conceptos del problema de explotación de información, con detalles de los atributos y valores.

- Tabla concepto - relación del problema de explotación de información (CRPEI): busca modelar las relaciones entre los conceptos del problema de explotación de información.

- Tabla de entradas/salidas del problema de explotación de información (E/S - PEI): es un listado de entradas/salidas del problema de explotación de información.

- Red semántica del problema de explotación de información (RSPEI): representación sistemática del problema de explotación de información.

- Red semántica del problema de explotación de información con datos de entrada y salida identificados (RSPEI - DE/S): modela el problema de explotación de información con los datos identificados de entrada y salida.

- Tabla concepto - atributo - valor Integrada (CAVI): representación sistemática integrada de los conceptos del dominio y del problema de explotación de información, con detalles de los atributos y valores.

- Tabla concepto - relación Integrada (CRI): modela de manera integrada las relaciones entre los conceptos del dominio y del problema de explotación de información.
- Red semántica integrada modelo negocio - explotación de información (RSI - MN - EI): representación sistemática integrada del modelo de negocio y del problema de explotación de información.

- Red semántica integrada modelo negocio - explotación de información con datos de entrada y salida identificados (RSI - MN - EI - DE/S): representación sistemática integrada del modelo de negocio y del problema de explotación de información con los datos identificados de entrada y salida.

TABLA III. PRocedimiento de derivación del Proceso de EXPLOTACIÓN DE INFORMACIÓN A PARTIR DEL MODELADO DEL DOMINIO DEL NEGOCIO

\begin{tabular}{|c|c|}
\hline \multicolumn{2}{|r|}{ Procedimiento de derivación } \\
\hline Paso 1: & Identificación de conceptos del dominio. \\
\hline Paso 2: & $\begin{array}{l}\text { Identificación de relaciones entre } \\
\text { conceptos. }\end{array}$ \\
\hline Paso 3: & Conceptualización del dominio. \\
\hline Paso 4: & $\begin{array}{l}\text { Identificación de conceptos y relaciones } \\
\text { del problema de explotación de } \\
\text { información. }\end{array}$ \\
\hline Paso 5: & $\begin{array}{l}\text { Conceptualización del problema de } \\
\text { explotación de información. }\end{array}$ \\
\hline Paso 6: & $\begin{array}{l}\text { Identificación de los datos de entradas y } \\
\text { resultados del problema de explotación de } \\
\text { información. }\end{array}$ \\
\hline Paso 7: & $\begin{array}{l}\text { Integración de las novaciones que } \\
\text { introduce el problema de explotación de } \\
\text { información al dominio. }\end{array}$ \\
\hline Paso 8: & $\begin{array}{l}\text { Integración de los conceptos del dominio y } \\
\text { del problema de explotación de } \\
\text { información. }\end{array}$ \\
\hline Paso 9: & $\begin{array}{l}\text { Identificación Integrada de los datos de } \\
\text { entrada y objetivo. }\end{array}$ \\
\hline Paso 10: & $\begin{array}{l}\text { Derivación del proceso de explotación de } \\
\text { información. }\end{array}$ \\
\hline
\end{tabular}

El procedimiento propuesto por [96] conceptualiza el dominio a partir de la identificación de los conceptos del dominio y las relaciones entre estos conceptos (pasos 1 a 3). En los pasos siguientes (4 a 6) se conceptualiza el problema de explotación de información con base en la identificación de conceptos y relaciones del problema de explotación de información y la identificación de los datos de entradas y resultados del problema de explotación de información. En la representación lograda hasta el momento se producen novaciones que introduce el problema de explotación de información al dominio, los mismos se incorporan a la representación del dominio. En este punto se pueden integrar los conceptos del dominio y del problema de explotación de información; e identificar de manera integral los datos de entrada y objetivo (pasos 7 a 9). A partir de este punto, y con base en los sub pasos del paso 10 que se presentan en la Tabla IV, se deriva el proceso de explotación de información.

Ante la falta de herramientas por parte de los educadores para evaluar a los alumnos, las estructuras, el contenido del curso y su eficacia en el proceso de aprendizaje, este trabajo propone como solución un recurso. El mismo permite estudiar el comportamiento de los estudiantes a lo largo de un curso o una carrera, identificando y resolviendo los distintos problemas asociados al aprendizaje y al favorable desarrollo de la materia. De esta manera, los docentes tendrán a su disposición una herramienta que favorece la comprensión del curso y la 
posibilidad de implementar medidas que les permitan detectar alumnos con dificultades para, así, intervenir de manera temprana con la posibilidad de corregir factores que impacten en el resultado de la cursada.

TABLA IV. Detalle De Los SUBPASOS DE DERIVACIÓN DEL PROCESO DE EXPLOTACIÓN DE INFORMACIÓN

Subpaso SI En la Red semántica integrada modelo negocio 10.1: - explotación de información con datos de entrada y salida identificados (RSI - MN - EI $\mathrm{DE} / \mathrm{S})$ se puede identificar un resultado intermedio.

ENTONCES Ir a Subpaso 10.5.

SINO Ir a Subpaso 10.2.

Subpaso SI

10.2:

El objetivo de la red semántica integrada modelo negocio - explotación de información con datos de entrada y salida identificados (RSI - MN - EI - DE/S) es un único nodo cuya arista se identifica con las palabras: pertenece, integra, es, es miembro de, u otras palabras de similar significado.

ENTONCES Aplicar proceso descubrimiento de grupos.

SINO Ir a Subpaso 10.3.

Subpaso SI En la red semántica del problema de 10.3: explotación de información con datos de entrada y salida identificados (RSPEI - DE/S) se busca detectar los valores que más se destacan o que aparecen con mayor frecuencia del conjunto de datos de salida

ENTONCES Aplicar proceso ponderación de interdependencia de atributos.

SINO Ir a Subpaso 10.4.

Subpaso SI

10.4:

En la red semántica del problema de explotación de información con datos de entrada y salida identificados (RSPEI - DE/S) se busca identificar, a partir del conjunto de datos de salida, el valor de un atributo determinado

ENTONCES Aplicar proceso descubrimiento de reglas de comportamiento.

SINO Representación errónea.

Subpaso SI

10.5 :

La Red semántica integrada modelo negocio explotación de información con datos de entrada y salida identificados (RSI - MN - EI $\mathrm{DE} / \mathrm{S}$ ) tiene un concepto resultado intermedio, para el cual el arco que llega se rotula con las palabras: "pertenece", “integra", "es", “es miembro de" u otras palabras de similar significado

ENTONCES Ir a Subpaso 10.6.

SINO Representación errónea.

Subpaso SI El resultado intermedio de la red semántica

10.6: integrada modelo negocio - explotación de información con datos de entrada y salida identificados (RSI - MN - EI - DE/S), cuya relación se define con las palabras pertenece, integra, es, es miembro de, u otras palabras de similar significado, es un nodo existente en la red semántica del modelo de negocio (RSMN).

ENTONCES Aplicar proceso ponderación de reglas de pertenencia a grupos (grupos definidos).

SINO Ir a Subpaso 10.7.

Subpaso SI

10.7:

En la Red semántica del problema de explotación de información con datos de entrada y salida identificados (RSPEI - DE/S) se busca detectar aquellos valores de los atributos pertenecientes al concepto identificado como resultado intermedio, que más se destacan o que aparecen con mayor frecuencia en el conjunto de datos de salida.

ENTONCES Aplicar proceso ponderación de reglas de pertenencia a grupos (grupos no definidos).

SINO Ir a Subpaso 10.8.

Subpaso SI

10.8:
En la red semántica del problema de explotación de información con datos de entrada y salida identificados (RSPEI - DE/S) se busca definir el identificador del resultado intermedio, de acuerdo con los atributos de salida

ENTONCES Aplicar proceso descubrimiento de reglas de pertenencia a grupos.

SINO

Representación errónea.

El proceso propuesto hace uso de los procesos de explotación de información $\mathrm{y}$ del de derivación del problema de explotación de información definido mencionados anteriormente.

TABLA V. Proceso PRopuesto PARA EL Estudio DEL COMPORTAMIENTO DE COMUNIDADES EDUCATIVAS

Paso 1: Conceptualización del Dominio

Subpaso1.1:Identificación de los elementos relevantes del dominio

Subpaso 1.2:Identificación de las relaciones entre elementos del dominio

Subpaso 1.3:Representación conceptual del dominio.

Paso 2: Conceptualización del Problema de Explotación de Información

Subpaso 2.1:Identificación del problema de negocio y su traducción al problema de explotación de información

Subpaso 2.2:Identificación de los conceptos pertenecientes al problema de explotación de información

Subpaso 2.3:Identificación de las relaciones entre elementos del problema de explotación de información

Subpaso 2.4:Identificación de dependencias entre los elementos conceptuales del problema

Subpaso 2.5:Representación del problema de explotación de información

Paso 3: Identificación del Proceso de Explotación de Información Derivación del proceso de explotación de información

Paso 4: Preparación de los Datos

Subpaso 4.1:Selección de los campos asociados al problema de explotación de información

Subpaso 4.2:Conversión de los datos

Subpaso 4.3:Generación de la base de datos

Paso 5: Implementación

Subpaso 5.1:Implementación

Subpaso 5.2:Interpretación de los resultados

A continuación se presenta el proceso propuesto compuesto por los siguientes 5 pasos:

El primer paso se orienta a la comprensión y conceptualización del negocio a analizar (reconociendo los distintos elementos que conforman al estudio del curso a analizar), identificando aquellos conceptos dependientes.

El segundo paso se orienta a la identificación del problema de negocio, entendiendo como problema de negocio a aquel objetivo que se quiere resolver, para el cual se requiere obtener información relevante que soporte la toma de decisión, su traducción a lenguaje técnico (problema de explotación de información), la identificación de los elementos que lo componen y la conceptualización del mismo.

El tercer paso consiste en identificar el proceso de explotación a utilizar, que es el que define las técnicas de minería de datos a implementar para dar solución al problema de negocio. 
El cuarto paso consiste en generar la base de datos y los datos acorde al proceso de explotación de información identificado y de los algoritmos de minería de datos a utilizar, convirtiendo los datos en base a las necesidades de los mismos.

El último paso es el que consiste en implementar e interpretar los resultados obtenidos, aportando información relevante para la olución del problema de negocio previamente identificado.

\section{VALIDACIÓN}

En esta sección se describen tres casos de validación. El primero de Identificación de Comportamiento de Recursantes Utilizando EVEAs (sección A), el segundo consiste en la Identificación del Conceptos Críticos de una Cursada (sección B), y por último de Identificación de Contenidos Débilmente Apropiados por Estudiantes (sección C).

\section{A. Proceso de Identificación de Comportamiento de Estudiantes Recursantes Utilizando EVEAs}

En esta sección se describe el caso de estudio (sección A1), luego se aplica el proceso (sección A2), y por último se describe la conclusión (sección A3).

\section{A1. Descripción del Caso}

Desde el año 2007, [99] la Secretaría de Gestión Académica de la Facultad Regional Buenos Aires (UTNFRBA) lidera un proyecto para la creación de aulas virtuales como apoyatura a la presencialidad, desarrollado en el marco del PROMEI (Programa de Mejoramiento para la Enseñanza de la Ingeniería) [100]. En el mismo se involucran distintas asignaturas homogéneas del plan de las Carreras de Ingeniería con la utilización de entornos virtuales, integrándolos paulatinamente al proceso de aprendizaje de los alumnos.

Un antecedente desarrollado en paralelo a este proyecto es la experiencia del curso de ingreso, en donde se pusieron en juego usos educativos de las TIC que se desarrollaron en el Entorno Virtual de Enseñanza y Aprendizaje (EVEA) que proveyó la Universidad para cada Facultad Regional.

A inicios del año 2008, profundizando esta línea de acción y atendiendo a la Ordenanza de la Universidad Tecnológica Nacional ํ 1129 "Cursado Intensivo" [101], la Secretaría de Gestión Académica de la F.R.B.A. presentó una nueva propuesta denominada "Mejoramiento de la calidad educativa favoreciendo la retención estudiantil mediante el uso de las nuevas tecnologías" cuyo objetivo General fue el de profundizar las acciones de Educación a Distancia en la Carrera de Grado en el Marco de la Ordenanza antes mencionada. Dentro de los objetivos específicos de dicha presentación se encontraban:

- Implementar el régimen de cursado intensivo para la aprobación de asignaturas de la carrera de grado en el ámbito de la Facultad Regional Buenos Aires.

- Integrar significativamente las nuevas tecnologías a la formación aprovechando las potencialidades que ofrecen.

- Capacitar a docentes/tutores en el uso de las herramientas de gestión del campus virtual de la Facultad.

- Preparar material didáctico apto para la intervención pedagógica en entornos virtuales.

Bajo estas circunstancias la Secretaría de Gestión Académica junto con la Cátedra de Matemática Discreta, asignatura del primer Nivel de la Carrera Ingeniería en Sistemas de Información, se abocaron a la generación del proyecto del "Cursado Intensivo de Matemática Discreta" [99].
La asignatura involucrada en esta investigación se dicta en forma cuatrimestral para la Carrera Ingeniería en Sistemas de Información que dicta la Facultad Regional Buenos Aires. Se pensó, en el momento de la implementación en cursos que se desarrollen con la modalidad a distancia, pero que tienen previsto instancias presenciales, dichas instancias tienen la siguiente característica:

[a] No obligatoria: clases de consulta

[b] Obligatoria: encuentro para la toma de parciales y recuperatorios.

Con la puesta en marcha de este Proyecto, la Facultad apunta a resolver, entre otros, problemas relacionados con la deserción y ofrecerle a los alumnos que tienen que recursar dicha asignatura, la posibilidad de cursarla bajo otra modalidad.

En la actualidad, para poder cursar de forma intensiva (Escuela de Verano presencial) una asignatura que la Facultad ofrece, los alumnos deben cumplir con las siguientes condiciones:

a) Posean la condición de alumno regular al momento de la inscripción.

b) Hayan sido cursantes de las asignaturas en cuestión en el Ciclo Lectivo que se realiza la inscripción a la Escuela de Verano en la UTN-FRBA y se hayan presentado, al menos, a dos instancias de evaluación.

c) No hayan sido dados de baja por inasistencias (estén incluidos en el Acta de Trabajos Prácticos - TPA).

d) Además, podrán inscribirse quienes no cumpliendo con los puntos b y c, hayan rendido por cuarta vez mal el final correspondiente (lo que los obligaría según Reglamento de Estudios a recursar la asignatura).

Las condiciones antes enunciadas han sido estipuladas fundamentalmente por temas presupuestarios, esto lleva aparejado que un número importante de alumnos no puedan cursarla, aunque sea su deseo hacerlo.

El hecho de poder hacer la cursada en forma semipresencial o a distancia lleva implícito, al entender de la Institución, varios elementos favorables a tener en cuenta:

a) La cursada podrá comenzar antes y así dedicarle más tiempo que el actual curso. Esto es así dado que no será necesario el trabajo de demasiados docentes, teniendo en cuenta que en el período de verano se encuentran de vacaciones.

b) Como ya se indicó, la institución ha establecido normas que restringen la inscripción, con el objeto de minimizar la cantidad de cursos a raíz de dos problemas centrales:

1- No es fácil conseguir los docentes que dicten este curso en época estival por una remuneración, además, que es menor a la establecida para una cursada estándar. Todo ello a raíz de cuestiones presupuestarias.

2- El recurso "aulas" es limitado dado que conviven en el mismo momento tres actividades académicas diferentes: los cursos de ingreso a las diferentes carreras, los exámenes finales y la Escuela de Verano. Con esta nueva propuesta, este tipo de restricciones no serían necesarias, dado que optimizaríamos tanto el recurso docente como el de espacio físico y, por ende, más alumnos podrían aprovechar esta oportunidad. Los alumnos podrían organizar su horario de estudio de mejor forma, ya que en la actualidad para este tipo de cursos hay un solo horario de cursada.

c) Teniendo en cuenta que los alumnos ya cursaron la asignatura en cuestión, cabe suponer que hay temas en los que solo necesitan repasar y otros a los que les debe dedicar más tiempo. 
d) Es un alto número de alumnos el que año tras año preguntan sobre la posibilidad de cursar estas asignaturas (la que conforman la escuela de verano) en la modalidad a distancia.

Por lo antes expuesto, el curso intensivo estaría dirigido a todos los alumnos que quieran cursar mediante esta modalidad y hayan sido cursantes, en este caso particular de la asignatura Matemática Discreta, en el Ciclo Lectivo que se realiza la inscripción en la UTN-FRBA o hayan rendido por cuarta vez mal el final correspondiente.

Entre los objetivos de propuesta podemos enumerar:

[a] Objetivo general:

[b] Implementar estrategias de innovación pedagógica basada en entornos virtuales.

Ofrecer una nueva modalidad de cursada, atendiendo en una primera instancia a alumnos de los dos primeros niveles de estudio apuntando al área de matemática.

Objetivos específicos:

[a] Desarrollar entornos virtuales de aprendizaje para el dictado de asignaturas del Ciclo General de Conocimientos Básicos, como ser, Matemática Discreta.

[b] Capacitar a los docente para trabajar bajo esta modalidad

[c] Capacitar a los tutores para acompañar el proceso de aprendizaje de los alumnos.

[d] Generar materiales multimediales que acompañen el proceso en el entorno virtual.

[e] Crear herramientas de gestión acordes a este proceso de enseñanza-aprendizaje.

[f] Desarrollar en los alumnos capacidades inherentes al compromiso que deben asumir con su propia formación.

La materia se encuentra dividida en unidades temáticas en las cuales el alumno deberá ir presentando trabajos prácticos para cada una de ellas. Un alumno aprueba la cursada a distancia si cumple con la entrega del $75 \%$ de los trabajos prácticos. La materia en esta modalidad fue cursada desde el año 2010 al 2012 por un total de 363 alumnos.

La materia está implementada en un EVEA bajo la plataforma Moodle la cual cuenta con módulos donde el alumno podrá realizar diferentes actividades:

1- Bajar el material de lectura: el alumno podrá bajar el material de lectura correspondiente a las diferentes unidades de la materia.

2- Subir trabajos prácticos: el alumno podrá subir los trabajos prácticos para cada una de las unidades (actividades). Los trabajos prácticos podrán ser subidos más de una vez si el docente lo requiere.

3- Leer foros: el alumno podrá acceder a leer los foros visualizando los diferentes temas de discusión. Una vez adentro de algún foro podrá entrar a leer algún tema de discusión específico del foro. Existen tres tipos de foros:

3.1. Aquellos relacionados con las diferentes unidades de las materias.

3.2. El foro de novedades, donde el docente publicará las novedades referentes a la materia.

3.3. Foro de alumnos, donde los alumnos podrán publicar cualquier tipo de consulta dirigida hacia los docentes o hacia el resto de los alumnos.

4- Crear nuevos temas de discusión en los foros. El alumno podrá crear nuevos temas de discusión en el foro 3.1 y el foro 3.3.
5- Agregar comentarios temas de discusión ya creados: el alumno podrá agregar algún comentario sobre algún tema de discusión de algún foro. Lo podrá realizar sobre los foros del tipo 3.1 y 3.3 "

Las variables relacionadas con cada una de las actividades descriptas anteriormente se ven reflejadas en la Tabla VI.

Cada uno de los campos previamente mencionados, tienen como valor posible los caracteres "SI" y "NO", con excepción del campo "Id_curso" e "Id_alumno", los cuáles son de tipo numérico.

El problema de negocio presentado consiste en estudiar a los alumnos con respecto a su participación en el curso con el objetivo de disminuir la cantidad de alumnos que desaprueban la cursada de la materia.

\section{B1.Aplicación del Proceso}

Paso 1: Conceptualización del dominio (figuras y tablas corridas)

La conceptualización del dominio del negocio se compone de 3 subpasos:

- Subpaso 1.1. Identificación los elementos relevantes del dominio

Para la idenificación de los elementos relevantes del dominio de negocio, se hace uso de las técnicas propuestas en [96]. Los formalismos resultantes de ejecutar dichas técnicas en el caso de estudio propuesto son la tabla término-categoríadefinición del dominio (Tabla VII) y la tabla conceptoatributo-relación-valor del dominio (Tabla VIII).

- Subpaso 1.2. Identificación de las relaciones entre elementos del dominio

TABLA VI. Listado de CAMPos REgistrados

\begin{tabular}{|c|c|}
\hline Campo & Descripción \\
\hline Id_curso & Es el número que identifica un único curso. \\
\hline id_alumno & Es el número que identifica a un único alumno. \\
\hline ingreso_curso & Cantidad de ingresos al EVEA. \\
\hline bajo_material & $\begin{array}{l}\text { Indica si el alumno bajó material de lectura de alguna } \\
\text { de las unidades de la materia. }\end{array}$ \\
\hline actividad tp & Indica si el alumno subió actividades de tp. \\
\hline subio_tp & Indica si subió más de un tp para alguna actividad. \\
\hline $\begin{array}{c}\text { vio_foro_unida } \\
\mathrm{d}\end{array}$ & $\begin{array}{l}\text { Indica si el alumno entro a alguno de los foros } \\
\text { correspondientes a las unidades de la materia. }\end{array}$ \\
\hline $\begin{array}{l}\text { vio_discusion } \\
\text { unidad }\end{array}$ & $\begin{array}{c}\text { Indica si el alumno entró a ver alguna discusión } \\
\text { particular de algún foro correspondiente a las } \\
\text { unidades. }\end{array}$ \\
\hline $\begin{array}{l}\text { comento_discu } \\
\text { sión_unidad }\end{array}$ & $\begin{array}{l}\text { Indica si el alumno realizó algún comentario en los } \\
\text { foros correspondientes a las unidades de la materia. }\end{array}$ \\
\hline $\begin{array}{c}\text { creo_discusion } \\
\text { unidad }\end{array}$ & $\begin{array}{l}\text { Indica si el alumno creo algún tema de discusión en un } \\
\text { foro correspondiente a una unidad }\end{array}$ \\
\hline $\begin{array}{c}\text { vio_foro_alum } \\
\text { no }\end{array}$ & Indica si el alumno entro a ver el foro de alumno. \\
\hline $\begin{array}{l}\text { vio_discusion } \\
\text { alumno }\end{array}$ & $\begin{array}{l}\text { Indica si el alumno entró a ver alguna discusión } \\
\text { particular del foro de alumnos. }\end{array}$ \\
\hline $\begin{array}{l}\text { comento_discu } \\
\text { sión_alumno }\end{array}$ & $\begin{array}{l}\text { Indica si el alumno comentó alguna discusión del foro } \\
\text { de alumnos. }\end{array}$ \\
\hline $\begin{array}{c}\text { creo_discusion } \\
\text { alumno }\end{array}$ & $\begin{array}{c}\text { Indica si el alumno creo algún tema de discusión en el } \\
\text { foro de alumnos. }\end{array}$ \\
\hline $\begin{array}{l}\text { vio_foro_nove } \\
\text { dades }\end{array}$ & Indica si el alumno entro a ver el foro de novedades. \\
\hline $\begin{array}{c}\text { vio_discusion } \\
\text { novedades }\end{array}$ & $\begin{array}{l}\text { Indica si el alumno entró a ver alguna discusión } \\
\text { particular del foro de novedades. }\end{array}$ \\
\hline $\begin{array}{c}\text { aprueba_cursa } \\
\mathrm{da}\end{array}$ & Indica si el alumno aprobó la cursada. \\
\hline
\end{tabular}

TABLA VII. TÉRMINO-CATEGORÍA-DEFINICIÓN DEL DOMINO APLICADA AL CASO DE ESTUDIO.

\begin{tabular}{|c|c|c|}
\hline Término & Categoría & Definición \\
\hline actividad_tp & Atributo & Indica si el alumno subió \\
\hline
\end{tabular}




\begin{tabular}{|c|c|c|}
\hline & & actividades de tp \\
\hline Alumno & Concepto & $\begin{array}{l}\text { Persona que realiza un } \\
\text { curso }\end{array}$ \\
\hline bajada_material & Atributo & $\begin{array}{c}\text { Indica si el alumno bajó } \\
\text { material de lectura de } \\
\text { alguna de las unidades de la } \\
\text { materia. }\end{array}$ \\
\hline $\begin{array}{c}\text { comentario_discusion } \\
\text { unidad }\end{array}$ & Atributo & $\begin{array}{l}\text { Indica si el alumno realizó } \\
\text { algún comentario en foros } \\
\text { correspondientes a unidades }\end{array}$ \\
\hline $\begin{array}{c}\text { comentarios_discusion } \\
\text { _alumno }\end{array}$ & Atributo & $\begin{array}{l}\text { Indica si el alumno comentó } \\
\text { alguna discusión del foro de } \\
\text { alumnos }\end{array}$ \\
\hline$\underset{\text { mno }}{\text { creacion_discusion_alu }}$ & Atributo & $\begin{array}{c}\text { Indica si el alumno creo } \\
\text { algún tema de discusión en } \\
\text { el foro de alumnos }\end{array}$ \\
\hline$\underset{\text { idad }}{\text { creacion_discusion_un }}$ & Atributo & $\begin{array}{l}\text { Indica si el alumno creo } \\
\text { algún tema de discusión en } \\
\text { un foro correspondiente a } \\
\text { una unidad }\end{array}$ \\
\hline Cursada & Atributo & $\begin{array}{c}\text { Indica si el alumno aprobó } \\
\text { la cursada }\end{array}$ \\
\hline Curso & Concepto & $\begin{array}{c}\text { Materia realizada en un } \\
\text { periodo del año }\end{array}$ \\
\hline Id_alumno & Atributo & $\begin{array}{l}\text { Identificación univoca de } \\
\text { cada alumno }\end{array}$ \\
\hline Id_curso & Atributo & $\begin{array}{l}\text { Identificación univoca de } \\
\text { cada curso }\end{array}$ \\
\hline $\begin{array}{c}\text { observaciones } \\
\text { discusion_foro_alum } \\
\text { no }\end{array}$ & Atributo & $\begin{array}{c}\text { Indica si el alumno entró a } \\
\text { ver alguna discusión } \\
\text { particular del foro de } \\
\text { alumnos } \\
\end{array}$ \\
\hline $\begin{array}{l}\text { observaciones_discusi } \\
\text { on_foro_novedades }\end{array}$ & Atributo & $\begin{array}{c}\text { Indica si el alumno entró a } \\
\text { ver alguna discusión } \\
\text { particular del foro de } \\
\text { novedades }\end{array}$ \\
\hline $\begin{array}{l}\text { observaciones_discusi } \\
\text { on_foro_unidad }\end{array}$ & Atributo & $\begin{array}{c}\text { Indica si el alumno entró a } \\
\text { ver alguna discusión } \\
\text { particular de algún foro } \\
\text { correspondiente a las } \\
\text { unidades }\end{array}$ \\
\hline $\begin{array}{c}\text { observaciones_foro_al } \\
\text { umno }\end{array}$ & Atributo & $\begin{array}{c}\text { Indica si el alumno entro a } \\
\text { ver el foro de alumno }\end{array}$ \\
\hline $\begin{array}{c}\text { observaciones_foro_no } \\
\text { vedades }\end{array}$ & Atributo & $\begin{array}{l}\text { Indica si el alumno entro a } \\
\text { ver el foro de novedades }\end{array}$ \\
\hline $\begin{array}{l}\text { Observaciones_foro_u } \\
\text { nidad }\end{array}$ & Atributo & $\begin{array}{c}\text { Indica si el alumno entro a } \\
\text { alguno de los foros } \\
\text { correspondientes a las } \\
\text { unidades de la materia. }\end{array}$ \\
\hline Obtuvo & Relación & $\begin{array}{l}\text { El alumno obtuvo como } \\
\text { resultado de la cursada }\end{array}$ \\
\hline Realiza & Relación & el alumno realiza un curso \\
\hline Realizó & Relación & $\begin{array}{c}\text { El alumno realizó la } \\
\text { descarga de algún material } \\
\text { de lectura del curso }\end{array}$ \\
\hline Realizó & Relación & $\begin{array}{c}\text { El alumno realizó más de } \\
\text { una subida de alguna } \\
\text { actividad del curso }\end{array}$ \\
\hline Realizó & Relación & $\begin{array}{c}\text { El alumno realizó } \\
\text { visualizaciones de algún } \\
\text { foro de las unidades de la } \\
\text { materia }\end{array}$ \\
\hline Realizó & Relación & $\begin{array}{c}\text { El alumno realizó } \\
\text { visualizaciones de alguna } \\
\text { discusión de algún foro } \\
\text { correspondiente a una } \\
\text { unidad } \\
\end{array}$ \\
\hline Realizó & Relación & $\begin{array}{l}\text { El alumno realizó algún } \\
\text { comentario en un foro de } \\
\text { unidad }\end{array}$ \\
\hline Realizó & Relación & $\begin{array}{c}\text { El alumno realizó la } \\
\text { creación de algún tema de } \\
\text { discusión en el algún foro } \\
\text { de unidad }\end{array}$ \\
\hline Realizó & Relación & $\begin{array}{c}\text { El alumno realizó } \\
\text { visualizaciones en el foro } \\
\text { de alumno }\end{array}$ \\
\hline Realizó & Relación & $\begin{array}{c}\text { El alumno realizó } \\
\text { visualizaciones en alguna }\end{array}$ \\
\hline
\end{tabular}

\begin{tabular}{|c|c|c|}
\hline Realizó & Relación & $\begin{array}{c}\text { discusión del foro de } \\
\text { alumnos }\end{array}$ \\
\hline Realizó & Relación & $\begin{array}{c}\text { El alumno realizó } \\
\text { comentarios en alguna } \\
\text { discusión del foro de } \\
\text { alumnos }\end{array}$ \\
\hline Realizó & Relación & $\begin{array}{c}\text { El alumno realizó la } \\
\text { creación de algún tema de } \\
\text { discusión en el foro de } \\
\text { alumnos }\end{array}$ \\
\hline Realizó & Relación & $\begin{array}{c}\text { El alumno realizó } \\
\text { visualizaciones en el foro } \\
\text { de novedades }\end{array}$ \\
\hline subida_tp & Atributo & $\begin{array}{c}\text { El alumno realizó } \\
\text { visualizaciones en alguna } \\
\text { discusión del foro de } \\
\text { novedades }\end{array}$ \\
\hline Subió & Relación & $\begin{array}{c}\text { El alumno subió actividades } \\
\text { para alguna actividad }\end{array}$ \\
\hline del curso
\end{tabular}

TABLA VIII. CONCEPTO-ATRIBUTO-RELACIÓN DEL DOMINO APLICADA AL CASO DE ESTUDIO.

\begin{tabular}{|c|c|c|c|}
\hline Concepto & Atributo & Relación & Valor \\
\hline Curso & Id curso & identifica & Numérico \\
\hline \multirow{15}{*}{ Alumno } & Id_alumno & identifica & Numérico \\
\hline & bajada material & realizó & SI - NO \\
\hline & actividad tp & subió & SI - NO \\
\hline & subida_tp & realizó & $\mathrm{SI}-\mathrm{NO}$ \\
\hline & observaciones_foro_unidad & realizó & SI - NO \\
\hline & $\begin{array}{l}\text { observaciones_discusion } \\
\text { foro alumno }\end{array}$ & realizó & $\mathrm{SI}-\mathrm{NO}$ \\
\hline & comentario_discusion_unidad & realizó & $\mathrm{SI}-\mathrm{NO}$ \\
\hline & creacion_discusion_unidad & realizó & SI - NO \\
\hline & $\begin{array}{c}\text { observaciones_discusion } \\
\text { foro_novedades }\end{array}$ & realizó & $\mathrm{SI}-\mathrm{NO}$ \\
\hline & observaciones_discusion_foro_unidad & realizó & SI - NO \\
\hline & comentarios_discusion_alumno & realizó & $\mathrm{SI}-\mathrm{NO}$ \\
\hline & creacion_discusion_alumno & realizó & $\mathrm{SI}-\mathrm{NO}$ \\
\hline & observaciones_foro_alumno & realizó & $\mathrm{SI}-\mathrm{NO}$ \\
\hline & observaciones_foro_novedades & realizó & SI - NO \\
\hline & cursada & obtuvo & SI - NO \\
\hline
\end{tabular}

TABLA IX. CONCEPTO-RELACIÓN DEL DOMINO APLICADA AL CASO DE ESTUDIO.

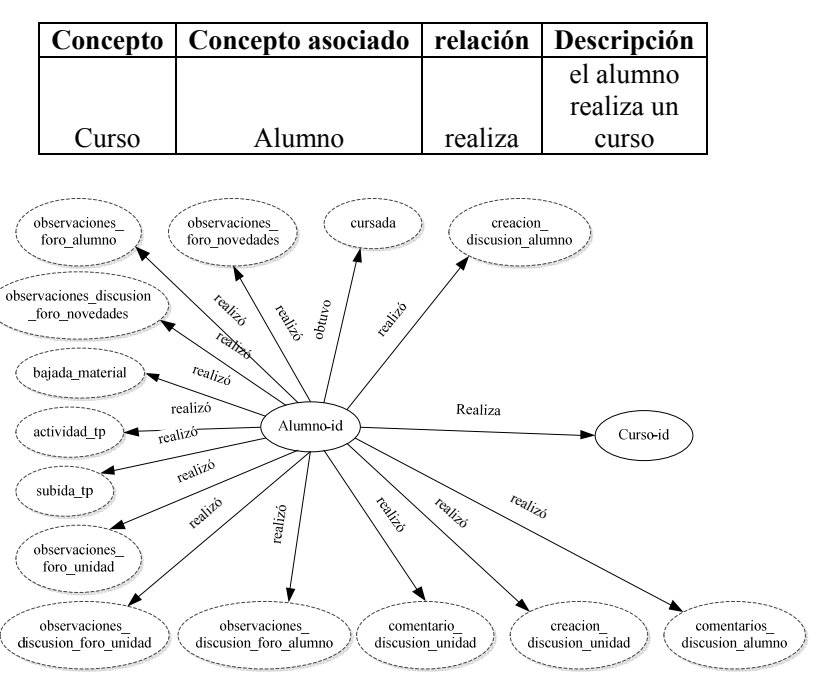

Fig. 10. Red Semántica del Modelo de Negocio aplicada al caso de estudio.

Para la identificación de las relaciones entre elementos del dominio de negocio, se hace uso la técnica propuesta en [96], la tabla concepto-relación del dominio. Como resultado de 
aplicar la técnica tabla concepto-relación del dominio al caso de estudio propuesto se obtiene la Tabla IX.

- Subpaso 1.3. Representación conceptual del dominio

Para la conceptualización del dominio del negocio, se hace uso de la técnica red semántica del modelo de negocio propuesto en [96]. El resultado de aplicar dicha técnica al caso de estudio propuesto, se presenta en la Figura 10.

Paso 2: Conceptualización del problema de explotación de información

La conceptualización del problema de explotación de información está compuesta por 5 subpasos:

- Subpaso 2.1. Identificación del problema de negocio y su traducción al problema de explotación de información.

A partir del problema de negocio definido en la descripción del caso de estudio (sección 5.1), se obtiene como problema de explotación de información:

"Identificar aquellas características relevantes del alumno que definen la aprobación o no del curso".

- Subpaso 2.2. Identificación de los conceptos pertenecientes al problema de explotación de información

A partir del problema de explotación de información se procede a seleccionar y determinar cuáles elementos están relacionados con el mismo. Para ello se implementa las técnicas tabla Término-Categoría-Definición del Problema de Explotación de Información y Tabla Concepto-AtributoRelación-Valor Extendida del Problema de Explotación de Información, propuestas en [96]. El resultado de aplicar cada una de ellas al caso de estudio propuesto, se presenta en las Tablas X y XI respectivamente.

- Subpaso 2.3. Identificación de las relaciones entre elementos del problema de explotación de información

Para la identificación de las relaciones entre elementos del problema de explotación de información, se implementa la técnica propuesta en [96]: la tabla concepto-relación del problema de explotación de información. El resultado de aplicar dicha tabla al caso de estudio propuesto se presenta en la Tabla XII.

- Subpaso 2.4. Identificación de dependencias entre los elementos conceptuales del problema

El objetivo de este paso es identificar aquellos elementos que presenten dependencias cognitivas con otros elementos los cuales brinden información redundante o afecten la comprensión del conocimiento oculto en los datos. Para ello se propone la tabla de dependencias cuyo objetivo es identificar las dependencias existentes entre los datos, y eliminar aquellas que se consideren perjudiciales para el desarrollo del proceso. La tabla de dependencias está compuesta por tres columnas: en la primera se registra el elemento que no posea dependencia, en la segunda el elemento dependiente del elemento anteriormente registrado, y en la tercera columna se registra la necesidad o no de eliminar el elemento dependiente. En la Tabla XIII se presentan los elementos identificados en el caso de estudio propuesto.

- Subpaso 2.5. Representación del problema de explotación de información

Para la conceptualización del problema de explotación de información, se hace uso de la técnica red semántica del problema de explotación propuesta en [96]. El resultado de aplicar dicha técnica al caso de estudio propuesto, se presenta en la Figura 11.

Paso 3: Identificación del proceso de explotación de información
A partir de las conceptualizaciones del dominio del negocio $\mathrm{y}$ del problema de explotación previamente presentadas, se establece el proceso de explotación de información a implementar, a través de aplicar el algoritmo de derivación del proceso de explotación de información propuesto en [96]. El proceso de explotación de información obtenido es: el proceso de Ponderación de Interdependencia de atributos.

Paso 4: Preparación de los datos

La preparación de los datos para la ejecución del proceso de explotación de información previamente detectado, consta de 3 subpasos:

- Subpaso 4.1: Selección de los campos asociados al problema de explotación de información

A partir de conceptualizar los distintos elementos involucrados se seleccionan aquellos campos asociados al problema de explotación de información previamente establecido, obteniéndose el listado de datos que conformarán la base de datos a implementar. En el caso de estudio propuesto, los campos a utilizar son:

- bajo_material

- actividad_tp

- subio_tp

- vio_foro_unidad

- vio_discusion_unidad

TABLA X. TÉRMINO-CATEGoRÍA-DEFINICIÓN DEL PROBLEMA DE EXPLOTACIÓN DE INFORMACIÓN APLICADA AL CASO DE ESTUDIO.

\begin{tabular}{|c|c|c|}
\hline Termino & Categoría & Descripción \\
\hline Alumno & Concepto & Persona que realiza un curso \\
\hline bajada_material & Atributo & $\begin{array}{l}\text { Indica si el alumno bajó material de } \\
\text { lectura de alguna de las unidades de } \\
\text { la materia. }\end{array}$ \\
\hline $\begin{array}{c}\text { Caracteristicas } \\
\text { relevantes }\end{array}$ & Concepto & $\begin{array}{c}\text { Las características relevantes definen } \\
\text { la aprobación de la cursada }\end{array}$ \\
\hline $\begin{array}{c}\text { comentario_discusio } \\
\text { n_unidad }\end{array}$ & Atributo & $\begin{array}{l}\text { Indica si el alumno realizó algún } \\
\text { comentario en los foros } \\
\text { correspondientes a las unidades de la } \\
\text { materia }\end{array}$ \\
\hline $\begin{array}{c}\text { comentarios_discusi } \\
\text { on_alumno }\end{array}$ & Atributo & $\begin{array}{l}\text { Indica si el alumno comentó alguna } \\
\text { discusión del foro de alumnos }\end{array}$ \\
\hline $\begin{array}{l}\text { creacion_discusion } \\
\text { alumno }\end{array}$ & Atributo & $\begin{array}{l}\text { Indica si el alumno creo algún tema } \\
\text { de discusión en el foro de alumnos }\end{array}$ \\
\hline $\begin{array}{c}\text { creacion_discusion_ } \\
\text { unidad }\end{array}$ & Atributo & $\begin{array}{c}\text { Indica si el alumno creo algún tema } \\
\text { de discusión en un foro } \\
\text { correspondiente a una unidad }\end{array}$ \\
\hline Cursada & Atributo & Indica si el alumno aprobó la cursada \\
\hline Id_alumno & Atributo & $\begin{array}{c}\text { Identificación univoca de cada } \\
\text { alumno }\end{array}$ \\
\hline $\begin{array}{c}\text { Id_caracteristicas_re } \\
\text { levantes }\end{array}$ & Atributo & $\begin{array}{c}\begin{array}{c}\text { Identificación univoca de las } \\
\text { características }\end{array} \\
\end{array}$ \\
\hline $\begin{array}{c}\text { observaciones } \\
\text { discusion_foro_alu } \\
\text { mno }\end{array}$ & Atributo & $\begin{array}{c}\text { Indica si el alumno entró a ver } \\
\text { alguna discusión particular del foro } \\
\text { de alumnos }\end{array}$ \\
\hline $\begin{array}{c}\text { observaciones_discu } \\
\text { sion } \\
\text { foro_novedades }\end{array}$ & Atributo & $\begin{array}{l}\text { Indica si el alumno entró a ver } \\
\text { alguna discusión particular del foro } \\
\text { de novedades }\end{array}$ \\
\hline $\begin{array}{l}\text { observaciones_discu } \\
\text { sion_foro_unidad }\end{array}$ & Atributo & $\begin{array}{l}\text { Indica si el alumno entró a ver } \\
\text { alguna discusión particular de algún } \\
\text { foro correspondiente a las unidades }\end{array}$ \\
\hline $\begin{array}{l}\text { observaciones_foro_ } \\
\text { alumno }\end{array}$ & Atributo & $\begin{array}{c}\text { Indica si el alumno entro a ver el } \\
\text { foro de alumno }\end{array}$ \\
\hline $\begin{array}{c}\text { observaciones_foro } \\
\text { novedades }\end{array}$ & Atributo & $\begin{array}{l}\text { Indica si el alumno entro a ver el } \\
\text { foro de novedades }\end{array}$ \\
\hline $\begin{array}{l}\text { Observaciones_foro } \\
\text { _unidad }\end{array}$ & Atributo & $\begin{array}{c}\text { Indica si el alumno entro a alguno de } \\
\text { los foros correspondientes a las } \\
\text { unidades de la materia. }\end{array}$ \\
\hline Según & Relación & $\begin{array}{c}\text { Las características relevantes del } \\
\text { alumno se definen según el resultado } \\
\text { de la cursada } \\
\end{array}$ \\
\hline Subconjunto & Relación & $\begin{array}{c}\text { bajada del material es un elemento } \\
\text { del conjunto de características } \\
\text { relevantes }\end{array}$ \\
\hline
\end{tabular}




\begin{tabular}{|c|c|c|}
\hline Subconjunto & Relación & $\begin{array}{l}\text { Observar discusiones del foro de } \\
\text { alumnos es un elemento del conjunto } \\
\text { de características relevantes }\end{array}$ \\
\hline Subconjunto & Relación & $\begin{array}{c}\text { Observar discusiones en el foro de } \\
\text { unidad es un elemento del conjunto } \\
\text { de características relevantes }\end{array}$ \\
\hline Subconjunto & Relación & $\begin{array}{l}\text { Observar discusiones del foro de } \\
\text { unidades es un elemento del conjunto } \\
\text { de características relevantes }\end{array}$ \\
\hline Subconjunto & Relación & $\begin{array}{l}\text { Observar el foro alumno es un } \\
\text { elemento del conjunto de } \\
\text { características relevantes }\end{array}$ \\
\hline Subconjunto & Relación & $\begin{array}{l}\text { Observar el foro novedades es un } \\
\text { elemento del conjunto de } \\
\text { características relevantes }\end{array}$ \\
\hline Subconjunto & Relación & $\begin{array}{c}\text { Observar el foro de las unidades es } \\
\text { un elemento del conjunto de } \\
\text { características relevantes }\end{array}$ \\
\hline Subconjunto & Relación & $\begin{array}{l}\text { Comentario en foro de unidad es un } \\
\text { elemento del conjunto de } \\
\text { características relevantes }\end{array}$ \\
\hline Subconjunto & Relación & $\begin{array}{l}\text { Comentarios sobre discusiones del } \\
\text { foro de alumnos es elemento } \\
\text { conjunto de características relevantes }\end{array}$ \\
\hline Subconjunto & Relación & $\begin{array}{l}\text { Crear un tema de discusión en foro } \\
\text { de alumnos es elemento del conjunto } \\
\text { de características relevantes }\end{array}$ \\
\hline Subconjunto & Relación & $\begin{array}{l}\text { Crear un tema de discusión en foro } \\
\text { de unidad es un elemento del } \\
\text { conjunto de características relevantes }\end{array}$ \\
\hline Subconjunto & Relación & $\begin{array}{c}\text { Subir más de un tp es un elemento } \\
\text { del conjunto de características } \\
\text { relevantes }\end{array}$ \\
\hline subida_tp & Atributo & $\begin{array}{c}\text { Indica si subió más de un tp para } \\
\text { alguna actividad }\end{array}$ \\
\hline
\end{tabular}

TABLA XI. CONCEPTO-ATRIBUTO-RELACIÓN-VALOR EXTENDIDA DEL PROBLEMA DE EXPLOTACIÓN DE INFORMACIÓN APLICADA AL CASO DE ESTUDIO.

\begin{tabular}{|c|c|c|c|c|}
\hline Concepto & Atributo & Relación & Entrada/ Salida & Valor \\
\hline \multirow[t]{12}{*}{$\begin{array}{c}\text { Características } \\
\text { relevantes }\end{array}$} & $\begin{array}{c}\text { Identifica } \\
\text { dor }\end{array}$ & identifica & Salida & $\begin{array}{c}\text { Numéric } \\
\text { o }\end{array}$ \\
\hline & $\begin{array}{c}\text { bajada_m } \\
\text { aterial }\end{array}$ & subconjunto & $\begin{array}{c}\text { Elemento } \\
\text { Conjunto Salida }\end{array}$ & $\mathrm{SI}-\mathrm{NO}$ \\
\hline & $\begin{array}{l}\text { actividad } \\
\text { tp }\end{array}$ & subconjunto & $\begin{array}{c}\text { Elemento } \\
\text { Conjunto Salida }\end{array}$ & $\mathrm{SI}-\mathrm{NO}$ \\
\hline & subida tp & subconjunto & $\begin{array}{c}\text { Elemento } \\
\text { Conjunto Salida }\end{array}$ & $\mathrm{SI}-\mathrm{NO}$ \\
\hline & $\begin{array}{l}\text { observaci } \\
\text { ones_for } \\
\text { o unidad }\end{array}$ & subconjunto & $\begin{array}{c}\text { Elemento } \\
\text { Conjunto Salida }\end{array}$ & $\mathrm{SI}-\mathrm{NO}$ \\
\hline & $\begin{array}{c}\text { observaci } \\
\text { ones_disc } \\
\text { usion } \\
\text { foro_alu } \\
\text { mno }\end{array}$ & subconjunto & $\begin{array}{c}\text { Elemento } \\
\text { Conjunto Salida }\end{array}$ & $\mathrm{SI}-\mathrm{NO}$ \\
\hline & $\begin{array}{c}\text { comentar } \\
\text { io_discus } \\
\text { ion_unid } \\
\text { ad }\end{array}$ & subconjunto & $\begin{array}{c}\text { Elemento } \\
\text { Conjunto Salida }\end{array}$ & SI - NO \\
\hline & $\begin{array}{c}\text { creacion_ } \\
\text { discusion } \\
\text { unidad }\end{array}$ & subconjunto & $\begin{array}{c}\text { Elemento } \\
\text { Conjunto Salida }\end{array}$ & SI - NO \\
\hline & $\begin{array}{c}\text { observaci } \\
\text { ones_disc } \\
\text { usion } \\
\text { foro_no } \\
\text { vedades }\end{array}$ & subconjunto & $\begin{array}{c}\text { Elemento } \\
\text { Conjunto Salida }\end{array}$ & SI - NO \\
\hline & $\begin{array}{l}\text { observaci } \\
\text { ones_disc } \\
\text { usion_for } \\
\text { o_unidad }\end{array}$ & subconjunto & $\begin{array}{c}\text { Elemento } \\
\text { Conjunto Salida }\end{array}$ & SI - NO \\
\hline & $\begin{array}{c}\text { comentar } \\
\text { ios_discu } \\
\text { sion_alu } \\
\text { mno }\end{array}$ & subconjunto & $\begin{array}{c}\text { Elemento } \\
\text { Conjunto Salida }\end{array}$ & SI - NO \\
\hline & & & Elemento & \\
\hline
\end{tabular}

\begin{tabular}{|c|c|c|c|c|}
\hline & $\begin{array}{c}\text { discusion } \\
\text { alumno }\end{array}$ & & Conjunto Salida & \\
\hline \multirow{7}{*}{$\begin{array}{c}\text { observaci } \\
\text { ones_for } \\
\text { o_alumn } \\
\text { o }\end{array}$} & subconjunto & & $\begin{array}{c}\text { Elemento } \\
\text { Conjunto Salida }\end{array}$ & \\
\cline { 2 - 5 } & $\begin{array}{c}\text { observaci } \\
\text { ones_for } \\
\text { o_noveda } \\
\text { des }\end{array}$ & subconjunto & SI - NO \\
\hline \multirow{7}{*}{ Alumno } & $\begin{array}{c}\text { Id_alumn } \\
\text { o }\end{array}$ & identifica & Nalida & SI - NO \\
\cline { 2 - 5 } & cursada & según & Entrada & SI - NO \\
\hline
\end{tabular}

TABLA XII. CONCEPTO-RELACIÓN DEL PROBlema DE EXPLOTACIÓN DE INFORMACIÓN APLICADA AL CASO DE ESTUDIO.

\begin{tabular}{|c|c|c|c|}
\hline Concepto & $\begin{array}{c}\text { Concept } \\
\text { o } \\
\text { asociado }\end{array}$ & $\begin{array}{c}\text { Relac } \\
\text { ión }\end{array}$ & Descripción \\
\hline $\begin{array}{c}\text { Característica } \\
\text { s relevantes }\end{array}$ & Alumno & $\begin{array}{c}\text { defin } \\
\text { en }\end{array}$ & $\begin{array}{c}\text { Las características relevantes } \\
\text { definen la cursada del alumno }\end{array}$ \\
\hline
\end{tabular}

TABLA XIII. DEPENDENCIAS APLICADAS AL CASO DE ESTUdio.

\begin{tabular}{|c|c|c|}
\hline Elemento & $\begin{array}{c}\text { Elemento } \\
\text { dependiente }\end{array}$ & Eliminar \\
\hline actividad_tp & subida_tp & NO \\
\hline
\end{tabular}

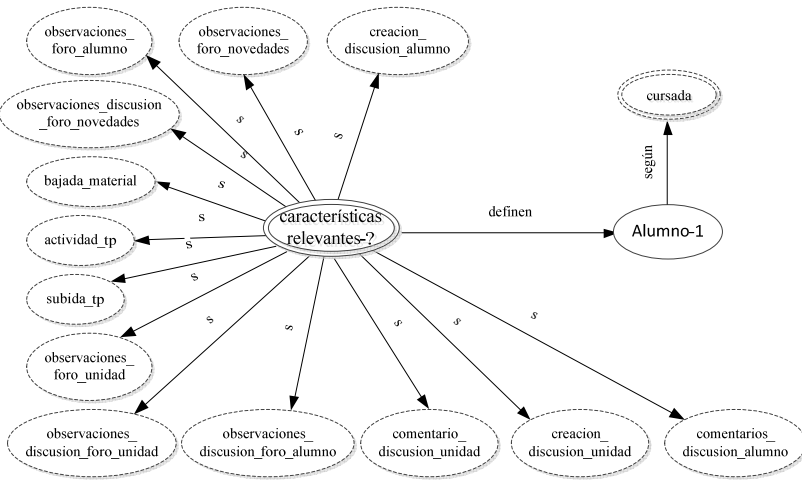

Fig. 11. Red Semántica del Problema de Explotación de Información aplicada al caso de estudio.

- comento_discusión_unidad

- creo_discusion_unidad

- vio_foro_alumno

- vio_discusion_alumno

- comento_discusión_alumno

- creo_discusion_alumno

- vio_foro_novedades

- vio_discusion_novedades

- aprueba_cursada

- Subpaso 4.2: Conversión de los datos A partir de los algoritmos de minería de datos seleccionados, en base al proceso de explotación de información determinado, puede ser necesario convertir el tipo de dato de alguno de los campos seleccionados. Para el caso de estudio propuesto, no fue necesario convertir ningún dato.

- Subpaso 4.3: Generación de la base de datos

Una vez identificados y convertidos los datos, es necesario realizar un proceso que integre todos los campos seleccionados en una única y misma fuente de datos. El resultado de aplicar el subpaso actual es la generación de la base de datos en la cual se implementará el proceso de explotación de información.

Paso 5: Implementación 
El paso implementación está conformado por 2 subpasos:

- Subpaso 5.1: Implementación

Este subpaso tiene como objetivo implementar el proceso de explotación de información identificado (mediante la ejecución de los algoritmos de minería de datos), en la base de datos generada en el paso anterior.

- Subpaso 5.2: Interpretación de los resultados

A partir de los resultados obtenidos en el subpaso anterior, se realiza una interpretación de los mismos cuyo objetivo es identificar información relevante, descartando aquella que no sea fiable, y presentar la información obtenida. La información obtenida del caso de estudio presentado es:

Los atributos de mayor incidencia para la desaprobación del curso son:

- comento_discusion_unidad $=\mathrm{NO}$, con un $91 \%$ de incidencia.

- vio_discusion_novedades $=\mathrm{NO}$, con un $86 \%$ de incidencia.

- comento_discusion_alumno $=\mathrm{NO}$, con un $81 \%$ de incidencia.

- actividad_tp $=$ NO, con un $73 \%$ de incidencia.

Adicionalmente, los atributos de mayor incidencia para la aprobación del curso son:

- actividad_tp $=$ SI, con un $100 \%$ de incidencia.

- vio_discusion_unidad=SI, con un $100 \%$ de incidencia.

- vio_foro_unidad $=$ SI, con un 100\% de incidencia.

Es decir, que los atributos que tienen mayor influencia para determinar que un alumno no apruebe la cursada son: si no comenta en algún foro de alguna unidad, si no observa las discusiones en los foros de novedades, si no comenta en las discusiones en los foros de alumnos y si no realiza las actividades. Mientras que para determinar que un alumno aprueba la cursada, son: que realice las actividades, que vea las discusiones y los foros de las unidades.

\section{A3. Conclusión del Caso de Validación}

En este caso de estudio se ha presentado un proceso basado en explotación de información orientado a encontrar patrones sobre el comportamiento de estudiantes que cursan asignaturas universitarias mediadas por EVEA.

Se ha ilustrado el uso del proceso propuesto con una prueba de concepto en el dominio de alumnos que recursan en la modalidad virtual una materia del área de ciencias básicas cuya primera cursada fue presencial. Este caso difiere de los descriptos en [28][24] en que a diferencia de los alumnos considerados en aquellos casos, en el que se presenta aquí los alumnos tuvieron un primer acercamiento presencial a los contenidos.

La población estudiada estuvo integrada por 363 estudiantes, que al término del curso virtual aprobaron el curso $31,95 \%$, lo desaprobaron el $41,32 \%$, y lo abandonaron el $26,72 \%$.

Los resultados obtenidos son intuitivamente válidos y no presentan indicios que contraríen las creencias del equipo docente sobre las condiciones de aprobación del curso en esta modalidad. Sin embargo, con relación a las condiciones de desaprobación y considerando que la población estudiada era pequeña, el hecho que los atributos de mayor incidencia para la desaprobación presenten porcentajes sensiblemente por debajo del $100 \%$ se considera un indicador que permite postular que la replicación del proceso sobre una población por lo menos mayor en un orden de magnitud, puede hacer emerger atributos específicos que permitan refinar en distintos grupos las causales de desaprobación.
El proceso propuesto constituye una nueva herramienta de diagnóstico en el área; y si bien los resultados obtenidos en este estadio son consistentes, solo sirven para ilustrar la aplicación de la solución propuesta.

\section{B. Identificación de Conceptos Críticos de una Cursada}

En esta sección se describe el caso de estudio (sección B1), luego se aplica el proceso (sección B2), y por último se describe la conclusión (sección B3).

\section{B1. Descripción del Caso}

La carrera Ingeniería en Sistemas de Información de la de la Universidad Tecnológica Nacional Facultad Regional Buenos Aires (UTN-FRBA) tiene un programa académico el cual divide la cursada de materias a lo largo de cinco años. Análisis de Sistemas [102] es una de las materias de segundo año y troncales de la carrera la cual se focaliza en la enseñanza de la herramienta: diagrama de Flujo de Datos (DFD). El aprendizaje de esta herramienta para el alumno resulta dificultosa generando una cantidad de desaprobados en los exámenes parciales, incluso generando a veces, que el alumno termine recursando la materia. Por tal motivo se desea describir la calificación final de los alumnos, en base a los resultados obtenidos en cada una de las áreas de evaluación. Cuando se evalúa al alumno, para aprobar DFD el alumno debe tener bien el Diagrama de Contexto, la Tabla de Eventos y el DFD propiamente dicho. Se registra un identificador por alumno, además de los atributos de evaluación vinculados que se identifican son (si el alumno es capaz de): definir alcance sistema, identificar entidades, identificar entradas, identificar salidas, identificar funciones, identificar activación, identificar respuestas, graficar procesos, asignar activación, asignar entradas, asignar salidas, definir demoras e identificar comunicación entre procesos. Los atributos pueden tomar los valores: bien (B), Regular (R) y Mal (M). Cada uno de los atributos de evaluación mencionados anteriormente corresponde a alguna de las herramientas que conforman el DFD. Por último se registra un campo que define el resultado de la cursada del alumno, cuyos valores son Aprobó (A) o Desaprobó (D) la cursada. La base de datos cuenta con 101 casos para su estudio.

\section{B1. Aplicación del Proceso}

Paso 1: $\quad$ Conceptualización del dominio

La conceptualización del dominio del negocio se compone de 3 subpasos:

- Subpaso 1.1. Identificación los elementos relevantes del dominio.

Los formalismos resultantes de ejecutar el paso actual son las tablas término-categoría-definición del dominio y conceptoatributo-relación-valor del dominio (tabla XIV y XV respectivamente).

- Subpaso 1.2. Identificación de las relaciones entre elementos del dominio.

La ejecución de la técnica tabla concepto-relación del dominio en el caso de estudio propuesto no identifica relaciones, dado que solo existe un único concepto.

- Subpaso 1.3. Representación conceptual del dominio El resultado de aplicar dicha técnica al caso de estudio, se presenta en la Figura 12.

Paso 2: Conceptualización del problema de explotación de información

La conceptualización del problema de explotación de información está compuesta por 5 subpasos: 
- Subpaso 2.1. Identificación del problema de negocio y su traducción al problema de explotación de información A partir del problema de negocio definido en la sección 5.1, se define el siguiente Problema de Explotación de Información: "Identificar las reglas que describan el resultado del alumno en base a las condiciones de evaluación."

- Subpaso 2.2. Identificación de los conceptos pertenecientes al problema de explotación de información

A partir del problema de explotación de información se procede a seleccionar y determinar cuáles elementos están relacionados con el mismo, implementando las tablas Término-Categoría-Definición del Problema de Explotación de Información y Tabla Concepto-Atributo-Relación-Valor Extendida del Problema de Explotación de Información (tablas XVI y XVII respectivamente).

TABLA XIV. TÉRMINO-CATEGORÍA-DEFINICIÓN DEL DOMINO APLICADA AL CASO DE ESTUDIO

\begin{tabular}{|c|c|c|}
\hline Término & Categoría & Definición \\
\hline Alumno & Concepto & $\begin{array}{l}\text { Estudiante de la materia Análisis de } \\
\text { Sistemas }\end{array}$ \\
\hline $\begin{array}{l}\text { Asigna las } \\
\text { entradas y salidas } \\
\text { a cada proceso }\end{array}$ & Atributo & $\begin{array}{c}\text { Posibilidad del alumno de Asignar las } \\
\text { entradas y salidas de cada proceso en el } \\
\text { DFD }\end{array}$ \\
\hline $\begin{array}{c}\text { Define las } \\
\text { demoras }\end{array}$ & Atributo & $\begin{array}{c}\text { Posibilidad del alumno de definir las } \\
\text { demoras }\end{array}$ \\
\hline es capaz de & Relación & $\begin{array}{l}\text { El alumno es capaz de identificar el } \\
\text { alcance del sistema }\end{array}$ \\
\hline es capaz de & Relación & $\begin{array}{l}\text { El alumno es capaz de Identifica entidades } \\
\text { externas }\end{array}$ \\
\hline es capaz de & Relación & $\begin{array}{l}\text { El alumno es capaz de Identifica entradas } \\
\text { y salidas }\end{array}$ \\
\hline es capaz de & Relación & $\begin{array}{l}\text { El alumno es capaz de Puede identificar } \\
\text { funciones? }\end{array}$ \\
\hline es capaz de & Relación & $\begin{array}{l}\text { El alumno es capaz de Identifica la forma } \\
\text { de activación }\end{array}$ \\
\hline es capaz de & Relación & $\begin{array}{c}\text { El alumno es capaz de Identifica las } \\
\text { respuestas }\end{array}$ \\
\hline es capaz de & Relación & $\begin{array}{c}\text { El alumno es capaz de Grafica los } \\
\text { procesos de nivel } 1 \text { según TE }\end{array}$ \\
\hline es capaz de & Relación & $\begin{array}{c}\text { El alumno es capaz de Asigna las entradas } \\
\text { y salidas a cada proceso }\end{array}$ \\
\hline es capaz de & Relación & $\begin{array}{l}\text { El alumno es capaz de Marca la activación } \\
\text { de los procesos }\end{array}$ \\
\hline es capaz de & Relación & $\begin{array}{c}\text { El alumno es capaz de Identifica la } \\
\text { comunicación entre procesos }\end{array}$ \\
\hline es capaz de & Relación & El alumno es capaz de Define las demoras \\
\hline $\begin{array}{l}\text { Grafica los } \\
\text { procesos de nivel } \\
1 \text { según TE }\end{array}$ & Atributo & $\begin{array}{l}\text { Posibilidad del alumno de graficar los } \\
\text { procesos de nivel } 1 \text { según la TE }\end{array}$ \\
\hline Identifica & Relación & $\begin{array}{c}\text { El alumno se identifica con un código } \\
\text { único }\end{array}$ \\
\hline $\begin{array}{l}\text { Identifica el } \\
\text { alcance del } \\
\text { sistema }\end{array}$ & Atributo & $\begin{array}{l}\text { Posibilidad del alumno de identificar el } \\
\text { alcance del sistema }\end{array}$ \\
\hline $\begin{array}{l}\text { Identifica } \\
\text { entidades } \\
\text { externas } \\
\end{array}$ & Atributo & $\begin{array}{c}\text { Posibilidad del alumno de identificar las } \\
\text { entidades externas que interactúan con el } \\
\text { sistema } \\
\end{array}$ \\
\hline $\begin{array}{c}\text { Identifica } \\
\text { entradas y salidas }\end{array}$ & Atributo & $\begin{array}{l}\text { Posibilidad del alumno de identificar las } \\
\text { entradas y salidas del sistema }\end{array}$ \\
\hline $\begin{array}{l}\text { Identifica la } \\
\text { comunicación } \\
\text { entre procesos }\end{array}$ & Atributo & $\begin{array}{l}\text { Posibilidad del alumno de identificar la } \\
\text { comunicación entre los procesos }\end{array}$ \\
\hline $\begin{array}{l}\text { Identifica la } \\
\text { forma de } \\
\text { activación }\end{array}$ & Atributo & $\begin{array}{l}\text { Posibilidad del alumno de identificar la } \\
\text { forma en la cual se activa el sistema }\end{array}$ \\
\hline $\begin{array}{l}\text { Identifica las } \\
\text { respuestas }\end{array}$ & Atributo & $\begin{array}{c}\text { Posibilidad del alumno de identificar las } \\
\text { respuestas que el sistema provee a las } \\
\text { entidades externas }\end{array}$ \\
\hline Identificador & Atributo & $\begin{array}{l}\text { Código Único que permite identificar a un } \\
\text { alumno }\end{array}$ \\
\hline $\begin{array}{c}\text { Marca la } \\
\text { activación de los } \\
\text { procesos }\end{array}$ & Atributo & $\begin{array}{l}\text { Posibilidad del alumno de identificar la } \\
\text { activación de los procesos }\end{array}$ \\
\hline
\end{tabular}

\begin{tabular}{|c|c|c|} 
Obtuvo & Relación & El alumno obtuvo un resultado \\
\hline $\begin{array}{c}\text { Puede identificar } \\
\text { funciones? }\end{array}$ & Atributo & $\begin{array}{c}\text { Posibilidad del alumno de identificar las } \\
\text { funcionalidades del sistema }\end{array}$ \\
\hline Resultado & Atributo & Calificación que obtuvo el alumno \\
\hline
\end{tabular}

- Subpaso 2.3. Identificación de las relaciones entre elementos del problema de explotación de información

Para la identificación de las relaciones entre elementos del problema de explotación de información, se implementa la técnica tabla concepto-relación del problema de explotación de información (Tabla XVIII).

- Subpaso 2.4. Identificación de dependencias entre los elementos conceptuales del problema

TABLA XV. CONCEPTO-ATRIBUTO-RELACIÓN-VALOR DEL DOMINO APLICADA AL CASO DE ESTUDIO

\begin{tabular}{|c|c|c|c|}
\hline Concepto & Atributo & Relación & Valor \\
\hline \multirow[t]{13}{*}{ Alumno } & identificador & identifica & Numérico \\
\hline & $\begin{array}{c}\text { Identifica el alcance del } \\
\text { sistema }\end{array}$ & es capaz de & $B-R-M$ \\
\hline & $\begin{array}{c}\text { Identifica entidades } \\
\text { externas }\end{array}$ & es capaz de & $B-R-M$ \\
\hline & Identifica entradas y salidas & es capaz de & $\mathrm{B}-\mathrm{R}-\mathrm{M}$ \\
\hline & $\begin{array}{l}\text { Puede identificar } \\
\text { funciones? }\end{array}$ & es capaz de & $B-R-M$ \\
\hline & $\begin{array}{c}\text { Identifica la forma de } \\
\text { activación }\end{array}$ & es capaz de & $\mathrm{B}-\mathrm{R}-\mathrm{M}$ \\
\hline & Identifica las respuestas & es capaz de & B - R - M \\
\hline & $\begin{array}{l}\text { Grafica los procesos de } \\
\text { nivel } 1 \text { según TE }\end{array}$ & es capaz de & $B-R-M$ \\
\hline & $\begin{array}{l}\text { Asigna las entradas y } \\
\text { salidas a cada proceso }\end{array}$ & es capaz de & $\mathrm{B}-\mathrm{R}-\mathrm{M}$ \\
\hline & $\begin{array}{l}\text { Marca la activación de los } \\
\text { procesos }\end{array}$ & es capaz de & $B-R-M$ \\
\hline & $\begin{array}{c}\text { Identifica la comunicación } \\
\text { entre procesos }\end{array}$ & es capaz de & $\mathrm{B}-\mathrm{R}-\mathrm{M}$ \\
\hline & Define las demoras & es capaz de & $\mathrm{B}-\mathrm{R}-\mathrm{M}$ \\
\hline & Resultado & Obtuvo & $\mathrm{D}-\mathrm{A}$ \\
\hline
\end{tabular}

TABLA XVI. TÉRMINO-CATEGORÍA-DEFINICIÓN DEL PROBLEMA DE EXPLOTACIÓN DE INFORMACIÓN APLICADA AL CASO DE ESTUDIO

\begin{tabular}{|c|c|c|}
\hline Termino & Categoría & Descripción \\
\hline Alumno & Concepto & $\begin{array}{l}\text { Estudiante de la materia Análisis de } \\
\text { Sistemas }\end{array}$ \\
\hline $\begin{array}{l}\text { Asigna las entradas } \\
\text { y salidas a cada } \\
\text { proceso } \\
\end{array}$ & Atributo & $\begin{array}{c}\text { Posibilidad del alumno de Asignar } \\
\text { las entradas y salidas de cada } \\
\text { proceso en el DFD }\end{array}$ \\
\hline Define las demoras & Atributo & $\begin{array}{l}\text { Posibilidad del alumno de definir las } \\
\text { demoras }\end{array}$ \\
\hline $\begin{array}{l}\text { Grafica los } \\
\text { procesos de nivel } 1 \\
\text { según TE }\end{array}$ & Atributo & $\begin{array}{l}\text { Posibilidad del alumno de graficar } \\
\text { los procesos de nivel } 1 \text { según la TE }\end{array}$ \\
\hline Identifica & Relación & $\begin{array}{l}\text { El alumno se identifica con un } \\
\text { código único }\end{array}$ \\
\hline Identifica & Relación & $\begin{array}{l}\text { Una regla se identifica a partir de un } \\
\text { código único }\end{array}$ \\
\hline $\begin{array}{l}\text { Identifica el alcance } \\
\text { del sistema }\end{array}$ & Atributo & $\begin{array}{l}\text { Posibilidad del alumno de identificar } \\
\text { el alcance del sistema }\end{array}$ \\
\hline $\begin{array}{l}\text { Identifica entidades } \\
\text { externas }\end{array}$ & Atributo & $\begin{array}{c}\text { Posibilidad del alumno de identificar } \\
\text { las entidades externas que } \\
\text { interactúan con el sistema }\end{array}$ \\
\hline $\begin{array}{l}\text { Identifica entradas } \\
\text { y salidas }\end{array}$ & Atributo & $\begin{array}{l}\text { Posibilidad del alumno de identificar } \\
\text { las entradas y salidas del sistema }\end{array}$ \\
\hline $\begin{array}{c}\text { Identifica la } \\
\text { comunicación entre } \\
\text { procesos } \\
\end{array}$ & Atributo & $\begin{array}{l}\text { Posibilidad del alumno de identificar } \\
\text { la comunicación entre los procesos }\end{array}$ \\
\hline $\begin{array}{l}\text { Identifica la forma } \\
\text { de activación }\end{array}$ & Atributo & $\begin{array}{l}\text { Posibilidad del alumno de identificar } \\
\text { la forma en la cual se activa el } \\
\text { sistema }\end{array}$ \\
\hline $\begin{array}{l}\text { Identifica las } \\
\text { respuestas }\end{array}$ & Atributo & $\begin{array}{l}\text { Posibilidad del alumno de identificar } \\
\text { las respuestas que el sistema provee } \\
\text { a las entidades externas }\end{array}$ \\
\hline
\end{tabular}




\begin{tabular}{|c|c|c|}
\hline Identificador & Atributo & $\begin{array}{c}\text { Código Único que permite } \\
\text { identificar a un alumno }\end{array}$ \\
\hline Identificador & Atributo & $\begin{array}{c}\text { Código Unico que permite } \\
\text { identificar a una regla }\end{array}$ \\
\hline $\begin{array}{c}\text { Marca la activación } \\
\text { de los procesos }\end{array}$ & Atributo & $\begin{array}{c}\text { Posibilidad del alumno de identificar } \\
\text { la activación de los procesos }\end{array}$ \\
\hline $\begin{array}{c}\text { Puede identificar } \\
\text { funciones? }\end{array}$ & Atributo & $\begin{array}{c}\text { Posibilidad del alumno de identificar } \\
\text { las funcionalidades del sistema }\end{array}$ \\
\hline Regla & Concepto & $\begin{array}{c}\text { Descripción del resultado obtenido } \\
\text { por el alumno en base a los } \\
\text { elementos de evaluación }\end{array}$ \\
\hline Resultado & Atributo & Calificación que obtuvo el alumno \\
\hline Según & Relación & $\begin{array}{c}\text { Las reglas que definen al alumno se } \\
\text { definen según los elementos de } \\
\text { evaluación }\end{array}$ \\
\hline Subconjunto & Relación & $\begin{array}{c}\text { Identifica el alcance del sistema es } \\
\text { un elemento del conjunto a evaluar }\end{array}$ \\
\hline Subconjunto & Relación & $\begin{array}{c}\text { Identifica entidades externas es un } \\
\text { elemento del conjunto a evaluar }\end{array}$ \\
\hline Subconjunto & Relación & $\begin{array}{c}\text { Identifica entradas y salidas es un } \\
\text { elemento del conjunto a evaluar }\end{array}$ \\
\hline Subconjunto & Relación & $\begin{array}{c}\text { Puede identificar funciones? es un } \\
\text { elemento del conjunto a evaluar }\end{array}$ \\
\hline Subconjunto a evaluar
\end{tabular}

TABLA XVII. CONCEPTO-ATRIBUTO-RELACIÓN-VALOR EXTENDIDA DEL PROCESO DE EXPLOTACIÓN DE INFORMACIÓN APLICADA AL CASO DE ESTUDIO

\begin{tabular}{|c|c|c|c|c|}
\hline Concepto & Atributo & Relación & Entrada/Salida & Valor \\
\hline \multirow[t]{10}{*}{ Regla } & Identificador & identifica & Salida & Numérico \\
\hline & $\begin{array}{c}\text { Identifica el } \\
\text { alcance del } \\
\text { sistema }\end{array}$ & subconjunto & $\begin{array}{c}\text { Elemento } \\
\text { Conjunto Salida }\end{array}$ & $\mathrm{B}-\mathrm{R}-\mathrm{M}$ \\
\hline & $\begin{array}{c}\text { Identifica } \\
\text { entidades } \\
\text { externas } \\
\end{array}$ & subconjunto & $\begin{array}{c}\text { Elemento } \\
\text { Conjunto Salida }\end{array}$ & $\mathrm{B}-\mathrm{R}-\mathrm{M}$ \\
\hline & $\begin{array}{c}\text { Identifica } \\
\text { entradas y } \\
\text { salidas } \\
\end{array}$ & subconjunto & $\begin{array}{c}\text { Elemento } \\
\text { Conjunto Salida }\end{array}$ & $\mathrm{B}-\mathrm{R}-\mathrm{M}$ \\
\hline & $\begin{array}{c}\text { Puede } \\
\text { identificar } \\
\text { funciones? }\end{array}$ & subconjunto & $\begin{array}{c}\text { Elemento } \\
\text { Conjunto Salida }\end{array}$ & $B-R-M$ \\
\hline & $\begin{array}{c}\text { Identifica la } \\
\text { forma de } \\
\text { activación }\end{array}$ & subconjunto & $\begin{array}{c}\text { Elemento } \\
\text { Conjunto Salida }\end{array}$ & $\mathrm{B}-\mathrm{R}-\mathrm{M}$ \\
\hline & $\begin{array}{c}\text { Identifica las } \\
\text { respuestas }\end{array}$ & subconjunto & $\begin{array}{c}\text { Elemento } \\
\text { Conjunto Salida }\end{array}$ & $\mathrm{B}-\mathrm{R}-\mathrm{M}$ \\
\hline & $\begin{array}{c}\text { Grafica los } \\
\text { procesos de } \\
\text { nivel } 1 \text { según } \\
\text { TE } \\
\end{array}$ & subconjunto & $\begin{array}{c}\text { Elemento } \\
\text { Conjunto Salida }\end{array}$ & $\mathrm{B}-\mathrm{R}-\mathrm{M}$ \\
\hline & $\begin{array}{c}\text { Asigna las } \\
\text { entradas y } \\
\text { salidas a cada } \\
\text { proceso }\end{array}$ & subconjunto & $\begin{array}{c}\text { Elemento } \\
\text { Conjunto Salida }\end{array}$ & $\mathrm{B}-\mathrm{R}-\mathrm{M}$ \\
\hline & $\begin{array}{c}\text { Marca la } \\
\text { activación de } \\
\text { los procesos }\end{array}$ & subconjunto & $\begin{array}{c}\text { Elemento } \\
\text { Conjunto Salida }\end{array}$ & $\mathrm{B}-\mathrm{R}-\mathrm{M}$ \\
\hline
\end{tabular}

\begin{tabular}{|c|c|c|c|c|}
\hline & $\begin{array}{c}\text { Identifica la } \\
\text { comunicación } \\
\text { entre procesos }\end{array}$ & subconjunto & $\begin{array}{c}\text { Elemento } \\
\text { Conjunto Salida }\end{array}$ & $\mathrm{B}-\mathrm{R}-\mathrm{M}$ \\
\cline { 2 - 5 } & $\begin{array}{c}\text { Define las } \\
\text { demoras }\end{array}$ & subconjunto & $\begin{array}{c}\text { Elemento } \\
\text { Conjunto Salida }\end{array}$ & $\mathrm{B}-\mathrm{R}-\mathrm{M}$ \\
\hline \multirow{2}{*}{ Alumno } & Id_alumno & identifica & No relevante & Numérico \\
\cline { 2 - 6 } & Resultado & según & Entrada & D - A \\
\hline
\end{tabular}

El objetivo de este paso es identificar aquellos elementos que presenten dependencias cognitivas con otros elementos los cuales brinden información redundante $\mathrm{o}$ afecten la comprensión del conocimiento oculto en los datos. En el caso

TABLA XVIII. CONCEPTO-RELACIÓN DEL PROBLEMA DE EXPLOTACIÓN DE INFORMACIÓN APLICADA AL CASO DE ESTUDIO

\begin{tabular}{|c|c|c|c|}
\hline Concepto & $\begin{array}{c}\text { Concepto } \\
\text { asociado }\end{array}$ & Relación & Descripción \\
\hline Regla & Alumno & define & $\begin{array}{c}\text { La regla define el resultado que } \\
\text { obtuvo el alumno }\end{array}$ \\
\hline
\end{tabular}

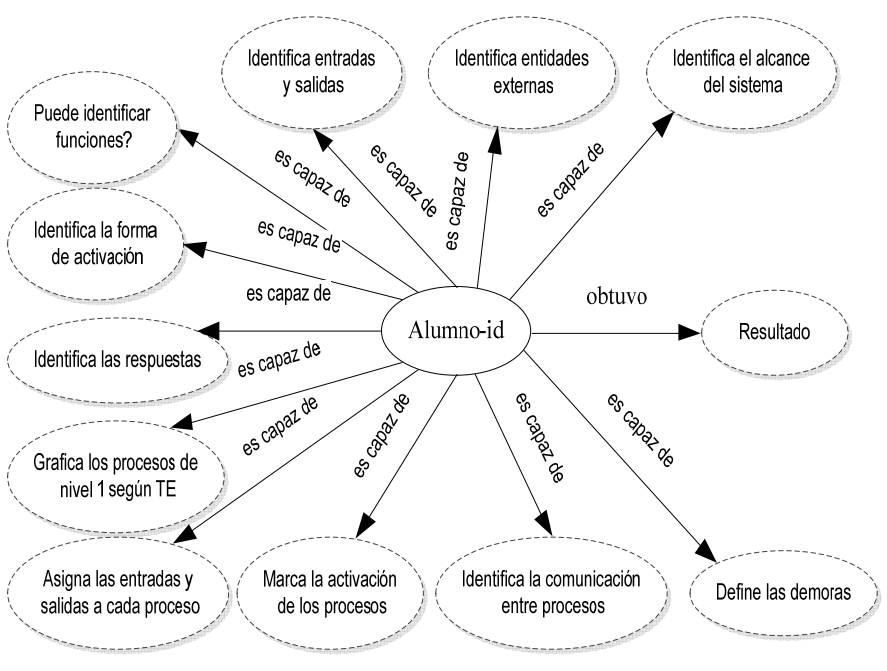

Fig. 12. Representación Conceptual del Domino.

de estudio propuesto, no se identifican datos dependientes que afecten los resultados del análisis.

- Subpaso 2.5. Representación del problema de explotación de información

Para la conceptualización del problema de explotación de información, se hace uso de la técnica red semántica del problema de explotación, cuyo resultado se presenta en la Figura 13.

Paso 3: Identificación del proceso de explotación de información

A partir de las conceptualizaciones del dominio del negocio y del problema de explotación previamente presentadas, se establece el proceso de explotación de información a implementar, a través de aplicar el algoritmo de derivación del proceso de explotación de información propuesto en [96]. El proceso de explotación de información obtenido es: el Proceso de Descubrimiento de Reglas de Comportamiento.

Paso 4: Preparación de los datos

La preparación de los datos para la ejecución del proceso de explotación de información previamente detectado, consta de 3 subpasos:

- Subpaso 4.1: Selección de los campos asociados al problema de explotación de información

Se presenta el listado de datos a utilizar para la ejecución del proceso de explotación de información previamente definido. 
Para el caso de estudio propuesto, solo se excluirá el identificador del alumno, dada su irrelevancia en el problema a analizar.

- Subpaso 4.2: Conversión de los datos

A partir de los algoritmos de minería de datos seleccionados, en base al proceso de explotación de información determinado, puede ser necesario convertir el tipo de dato de alguno de los campos seleccionados.

Para el caso de estudio propuesto, no fue necesario convertir ningún dato.

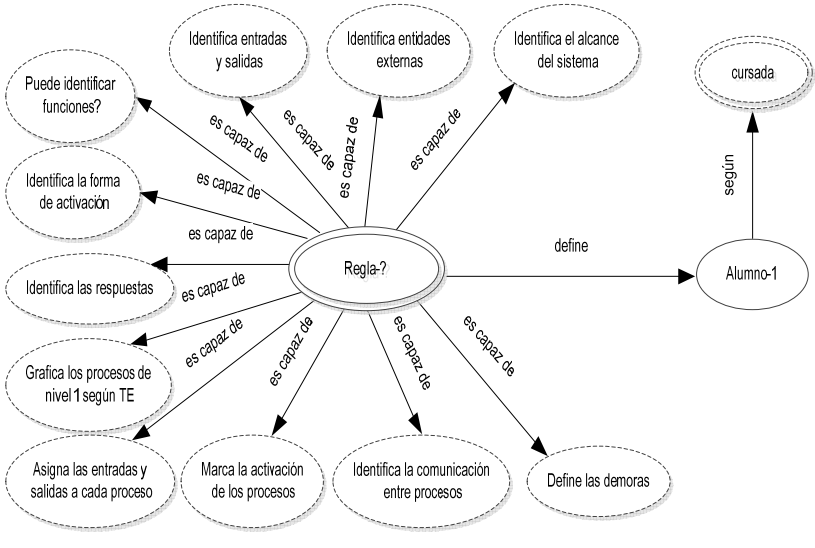

Fig. 13. Red Semántica del Problema de Explotación de Información aplicada al caso de estudio.

- Subpaso 4.3: Generación de la base de datos

Una vez identificados y convertidos los datos, es necesario realizar un proceso que integre todos los campos seleccionados en una única y misma fuente de datos. El resultado de aplicar el subpaso actual es la generación de la base de datos sobre la cual se implementará el proceso de explotación de información.

Paso 5: Implementación

El paso implementación está conformado por 2 subpasos:

- Subpaso 5.1: Implementación

Este subpaso tiene como objetivo implementar el proceso de explotación de información identificado (mediante la ejecución de los algoritmos de minería de datos), en la base de datos generada en el paso anterior.

- Subpaso 5.2: Interpretación de los resultados

A partir de los resultados obtenidos en el subpaso anterior, se descartan aquellos patrones irrelevantes, informando aquellas piezas de conocimientos útiles para dar soporte a la toma de decisiones.

En el caso de estudio propuesto, se identificaron dos reglas que definen al comportamiento de los alumnos:

[a] Los alumnos que aprueban, se caracterizan por realizar bien la asignación de las entradas y salidas de cada proceso e identificar las respuestas de cada proceso de manera bien (regla soportada por el 62.5\% de los alumnos aprobados);

[b] Los alumnos que aprueban, se caracterizan por realizar bien la asignación de las entradas y salidas de cada proceso e identificar las respuestas de cada proceso de manera regular (regla soportada por el $30 \%$ de los alumnos aprobados); y

[c] Los alumnos que desaprueban, se caracterizan por realizar regular o mal la asignación de las entradas y salidas de cada proceso (regla soportada por el $100 \%$ de los alumnos desaprobados). Se identifica que la comprensión de la asignación de las entradas y salidas junto con la identificación de las respuestas de cada proceso son claves para la aprobación del tema, siendo apoyado por más de un $90 \%$ de los casos.
Asimismo, se resalta que no realizar de forma correcta (Bien) la asignación de las entradas y salidas de cada proceso, garantiza la desaprobación del alumno.

\section{B3. Conclusión del Caso de Validación}

El proceso propuesto, permite identificar los conceptos fundamentales para la aprobación de la cursada, permitiendo generar acciones para fortalecer a los alumnos en dicho tema, garantizando un mayor grado de aprobados.

\section{Identificación de Conceptos Débilmente Apropiados por Estudiantes}

En esta sección se describe el caso de estudio (sección C1), luego se aplica el proceso (sección $\mathrm{C} 2$ ), y por último se describe la conclusión (sección C3).

\section{C1. Descripción del Caso}

La carrera Ingeniería en Sistemas de Información de la de la Universidad Tecnológica Nacional Facultad Regional Buenos Aires (UTN - FRBA) tiene un programa académico el cual divide la cursada de materias a lo largo de cinco años. Sistemas y Organizaciones es una de las materias de primer año y troncales de la carrera [102]. Dicha materia es el primer acercamiento del alumno con los conceptos de sistemas de información y circuitos administrativos siendo de gran importancia la comprensión de estos temas por parte del alumno y la aprobación de la materia. Por tal motivo se desea poder entender el desempeño de los alumnos en esta materia en base a los exámenes finales.

Para el desarrollo del actual trabajo se han utilizado 449 exámenes finales correspondientes al período comprendido entre octubre 2012 y febrero 2013. Los temas evaluados en dichos exámenes se corresponden con los siguientes temas:

Metodología de Sistemas de Información (Teoría de Metodología): el alumno debe poder describir el objetivo, las principales actividades, las técnicas y herramientas de cada una de las etapas de la Metodología de Sistemas de Información.

Teoría General (V/F Teoría): abarca preguntas teóricas de todos los conceptos de la asignatura.

Circuitos Administrativos (Teoría de Circuitos): comprende teoría sobre los circuitos básicos de una organización genérica junto con las normas de control interno.

Cursograma (Práctica de Cursograma): consiste en señalar los errores de un ejercicio resuelto mediante esta técnica gráfica.

Las condiciones de aprobación del examen son tener al menos la mitad de cada ejercicio respondido correctamente. Las preguntas no respondidas al igual que las respondidas erróneamente, no suman ni restan en la nota final. Además se debe considerar que los finales pueden ser de dos tipos de acuerdo a los temas evaluados: Cursograma (347 finales) o Circuitos Administrativo (102 finales). En la siguiente tabla se pueden los tipos de ejercicios y las cantidades según tipo de final [103].

Las variables relacionadas con el caso de estudio propuesto, se presentan en la Tabla XIX.

\section{C2. Aplicación del Proceso}

\section{Paso 1: $\quad$ Conceptualización del dominio}

La conceptualización del dominio del negocio se compone de 3 subpasos:

- Subpaso 1.1. Identificación los elementos relevantes del dominio

Para la identificación de los elementos relevantes del dominio de negocio, se hace uso de las técnicas propuestas en [96]. 
Los formalismos resultantes de ejecutar dichas técnicas en el caso de estudio propuesto son la tabla término-categoríadefinición del dominio (Tabla XX) y la tabla conceptoatributo-relación-valor del dominio (Tabla XXI).

TABLA XIX. TÉRMINo-CATEgORÍa-DeFINICIÓn DEL PROBLEMA DE EXPLOTACIÓN DE INFORMACIÓN APLICADO AL CASO DE ESTUDIO.

\begin{tabular}{|c|c|c|}
\hline Campo & Descripción & Valores \\
\hline MET_1 & $\begin{array}{c}1^{\circ} \text { Pregunta Teórica de } \\
\text { Metodología }\end{array}$ & $0,0.5$ y 1 \\
\hline MET_2 & $\begin{array}{l}2^{\circ} \text { Pregunta Teórica de } \\
\text { Metodología }\end{array}$ & $0,0.5$ y 1 \\
\hline ToF_1 & $\begin{array}{c}1^{\circ} \text { Afirmación } \\
\text { Verdadero o Falso }\end{array}$ & $0,0.5$ y 1 \\
\hline ToF_2 & $\begin{array}{c}2^{\circ} \text { Afirmación } \\
\text { Verdadero o Falso }\end{array}$ & $0,0.5$ y 1 \\
\hline ToF_3 & $\begin{array}{c}3^{\circ} \text { Afirmación } \\
\text { Verdadero o Falso }\end{array}$ & $0,0.5$ y 1 \\
\hline ToF_4 & $\begin{array}{c}4^{\circ} \text { Afirmación } \\
\text { Verdadero o Falso }\end{array}$ & $0,0.5$ y 1 \\
\hline Tipo & $\begin{array}{l}\text { Es el tipo de final } \\
\text { tomado }\end{array}$ & Circuito - Cursograma \\
\hline \multirow{2}{*}{ CIR_1 } & \multirow{2}{*}{$\begin{array}{c}1^{\circ} \text { Ejercicio para } \\
\text { completar Teoría de } \\
\text { Circuitos }\end{array}$} & -1: En caso de que no aplique \\
\hline & & $0,0.5$ o 1 : En caso de que aplique \\
\hline \multirow{2}{*}{ CIR_2 } & \multirow{2}{*}{$\begin{array}{c}2^{\circ} \text { Ejercicio para } \\
\text { completar Teoría de } \\
\text { Circuitos }\end{array}$} & -1: En caso de que no aplique \\
\hline & & $0,0.5$ o 1 : En caso de que aplique \\
\hline \multirow{2}{*}{ CIR_3 } & \multirow{2}{*}{$\begin{array}{c}3^{\circ} \text { Ejercicio para } \\
\text { completar Teoría de } \\
\text { Circuitos }\end{array}$} & -1: En caso de que no aplique \\
\hline & & $0,0.5$ o $1:$ En caso de que aplique \\
\hline \multirow{2}{*}{ CIR_4 } & \multirow{2}{*}{$\begin{array}{c}4^{\circ} \text { Ejercicio para } \\
\text { completar Teoría de } \\
\text { Circuitos }\end{array}$} & -1: En caso de que no aplique \\
\hline & & $0,0.5$ o 1 : En caso de que aplique \\
\hline \multirow{2}{*}{ CUR_1 } & \multirow{2}{*}{$1^{\circ}$ Ejercicio cursograma } & -1: En caso de que no aplique \\
\hline & & $0,0.5$ o 1 : En caso de que aplique \\
\hline \multirow{2}{*}{ CUR_2 } & \multirow{2}{*}{$2^{\circ}$ Ejercicio cursograma } & $-1:$ En caso de que no aplique \\
\hline & & $0,0.5$ o $1:$ En caso de que aplique \\
\hline \multirow{2}{*}{ CUR_3 } & \multirow{2}{*}{$3^{\circ}$ Ejercicio cursograma } & -1: En caso de que no aplique \\
\hline & & $0,0.5$ o 1 : En caso de que aplique \\
\hline \multirow{2}{*}{ CUR_4 } & \multirow{2}{*}{$4^{\circ}$ Ejercicio cursograma } & -1 : En caso de que no aplique \\
\hline & & $0,0.5$ o $1:$ En caso de que aplique \\
\hline \multirow{2}{*}{ CUR_5 } & \multirow{2}{*}{$5^{\circ}$ Ejercicio cursograma } & -1 : En caso de que no aplique \\
\hline & & $0,0.5$ o $1:$ En caso de que aplique \\
\hline \multirow{2}{*}{ Resultado } & \multirow{2}{*}{$\begin{array}{l}\text { Indica si el alumno } \\
\text { aprobó o no el final }\end{array}$} & A: Aprobado \\
\hline & & D: Desaprobado \\
\hline
\end{tabular}

- Subpaso 1.2. Identificación de las relaciones entre elementos del dominio

Para la identificación de las relaciones entre elementos del dominio de negocio, se hace uso la técnica propuesta en [96], la tabla concepto-relación del dominio. Como resultado de aplicar la técnica tabla concepto-relación del dominio al caso de estudio propuesto se obtiene la Tabla XXII.

- Subpaso 1.3. Representación conceptual del dominio

Para la conceptualización del dominio del negocio, se hace uso de la técnica red semántica del modelo de negocio propuesto en [96]. El resultado de aplicar dicha técnica al caso de estudio propuesto, se presenta en la figura 14.

Paso 2: Conceptualización del problema de explotación de información

La conceptualización del problema de explotación de información está compuesta por 5 subpasos:
- Subpaso 2.1. Identificación del problema de negocio y su traducción al problema de explotación de información

TABLA XX. TÉRMINO-CATEGORÍA-DEFINICIÓN DEL DOMINIO APLICADA AL CASO DE ESTUDIO.

\begin{tabular}{|c|c|c|}
\hline Término & Categoría & Definición \\
\hline Alumno & Concepto & Persona que realiza la cursada de $\mathrm{SyO}$ \\
\hline CIR_1 & Atributo & $\begin{array}{l}1^{\circ} \text { Ejercicio para completar Teoría de } \\
\text { Circuitos }\end{array}$ \\
\hline CIR_2 & Atributo & $\begin{array}{l}2^{\circ} \text { Ejercicio para completar Teoría de } \\
\text { Circuitos }\end{array}$ \\
\hline CIR_3 & Atributo & $\begin{array}{l}3^{\circ} \text { Ejercicio para completar Teoría de } \\
\text { Circuitos }\end{array}$ \\
\hline CIR_4 & Atributo & $\begin{array}{c}4^{\circ} \text { Ejercicio para completar Teoría de } \\
\text { Circuitos }\end{array}$ \\
\hline contiene & Relación & $\begin{array}{l}\text { El examen contiene una primer pregunta } \\
\text { teórica de metodología }\end{array}$ \\
\hline contiene & Relación & $\begin{array}{l}\text { El examen contiene una segunda pregunta } \\
\text { teórica de metodología }\end{array}$ \\
\hline contiene & Relación & $\begin{array}{l}\text { El examen contiene una primer pregunta de } \\
\text { afirmación }\end{array}$ \\
\hline contiene & Relación & $\begin{array}{l}\text { El examen contiene una segunda pregunta } \\
\text { de afirmación }\end{array}$ \\
\hline contiene & Relación & $\begin{array}{l}\text { El examen contiene una tercera pregunta de } \\
\text { afirmación }\end{array}$ \\
\hline contiene & Relación & $\begin{array}{c}\text { El examen contiene una cuarta pregunta de } \\
\text { afirmación }\end{array}$ \\
\hline CUR_1 & Atributo & $1^{\circ}$ Ejercicio cursograma \\
\hline CUR_2 & Atributo & $2^{\circ}$ Ejercicio cursograma \\
\hline CUR_3 & Atributo & $3^{\circ}$ Ejercicio cursograma \\
\hline CUR_4 & Atributo & $4^{\circ}$ Ejercicio cursograma \\
\hline CUR_5 & Atributo & $5^{\circ}$ Ejercicio cursograma \\
\hline es & Relación & El examen es de un tipo posible \\
\hline Examen & Concepto & Evaluación final de la cursada \\
\hline id_alumno & Atributo & Identificador único del alumno \\
\hline id_examen & Atributo & Identificador único del examen \\
\hline identifica & Relación & el id_alumno identifica a un alumno \\
\hline identifica & Relación & el id_examen identifica a un examen \\
\hline MET_1 & Atributo & $1^{\circ}$ Pregunta Teórica de Metodología \\
\hline MET_2 & Atributo & $2^{\circ}$ Pregunta Teórica de Metodología \\
\hline Nota & Atributo & Indica si el alumno aprobó o no el final \\
\hline obtiene & Relación & $\begin{array}{l}\text { El alumno obtiene una calificación por el } \\
\text { examen realizado }\end{array}$ \\
\hline puede contener & Relación & $\begin{array}{c}\text { El examen puede contener un primer } \\
\text { ejercicio de teoría de circuitos }\end{array}$ \\
\hline puede contener & Relación & $\begin{array}{l}\text { El examen puede contener un segundo } \\
\text { ejercicio de teoría de circuitos }\end{array}$ \\
\hline puede contener & Relación & $\begin{array}{l}\text { El examen puede contener un tercero } \\
\text { ejercicio de teoría de circuitos }\end{array}$ \\
\hline puede contener & Relación & $\begin{array}{l}\text { El examen puede contener un cuarto } \\
\text { ejercicio de teoría de circuitos }\end{array}$ \\
\hline puede contener & Relación & $\begin{array}{c}\text { El examen puede contener un primer } \\
\text { ejercicio de cursograma }\end{array}$ \\
\hline puede contener & Relación & $\begin{array}{l}\text { El examen puede contener un segundo } \\
\text { ejercicio de cursograma }\end{array}$ \\
\hline puede contener & Relación & $\begin{array}{c}\text { El examen puede contener un tercero } \\
\text { ejercicio de cursograma }\end{array}$ \\
\hline puede contener & Relación & $\begin{array}{l}\text { El examen puede contener un cuarto } \\
\text { ejercicio de cursograma }\end{array}$ \\
\hline puede contener & Relación & $\begin{array}{c}\text { El examen puede contener un quinto } \\
\text { ejercicio de cursograma }\end{array}$ \\
\hline Rinde & Relación & El alumno rinde el examen final \\
\hline Tipo & Atributo & Es el tipo de final tomado \\
\hline ToF_1 & Atributo & $1^{\circ}$ Afirmación Verdadero o Falso \\
\hline ToF_2 & Atributo & $2^{\circ}$ Afirmación Verdadero o Falso \\
\hline ToF_3 & Atributo & $3^{\circ}$ Afirmación Verdadero o Falso \\
\hline ToF_4 & Atributo & $4^{\circ}$ Afirmación Verdadero o Falso \\
\hline
\end{tabular}


TABLA XXI. CONCEPTO-ATRIBUTO-RELACIÓN-VALOR DEL DOMINO APLICADA AL CASO DE ESTUDIO

\begin{tabular}{|c|c|c|c|}
\hline Concepto & Atributo & Relación & Valor \\
\hline Alumno & Id_Alumno & identifica & Numérico \\
\hline & Nota & obtiene & A - D \\
\hline Examen & Id_examen & identifica & Numérico \\
\hline & MET_1 & contiene & $0,0.5$ y 1 \\
\hline & MET_2 & contiene & $0,0.5$ y 1 \\
\hline & ToF_1 & contiene & $0,0.5$ y 1 \\
\hline & ToF_2 & contiene & $0,0.5$ y 1 \\
\hline & ToF_3 & contiene & $0,0.5$ y 1 \\
\hline & ToF_4 & contiene & $0,0.5$ y 1 \\
\hline & Tipo & es & Circuito - \\
\hline & CIR_1 & puede contener & $0,0.5,1 \mathrm{y}-1$ \\
\hline & CIR_2 & puede contener & $0,0.5,1 \mathrm{y}-1$ \\
\hline & CIR_3 & puede contener & $0,0.5,1 \mathrm{y}-1$ \\
\hline & CIR_4 & puede contener & $0,0.5,1 \mathrm{y}-1$ \\
\hline & CUR_1 & puede contener & $0,0.5,1 \mathrm{y}-1$ \\
\hline & CUR_2 & puede contener & $0,0.5,1 \mathrm{y}-1$ \\
\hline & CUR_3 & puede contener & $0,0.5,1 \mathrm{y}-1$ \\
\hline & CUR_4 & puede contener & $0,0.5,1 \mathrm{y}-1$ \\
\hline & CUR_5 & puede contener & $0,0.5,1 \mathrm{y}-1$ \\
\hline
\end{tabular}

TABLA XXII. CONCEPTO-RELACIÓN DEL DOMINIO APLICADA AL CASO DE ESTUDIO

\begin{tabular}{|c|c|c|c|}
\hline Concepto & Concepto asociado & relación & Descripción \\
\hline Alumno & Examen & rinde & el alumno rinde un examen \\
\hline
\end{tabular}

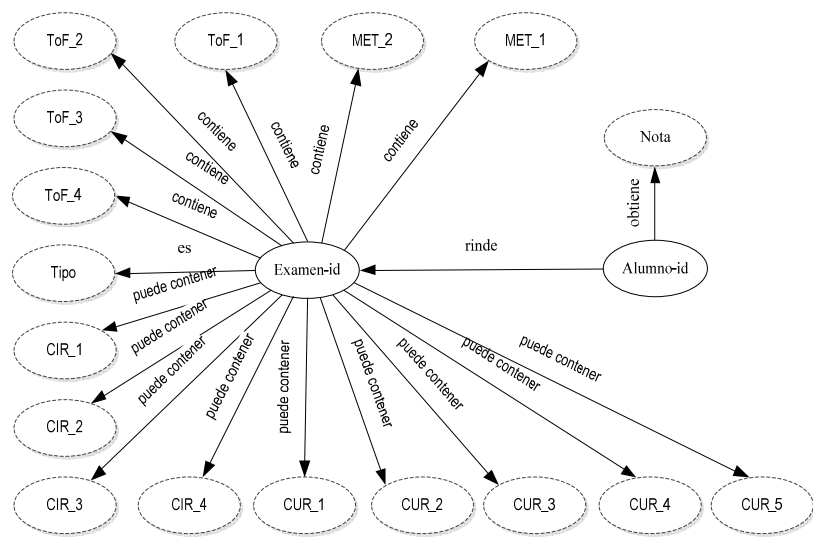

Fig. 14. Red semántica del Modelo de Negocio aplicada al caso de estudio

A partir del problema de negocio definido en la descripción del caso de estudio (sección 5.1), se obtiene como problema de explotación de información: "comprender cuales son los elementos (preguntas) relevantes para la aprobación o no del examen".

- Subpaso 2.2. Identificación de los conceptos pertenecientes al problema de explotación de información

A partir del problema de explotación de información se procede a seleccionar y determinar cuáles elementos están relacionados con el mismo. Para ello se implementa las técnicas tabla Término-Categoría-Definición del Problema de Explotación de Información y Tabla Concepto-AtributoRelación-Valor Extendida del Problema de Explotación de Información, propuestas en [96]. El resultado de aplicar cada una de ellas al caso de estudio propuesto, se presenta en las tablas XXIII y XXIV respectivamente.

- Subpaso 2.3. Identificación de las relaciones entre elementos del problema de explotación de información

Para la identificación de las relaciones entre elementos del problema de explotación de información, se implementa la técnica propuesta en [96]: la tabla concepto-relación del problema de explotación de información. El resultado de aplicar dicha tabla al caso de estudio propuesto se presenta en la tabla XXV.

- Subpaso 2.4. Identificación de dependencias entre los elementos conceptuales del problema

El objetivo de este paso es identificar aquellos elementos que presenten dependencias cognitivas con otros elementos los cuales brinden información redundante o afecten la comprensión del conocimiento oculto en los datos. Para ello se propone la tabla de dependencias cuyo objetivo es identificar las dependencias existentes entre los datos, y eliminar aquellas que se consideren perjudiciales para el desarrollo del proceso. La tabla de dependencias está compuesta por tres columnas: en la primera se registra el elemento que no posea dependencia, en la segunda el elemento dependiente del elemento anteriormente registrado, y en la tercera columna se registra la acción a realizar. En la tabla XXVI se presentan los elementos identificados en el caso de estudio propuesto.

- Subpaso 2.5. Representación del problema de explotación de información

Para la conceptualización del problema de explotación de información, se hace uso de la técnica red semántica del problema de explotación propuesta en [96]. El resultado de aplicar dicha técnica al caso de estudio propuesto, se presenta en la figura 15.

Paso 3: Identificación del proceso de explotación de información

A partir de las conceptualizaciones del dominio del negocio y del problema de explotación previamente presentadas, se establece el proceso de explotación de información a implementar, a través de aplicar el algoritmo de derivación del proceso de explotación de información propuesto en [96]. El proceso de explotación de información obtenido es: el Proceso de Ponderación de Reglas de Pertenencia a Grupos (Grupos definidos).

Paso 4: Preparación de los datos

La preparación de los datos para la ejecución del proceso de explotación de información previamente detectado, consta de 3 subpasos:

- Subpaso 4.1: Selección de los campos asociados al problema de explotación de información

A partir de conceptualizar los distintos elementos involucrados se seleccionan aquellos campos asociados al problema de explotación de información previamente establecido, obteniéndose el listado de datos que conformarán la base de datos a implementar. En el caso de estudio propuesto, los campos a utilizar son todos los datos identificados en la tabla XIX.

- Subpaso 4.2: Conversión de los datos

A partir de los algoritmos de minería de datos seleccionados, en base al proceso de explotación de 
TABLA XXIII. TÉRMINO-CATEGORÍA-DEFINICIÓN DEL PROBLEMA DE EXPLOTACIÓN DE INFORMACIÓN APLICADA AL CASO DE ESTUDIO

\begin{tabular}{|c|c|c|}
\hline Termino & Categoría & Descripción \\
\hline Examen & Concepto & Evaluación final de la cursada $\mathrm{SyO}$ \\
\hline CIR_1 & Atributo & $\begin{array}{l}1^{\circ} \text { Ejercicio para completar Teoría de } \\
\text { Circuitos }\end{array}$ \\
\hline CIR_2 & Atributo & $\begin{array}{l}2^{\circ} \text { Ejercicio para completar Teoría de } \\
\text { Circuitos }\end{array}$ \\
\hline CIR_3 & Atributo & $\begin{array}{l}3^{\circ} \text { Ejercicio para completar Teoría de } \\
\text { Circuitos }\end{array}$ \\
\hline CIR_4 & Atributo & $\begin{array}{l}4^{\circ} \text { Ejercicio para completar Teoría de } \\
\text { Circuitos }\end{array}$ \\
\hline CUR_1 & Atributo & $1^{\circ}$ Ejercicio cursograma \\
\hline CUR_2 & Atributo & $2^{\circ}$ Ejercicio cursograma \\
\hline CUR_3 & Atributo & $3^{\circ}$ Ejercicio cursograma \\
\hline CUR_4 & Atributo & $4^{\circ}$ Ejercicio cursograma \\
\hline CUR_5 & Atributo & $5^{\circ}$ Ejercicio cursograma \\
\hline elementos relevantes & Concepto & $\begin{array}{l}\text { Conjunto de elementos del examen que } \\
\text { definen la calificación }\end{array}$ \\
\hline Es & Atributo & el examen es de un tipo \\
\hline Id_Examen & Atributo & Identificador único del examen \\
\hline Identifica & Relación & el id_examen identifica al examen \\
\hline MET_1 & Atributo & $1^{\circ}$ Pregunta Teórica de Metodología \\
\hline MET_2 & Atributo & $2^{\circ}$ Pregunta Teórica de Metodología \\
\hline Nota & Atributo & Indica la calificación del examen \\
\hline Pertenecen & Relación & $\begin{array}{l}\text { Los elementos relevantes pertenecen al } \\
\text { examen final }\end{array}$ \\
\hline Según & Relación & $\begin{array}{c}\text { la nota del examen se caracteriza según } \\
\text { los resultados en elementos } \\
\text { identificados }\end{array}$ \\
\hline Subconjunto & Relación & $\begin{array}{c}\text { los elementos (preguntas) del examen } \\
\text { son el subconjunto de elementos } \\
\text { relevantes }\end{array}$ \\
\hline Tipo & Atributo & Es el tipo de final tomado \\
\hline ToF_1 & Atributo & $1^{\circ}$ Afirmación Verdadero o Falso \\
\hline ToF_2 & Atributo & $2^{\circ}$ Afirmación Verdadero o Falso \\
\hline ToF_3 & Atributo & $3^{\circ}$ Afirmación Verdadero o Falso \\
\hline ToF_4 & Atributo & $4^{\circ}$ Afirmación Verdadero o Falso \\
\hline
\end{tabular}

TABLA XXIV. CONCEPTO-ATRIBUTO-RELACIÓN-VALOR EXTENDIDA DEL PROBLEMA DE EXPLOTACIÓN DE INFORMACIÓN APLICADA AL CASO DE ESTUDO.

\begin{tabular}{|c|c|c|c|c|}
\hline \begin{tabular}{|c|} 
oncepto \\
\end{tabular} & Atributo & Relación & Entrada/Salida & Valor \\
\hline \multirow[t]{13}{*}{$\begin{array}{l}\text { caracteristicas } \\
\text { relevantes }\end{array}$} & MET_1 & subconjunto & $\begin{array}{c}\text { Elemento } \\
\text { Conjunto Salida }\end{array}$ & $0,0.5$ y 1 \\
\hline & MET_2 & subconjunto & $\begin{array}{c}\text { Elemento } \\
\text { Conjunto Salida }\end{array}$ & $0,0.5$ y 1 \\
\hline & ToF_1 & subconjunto & $\begin{array}{c}\text { Elemento } \\
\text { Conjunto Salida }\end{array}$ & $0,0.5$ y 1 \\
\hline & ToF_2 & subconjunto & $\begin{array}{c}\text { Elemento } \\
\text { Conjunto Salida } \\
\end{array}$ & $0,0.5$ y 1 \\
\hline & ToF_3 & subconjunto & $\begin{array}{c}\text { Elemento } \\
\text { Conjunto Salida }\end{array}$ & $0,0.5$ y 1 \\
\hline & ToF_4 & subconjunto & $\begin{array}{c}\text { Elemento } \\
\text { Conjunto Salida }\end{array}$ & $0,0.5$ y 1 \\
\hline & Tipo & subconjunto & $\begin{array}{c}\text { Elemento } \\
\text { Conjunto Salida } \\
\end{array}$ & $\begin{array}{c}\text { Circuito - } \\
\text { Cursograma } \\
\end{array}$ \\
\hline & CIR_1 & subconjunto & $\begin{array}{c}\text { Elemento } \\
\text { Conjunto Salida }\end{array}$ & $0,0.5,1 \mathrm{y}-1$ \\
\hline & CIR_2 & subconjunto & $\begin{array}{c}\text { Elemento } \\
\text { Conjunto Salida } \\
\end{array}$ & $0,0.5,1 \mathrm{y}-1$ \\
\hline & CIR_3 & subconjunto & $\begin{array}{c}\text { Elemento } \\
\text { Conjunto Salida }\end{array}$ & $0,0.5,1 \mathrm{y}-1$ \\
\hline & CIR_4 & subconjunto & $\begin{array}{c}\text { Elemento } \\
\text { Conjunto Salida }\end{array}$ & $0,0.5,1 \mathrm{y}-1$ \\
\hline & CUR_1 & subconjunto & $\begin{array}{c}\text { Elemento } \\
\text { Conjunto Salida } \\
\end{array}$ & $0,0.5,1 \mathrm{y}-1$ \\
\hline & CUR_2 & subconjunto & $\begin{array}{c}\text { Elemento } \\
\text { Conjunto Salida }\end{array}$ & $0,0.5,1 \mathrm{y}-1$ \\
\hline
\end{tabular}

\begin{tabular}{|c|c|c|c|c|}
\hline & CUR_3 & subconjunto & $\begin{array}{c}\text { Elemento } \\
\text { Conjunto Salida }\end{array}$ & $0,0.5,1 \mathrm{y}-1$ \\
\cline { 2 - 5 } & CUR_4 & subconjunto & $\begin{array}{c}\text { Elemento } \\
\text { Conjunto Salida }\end{array}$ & $0,0.5,1 \mathrm{y}$-1 \\
\cline { 2 - 5 } & CUR_5 & subconjunto & $\begin{array}{c}\text { Elemento } \\
\text { Conjunto Salida }\end{array}$ & $0,0.5,1 \mathrm{y}$-1 \\
\hline \multirow{2}{*}{ Examen } & Id_Examen & identifica & No relevante & Numérico \\
\cline { 2 - 5 } & Nota & según & Entrada & A - D \\
\hline
\end{tabular}

TABLA XXV. CONCEPTo-Relación del Problema de EXPLOTACIÓN DE INFORAMCIÓN APLICADA AL CASO DE ESTUDIO.

\begin{tabular}{|c|c|c|c|}
\hline Concepto & $\begin{array}{c}\text { Concepto } \\
\text { asociado }\end{array}$ & Relación & Descripción \\
\hline $\begin{array}{c}\text { elementos } \\
\text { relevantes }\end{array}$ & Examen & pertenecen & $\begin{array}{c}\text { Los elementos relevantes } \\
\text { pertenecen al examen final }\end{array}$ \\
\hline
\end{tabular}

TABLA XXVI. DePENDENCIAS APLICADAS AL CASO DE ESTUdiO

\begin{tabular}{|c|c|c|}
\hline Elemento & Elemento dependiente & Acción \\
\hline Tipo & CIR_1 & \multirow{9}{*}{$\begin{array}{c}\text { Incorporar al } \\
\text { elemento Tipo como } \\
\text { variable del problema } \\
\text { de explotación de } \\
\text { información }\end{array}$} \\
\hline Tipo & CIR_2 & \\
\hline Tipo & CIR_3 & \\
\hline Tipo & CIR_4 & \\
\hline Tipo & CUR_1 & \\
\hline Tipo & CUR_2 & \\
\hline Tipo & CUR_3 & \\
\hline Tipo & CUR_4 & \\
\hline Tipo & CUR 5 & \\
\hline
\end{tabular}

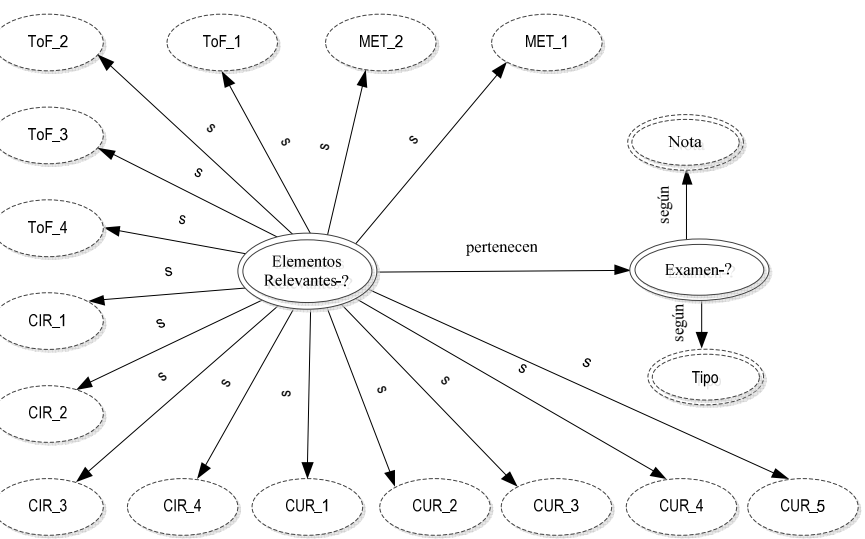

Fig. 15. Semántica del Problema de Explotación de Información aplicada al caso de estudio

información determinado, puede ser necesario convertir el tipo de dato de alguno de los campos seleccionados. Para el caso de estudio propuesto, no fue necesario convertir ningún dato.

- Subpaso 4.3: Generación de la base de datos

Una vez identificados y convertidos los datos, es necesario realizar un proceso que integre todos los campos seleccionados en una única y misma fuente de datos. El resultado de aplicar el subpaso actual es la generación de la base de datos en la cual se implementará el proceso de explotación de información.

Paso 5: Implementación

El paso implementación está conformado por 2 subpasos:

- Subpaso 5.1: Implementación

Este subpaso tiene como objetivo implementar el proceso de explotación de información identificado (mediante la ejecución de los algoritmos de minería de datos), en la base de datos generada en el paso anterior.

- Subpaso 5.2: Interpretación de los resultados A partir de los resultados obtenidos en el subpaso anterior, se realiza una interpretación de los mismos cuyo objetivo es 
identificar información relevante, descartando aquella que no sea fiable, y presentar la información obtenida. La información obtenida del caso de estudio presentado es:

Se identifican distintos elementos ponderantes a partir de las dependencias conceptuales identificadas en el paso 2.4, es decir, que según el tipo de examen se identificó la relevancia de distintas preguntas.

Para el examen de cursograma, los elementos relevantes para la aprobación o no del mismo son las Preguntas Teóricas de Metodología, con una ponderación aproximadamente del $95 \%$. Mientras que para el examen de Circuito, los ejercicios para completar de la Teoría de Circuitos presentan una ponderación del $81 \%$.

A parir de los resultados obtenidos, puede afirmarse que los conceptos a reforzar para mejorar la calidad de los resultados de los estudiantes son:

[a] La teoría sobre la Metodología de Sistemas de Información, y

[b] La teoría sobre Circuitos Administrativos.

\section{C3. Conclusión del Caso de Validación}

La Explotación de Información Educativa tiene un desarrollo de más de una década y emerge como una contribución a la sistematización del entendimiento de: comportamientos estudiantiles, fallas en los procesos de enseñanza, contenidos mal apropiados, entre otros patrones de conocimiento identificables mediante los procesos y las técnicas que propone la Ingeniería de Explotación de Información. Si bien las primeras aplicaciones se centraron en la información provista por los espacios virtuales de enseñanza aprendizaje y los sistemas de gestión de calificaciones y perfiles de estudiantes; hace más de un lustro que se vienen desarrollando experiencias sobre aplicaciones a la evaluación de procesos de enseñanza-aprendizaje presenciales [Britos et al., 2008a; 2008b; Saavedra-Martinez et al., 2012].

En este trabajo, se ha propuesto un proceso que permite identificar contenidos débilmente apropiados por los estudiantes. En el caso de estudio estos son:

[a] la teoría sobre la Metodología de Sistemas de Información, y

[b] la teoría sobre Circuitos Administrativos.

Esta identificación, permite generar acciones para fortalecer los aprendizajes en dichos temas.

\section{CONCLUSIÓN}

En esta sección se exponen los aportes realizados por este trabajo (sección A), y se presentan las futuras líneas de investigación (sección B).

\section{A. Aportaciones del trabajo.}

La Explotación de Información Educativa tiene un desarrollo de más de una década y emerge como una contribución a la sistematización del entendimiento de: comportamientos estudiantiles, fallas en los procesos de enseñanza, contenidos mal apropiados, entre otros patrones de conocimiento identificables mediante los procesos y las técnicas que propone la Ingeniería de Explotación de Información. Si bien los primeros resultados se centraron en la información provista por los espacios virtuales de enseñanza aprendizaje y los sistemas de gestión de calificaciones y perfiles de estudiantes; hace más de un lustro que se vienen desarrollado experiencias sobre aplicaciones a la evaluación de procesos de enseñanza-aprendizaje presenciales [28][48][79].
En este trabajo se ha presentado un proceso basado en explotación de información que permite estudiar el comportamiento de los estudiantes durante el desarrollo de un curso o una carrera, logrando identificar y resolver distintos problemas asociados a la apropiación de los conceptos y al favorable desarrollo de la materia, brindando una herramienta que favorezca la comprensión del curso y la posibilidad de implementar medidas que permitan detectar alumnos con dificultades, e intervenir de manera temprana pudiendo corregir factores que impacten en el resultado de la cursada.

Este proceso se ha validado con tres casos de estudio: [a] procesos de identificación de comportamiento de estudiantes recursantes utilizando EVEAs, [b] identificación de conceptos críticos de una cursada, [c] identificación de contenidos débilmente apropiados por estudiantes.

En [a] se ilustra el uso del proceso propuesto con una prueba de concepto en el dominio de alumnos que recursan en la modalidad virtual una materia del área de ciencias básicas cuya primera cursada fue presencial. Los resultados obtenidos son intuitivamente válidos y no presentan indicios que contraríen las creencias del equipo docente sobre las condiciones de aprobación del curso en esta modalidad. Sin embargo, con relación a las condiciones de desaprobación y considerando que la población estudiada era pequeña, el hecho que los atributos de mayor incidencia para la desaprobación presenten porcentajes sensiblemente por debajo del $100 \%$ se considera un indicador que permite postular que la replicación del proceso sobre una población por lo menos sea mayor en un orden de magnitud, permitiendo emerger atributos específicos sobre los distintos grupos de causales de desaprobación. En cambio en [b] y [c] se identificaron reglas que definen fuertemente el comportamiento de los estudiantes.

De lo anterior se desprende que el proceso propuesto constituye una nueva herramienta de diagnóstico en el área; y si bien en [a] los resultados obtenidos son consistentes pero sólo sirven para ilustrar la aplicación de la solución propuesta en [b] y [c] se refleja el comportamiento del alumno permitiendo identificar los conceptos fundamentales para la aprobación de la cursada, posibilitando la generación de acciones para fortalecer a los alumnos en dicho tema, garantizando un mayor grado de aprobados.

\section{B. Futuras Líneas de Investigación}

En este trabajo se propuso obtener procesos de comportamiento de comunidades educativas basadas en Entornos Virtuales de Enseñanza y Aprendizaje, dada la característica de los mismos que poseen toda la información de interacción alumno -profesor almacenada en un único repositorio de datos. De esta forma, se obtiene la información para el análisis del comportamiento al alcance, siendo de fácil acceso y procesamiento.

Los resultados obtenidos del proceso de adquisición de patrones en búsqueda de comportamiento a partir de la información disponible en EVEAs, el reducido tamaño de las muestras utilizadas para la búsqueda de patrones si bien arrojo resultados promisorios, no son concluyentes y se planea continuar en esta línea de trabajo con poblaciones mayores.

De las otras validaciones ha surgido que los docentes usan explotación de información desde distintas visiones. Unos para revisar sus prácticas docentes, es decir, qué temas el docente cree que está enseñando bien, pero no es necesariamente así. En tanto, otros la utilizan para revisar e identificar aquellos conceptos críticos, es decir, qué conceptos tienen una complejidad tal que más allá de ser bien transmitidos por los 
docentes, no son correctamente apropiados por los alumnos. En este contexto, surgen como futuras líneas de trabajo: proponer extensiones al proceso propuesto que contribuyan a la gestión de la información disponible necesaria para evaluar cada una de estas dos visiones.

\section{ACKNOWLEDGMENT}

The preferred spelling of the word "acknowledgment" in America is without an "e" after the "g". Avoid the stilted expression, "One of us (R. B. G.) thanks . . ." Instead, try "R. B. G. thanks". Put applicable sponsor acknowledgments here; DO NOT place them on the first page of your paper or as a footnote.

\section{REFERENCES}

[1] Tiffin, J., \& Rajasingham, L. (1997). En busca de la clase virtual: la educación en la sociedad de la información. (Vol. 43). Editorial Paidós.

[2] Moore, M. G. y Kearsley, G. (1996), Distance Education. A Systems View, Belmont, CA, Wadsworth Publishing Company.

[3] L. G. Aretio, L. G. "Hacia una definición de educación a distancia." Boletín informativo de la Asociación Iberoamericana de Educación Superior a Distancia. Abril, 1987. Año 4, N 18, $4 \mathrm{pp}$.

[4] Quesada Catillo, Rocío. (2006). Evaluación del aprendizaje en la educación a distancia "en línea". RED Revista de Educación a Distancia

[5] Charum, V, (2007). Modelo de Evaluación de Plataformas Tecnológicas. Tesis de Magíster en Telecomunicaciones. Escuela de Posgrado, Instituto Tecnológico de Buenos Aires.

[6] Spotts, T y Bowman, M. (1995). Faculty Use of Instructional Technologies in Higher Education, en Educational Technology, 35(2): 56-64.

[7] Larose, D. T. (2005). Discovering Knowledge in Data, an introduction to Data Mining. John Wiley \& Sons

[8] Negash, S. Gray, P. (2008). Business Intelligence. In Handbook on Decision Support Systems 2, eds. F. Burstein y C. Holsapple (Heidelberg, Springer), Pp. 175-193.

[9] Schiefer, J., Jeng, J., Kapoor, S. Chowdhary, P. (2004). Process Information Factory: A Data Management Approach for Enhancing Business Process Intelligence. Proceedings IEEE International Conference on E-Commerce Technology. Pp. 162169.

[10] Curtis, B., Kellner, M., Over, J. (1992). Process Modelling. Communications of the ACM, 35(9): 75-90.

[11] Ferreira, J., Takai, O., Pu, C. (2005). Integration of Business Processes with Autonomous Information Systems: A Case Study in Government Services. Proceedings Seventh IEEE International Conference on Ecommerce Technology. Pp. 471474.

[12] Kanungo, S. (2005). Using Process Theory to Analyze Direct and Indirect Value-Drivers of information Systems. Proceedings of the 38th Annual Hawaii International Conference on System Sciences. Pp. 231-240.

[13] Britos, P. (2008). Procesos de Explotación de Información Basados en Sistemas Inteligentes. Tesis de Doctorado en Ciencias Informáticas. Facultad de Informática. Universidad Nacional de La Plata.

[14] García - Martínez, R., Britos, P., Rodríguez, D. (2013). Information Mining Processes Based on Intelligent Systems. Lecture Notes on Artificial Intelligence, 7906: 402 - 410. ISBN 978 - 3 - 642 - 38576 - 6

[15] Barnes, T., Desmarais, M., Romero, C., Ventura, S. (2009). Educational Data Mining 2009: 2nd International Conference on Educational Data Mining, Proceedings. Cordoba, Spain.
[16] Baker, R (2010). Data Mining for Education. To appear in McGaw, B., Peterson, P., Baker, E. (Eds.) International Encyclopedia of Education (3rd edition). Oxford, UK: Elsevier.

[17] Koedinger, K., Cunningham, K., Skogsholm A., Leber, B. (2008). An open repository and analysis tools for fine-grained, longitudinal learner data. In 1st International Conference on Educational Data Mining, Montreal, 157-166.

[18] Castro, F., Vellido, A., Nebot, A. Mugica, F. (2007). Applying Data Mining Techniques to e-Learning Problems. In: Jain, L.C., Tedman, R. and Tedman, D. (eds.) Evolution of Teaching and Learning Paradigms in Intelligent Environment. Studies in Computational Intelligence, 62, Springer-Verlag, 183-221

[19] Romero, C., Ventura, S. (2010). Educational data mining: a review of the state of the art. Systems, Man, and Cybernetics, Part C: Applications and Reviews, IEEE Transactions on, 40(6), 601-618.

[20] Luan, J. (2002). Data mining and its applications in higher education. New directions for institutional research, 2002(113), 17-36.

[21] Baker, R. S., Yacef, K. (2009). The state of educational data mining in 2009: A review and future visions. JEDM-Journal of Educational Data Mining, 1(1), 3-17.

[22] Romero, C., Ventura, S. (2007). Educational data mining: A survey from 1995 to 2005. Expert systems with applications, 33(1), 135-146.

[23] Romero, C., Ventura, S., García, E. (2008). Data mining in course management systems: Moodle case study and tutorial. Computers \& Education, 51(1), 368-384.

[24] Minaei-Bidgoli, B., Kashy, D. A., Kortmeyer, G., Punch, W. F. (2003). Predicting student performance: an application of data mining methods with an educational web-based system. In Frontiers in Education, 2003. FIE 2003 33rd Annual (Vol. 1, pp. T2A-13). IEEE.

[25] Bravo, J., Ortigosa, A. (2009). Detecting Symptoms of Low Performance Using Production Rules. International Working Group on Educational Data Mining.

[26] Dekker, G. W., Pechenizkiy, M., \& Vleeshouwers, J. M. (2009). Predicting Students Drop Out: A Case Study. International Working Group on Educational Data Mining.

[27] Jiménez Rey, E. M., Rodríguez, D., Britos, P. V., García Martínez, R. (2008). Identificación de problemas de aprendizaje de programación con explotación de información. In XIV Congreso Argentino de Ciencias de la Computación.

[28] Britos, P., Jiménez Rey, E., García-Martínez, E. (2008a). Work in Progress: Programming Misunderstandings Discovering Process Based On Intelligent Data Mining Tools.Proceedings 38th ASEE/IEEE Frontiers in Education Conference. Session F4H: Assessing and Understanding student Learning. ISBN 978-1-4244-1970-8.

[29] Perkings, D. (1995), La escuela inteligente. Gedisa.

[30] Kuna, H., García Martínez, R., Villatoro, F. (2009). Identificación de Causales de Abandono de Estudios Universitarios. Uso de Procesos de Explotación de Información. Revista Iberoamericana de Tecnología en Educación y Educación en Tecnología 5: 39-44.

[31] Kuna, H., García Martínez, R. Villatoro, F. (2010). Pattern Discovery in University Students Desertion Based on Data Mining. Advances and Applications in Statistical Sciences Journal, 2(2): 275-286. ISSN 0974-6811.

[32] SIU-Guarani. (2014). ¿Qué es SIU Guaraní y para qué sirve? $\mathrm{http} / /$ www.perio.unlp.edu.ar/ node/1014. Último acceso septiembre 2014.

[33] Saavedra Martínez, P., Pollo Cattaneo, M. F., Pytel, P., Rodríguez, D., García Martínez, R. (2012). Detección de problemas de aprendizaje basado en explotación de información. 
[34] Reinschmidt, J., Allison F. (2000). Business Intelligence Certification Guide. IBM International Technical Support Organization. SG24-5747-00.

[35] Negash, S. Gray, P. (2008). Business Intelligence. In Handbook on Decision Support Systems 2, eds. F. Burstein y C. Holsapple (Heidelberg, Springer), Pp. 175-193.

[36] Lönnqvist, A., Pirttimäki, V. (2006). The Measurement of Business Intelligence. Information Systems Management, 23(1): 32-40.

[37] Grigori, D., Casati, F., Castellanos, M., Dayal, u., Sayal, M., Shan, M. (2004). Business Process Intelligence. Computers in Industry 53(3): 321-343

[38] Michalski, R. Bratko, I. Kubat, M. (1998). Machine Learning and Data Mining, Methods and Applications (Editores) John Wiley \& Sons.

[39] Kononenko, I., Cestnik, B. (1986). Lymphography Data Set. UCI Machine Learning Repository. http://archive.ics.uci.edu/ml/datasets/Lymphography. Último acceso 29 de Abril del 2008.

[40] Michalski, R. (1983). A Theory and Methodology of Inductive Learning. Artificial Intelligence, 20: 111-161

[41] Chen, M., Han, J., Yu, P. (1996). Data Mining: An Overview from a Database Perspective. IEEE Transactions on Knowledge and Data Engineering, 8(6): 866-883.

[42] Chung, W., Chen, H., Nunamaker, J. (2005). A Visual Framework for Knowledge Discovery on the Web: An Empirical Study of Business Intelligence Exploration. Journal of Management Information Systems, 21(4): 57-84.

[43] Chau, M., Shiu, B., Chan, I., Chen, H. (2007). Redips: Backlink Search and Analysis on the Web for Business Intelligence Analysis. Journal of the American Society for Information Science and Technology, 58(3): 351-365.

[44] Golfarelli, M., Rizzi, S., Cella, L. (2004). Beyond data warehousing: what's next in business intelligence? Proceedings 7th ACM international workshop on Data warehousing and OLAP. Pág. 1-6.

[45] Koubarakis, M., Plexousakis, D. (2000). A Formal Model for Business Process Modeling and Design. Lecture Notes in Computer Science, 1789: 142-156.

[46] Musen, M., Neumann, B., Studer, R. (2003). Guest Editors' Introduction: IFIP Conference on Intelligent Information Processing. IEEE Intelligent Systems 18(2): 16-17.

[47] García Martínez, R., Britos, P. (2004) Ingeniería de Sistemas Expertos. Editorial Nueva Librería. ISBN 987 - 1104 - 15 - 4

[48] Britos, P., Grosser, H., Rodríguez, D., García-Martínez, R. (2008b). Detecting Unusual Changes of Users Consumption. In Artificial Intelligence in Theory and Practice II, ed. M. Bramer, (Boston: Springer), en prensa.

[49] Hanna, M. (2004). Data mining in the e-learning domain. In Campus-Wide Information Systems, Volume 21, Number 1, 2934

[50] Romero, C., Ventura, S. (2010). Educational data mining: a review of the state of the art. Systems, Man, and Cybernetics, Part C: Applications and Reviews, IEEE Transactions on, 40(6), 601-618.

[51] Srivastava, J., Cooley, R., Deshpande, M., Tan, P. (2000). Web usage mining: Discovery and applications of usage patterns from web data. SIGKDD Explorations, 1(2), 12-23.

[52] Romero, C., Ventura, S., Bra, P. D. (2004). Knowledge discovery with genetic programming for providing feedback to courseware author. User Modeling and User-Adapted Interaction: The Journal of Personalization Research, 14(5), 425-464.

[53] Pahl, C., Donnellan, C. (2003). Data mining technology for the evaluation of web-based teaching and learning systems. In Proceedings of the congress e-learning, Montreal, Canada. Paulsen, M. (2003). Online education and learning
[54] Li, J., Zaïane, O. (2004). Combining usage, content, and structure data to improve web site recommendation. In International conference on ecommerce and web technologies (pp. 305-315).

[55] Arruabarrena, R., Pérez, T. A., López-Cuadrado, J., Vadillo, J. G. J. (2002). On evaluating adaptive systems for education. In Adaptive hypermedia (pp. 363-367).

[56] Zorrilla, M. E., Menasalvas, E., Marin, D., Mora, E., Segovia, J. (2005). Web usage mining project for improving web-based learning sites. In Web mining workshop, Cataluna.

[57] Johnson, S., Arago, S., Shaik, N., Palma-Rivas, N. (2000). Comparative analysis of learner satisfaction and learning outcomes in online and face-to-face learning environments. Journal of Interactive Learning Research, 11(1), 29-49.

[58] Ma, Y., Liu, B., Wong, C., Yu, P., Lee, S. (2000). Targeting the right students using data mining. In KDD '00: Proceedings of the sixth ACM SIGKDD international conference on Knowledge discovery and data mining (pp. 457-464).

[59] Yu, P., Own, C., Lin, L. (2001). On learning behavior analysis of web based interactive environment. In Proceedings of ICCEE, Oslo/Bergen, Norway

[60] Ingram, A. (1999). Using web server logs in evaluating instructional web sites. Journal of Educational Technology Systems, 28(2), 137-157.

[61] Frias-Martinez, E., Chen, S. Y., Liu, X. (2006). Survey of data mining approaches to user modeling for adaptive hypermedia. Systems, Man, and Cybernetics, Part C: Applications and Reviews, IEEE Transactions on, 36(6), 734749.

[62] Freeman, L. (2006). The Development of Social Network Analysis. Empirical Press.

[63] Novak, J.D., Cañas, A.J. (2006). The theory underlying concept maps and how to construct and use them. Technical Report IHMC CmapTools 2006-01.

[64] Corbertt, A.T. (2001). Cognitive Computer Tutors: Solving the Two-Sigma Problem. In Proceedings of the International Conference on User Modeling, 137-147.

[65] Romero, C., Ventura, S. (2007). Educational data mining: A survey from 1995 to 2005. Expert systems with applications, 33(1), 135-146

[66] Tsantis, L., Castellani, J., (2001). Enhancing learning environments through solution-based knowledge discovery tools. Journal of Special Education Technology, 16 (4), 1-35.

[67] Shen, R., Yang, F., \& Han, P. (2002). Data analysis center based on elearning platform. In Proceedings of the 5th international workshop on the internet challenge: Technology and applications (pp. 19-28).

[68] Grobelnik, M., Mladenic, D., Jermol, M. (2002). Exploiting text mining in publishing and education. In Proceedings of the ICML-2002 workshop on data mining lessons learned (pp. 3439).

[69] Beck, J.E., Mostow, J. (2008). How who should practice: Using learning decomposition to evaluate the efficacy of different types of practice for different types of students. In Proceedings of the 9th International Conference on Intelligent Tutoring Systems, 353-362.

[70] Cocea, M., Hershkovitz, A. and Baker, R.S.J.D. (2009). The Impact of Off-task and Gaming Behaviors on Learning: Immediate or Aggregate? In Proceedings of the 14th International Conference on Artificial Intelligence in Education, 507-514.

[71] Jeong, H. and Biswas, G. (2008). Mining Student Behavior Models in Learning-by-Teaching Environments. In Proceedings of the 1st International Conference on Educational Data Mining, 127-136.

[72] Britos, P., García-Martínez, R. (2009). Propuesta de Procesos de Explotación de Información. Proceedings XV Congreso 
Argentino de Ciencias de la Computación. Workshop de Base de Datos y Minería de Datos. Págs. 1041-1050. ISBN 978-89724068-4-1.

[73] Romero, C., Porras, A.R., Ventura, S., Hervás, C., Zafra, A. (2006). Using sequential pattern mining for links recommendation in adaptive hipermedia educational systems. In International Conference Current Developments in TechnologyAssisted Education. Sevilla, Spain (pp.1016-1020).

[74] Romero, C., Ventura, S. (2006). Data mining in e-learning, Southampton, UK: Wit Press.

[75] MSU (2014). Computer Science and Engineering - Michigan State University. http://www.cse.msu.edu. Último acceso octubre 2014.

[76] Tan, P., Steinbach, M., Kumar, V. (2006). Introduction to Data Mining. Pearson-Addison Wesley Publishers, Boston, USA.

[77] Dekker, G. W., Pechenizkiy, M., \& Vleeshouwers, J. M. (2009). Predicting Students Drop Out: A Case Study. International Working Group on Educational Data Mining.

[78] Saavedra-Martínez, P., Pollo-Cattaneo, F., Rodríguez, D., Britos, P., \& García-Martínez, R. (2012b). Proceso de identificación de errores de apropiación de conceptos basado en explotación de información. In VII Congreso de Tecnología en Educación y Educación en Tecnología.

[79] Saavedra Martínez, P., Pollo Cattaneo, M. F., Pytel, P., Rodríguez, D., García Martínez, R. (2012a). Detección de problemas de aprendizaje basado en explotación de información.

[80] Cigliuti, P., Pollo Cattaneo, M. F., García Martínez, R. (2012). Procesos de identificación de comportamiento de comunidades educativas centradas en EVEAs. In XIV Workshop de Investigadores en Ciencias de la Computación.

[81] Deroche, A., Pytel, P., Pollo Cattaneo, M. F. (2013). Propuesta de mejora en asignatura de grado mediante Explotación de Información. In VIII Congreso de Tecnología en Educación y Educación en Tecnología.

[82] Quinlan J. (1990). Learning Logic Definitions from Relations. Machine Learning, 5:239-266.

[83] Delling, R.M. (1987). Towards a theory of distance education. ICDE Boulletin, 13, pp. 21-25.

[84] Holmberg, B. (1989), Theory and Practice of Distance Education.

[85] Sherman, B. Y Judkins, P. (1992), Glimpses of Heaven, Visions of Hell. Londres, Hodder \& Stoughton.

[86] Pedró, F. (1997), Didactic design, production and distribution of study materials in open higher education. A case-study on the transition from printed materials to digital media. Paper submitted to the ICDE Conference, Pennsylvania State University

[87] Alsina, C. (1997). Tutoring versus academic counselling in open and distance learning. A case-study on the redefinition of tutoring in a virtual campus. Paper submitted to the ICDE Conference, Pennsylvania State University.

[88] Herin, D. Sala, M. Pompidor, P. (2002). Evaluating and Revising Courses from Web Resources Educational. In Int. Conf. on Intelligent Tutoring Systems, Spain (pp. 208-218).

[89] Ortigosa, A., Carro, R.M. (2003). The Continuous Empirical Evaluation Approach: Evaluating Adaptive Web-based Courses. In Int. Conf. User Modeling, Canada (pp. 163-167).

[90] Gaudioso, E., Talavera, L. Data mining to support tutoring in virtual learning communities: experiences and challenges. Data mining in e-learning. Eds. Romero, C, Ventura, S., Southampton, UK: Wit Press. (pp. 207-226).

[91] Brusilovsky, P., Peylo, C., (2003). Adaptive and intelligent webbased educational systems. International Journal of Artificial Intelligence in Education, 13, 156-169.

[92] Cole, J. (2005). Using Moodle. O’Reilly.
[93] Mostow, J., Beck., J. (2006). Some useful tactics to modify, map and mine data from intelligent tutors. In Journal Natural Language Engineering, 12 ,2, 195-208.

[94] Mostow, J., Beck, J., Cen, H., Cuneo, A., Gouvea, E., Heiner, C., (2005). An educational data mining tool to browse tutorstudent interactions: Time will tell! In Proceedings of the Workshop on Educational Data Mining, Pittsburgh, USA (pp. 15-22).

[95] Zaïane, O., Luo, J. (2001). Web usage mining for a better webbased learning environment. In Proceedings of conference on advanced technology for education, Banff, Alberta (pp. 60-64).

[96] Martins, S. (2014). Derivación del Proceso de Explotación de Información Desde el Modelado del Negocio. Revista Latinoamericana de Ingeniería de Software, 2(1): 53-76, ISSN 2314-2642

[97] Sowa, J. (1992). Semantic Networks. En Encyclopedia of Artificial intelligence (Editor S. Shapiro, 2da edicion). Wiley \& Sons. ISBN 978 - 0471503071.

[98] García Martínez, R., Britos, P. (2004) Ingeniería de Sistemas Expertos. Editorial Nueva Librería. ISBN 987 - 1104 - 15 - 4

[99] Cuzzani, Karina. (2014). Proceso de Evaluación Constante: "Una herramienta indispensable en el momento de re-definir Proyectos de Educación Semi-Presencial", Tesis de Maestría de Educación a Distancia. Universidad de Morón. Facultad de Filosofía, Ciencias de la Educación y Humanidades. Versión preliminar facilitado por la autora.

[100] PROMEI. (2014). Programa de Mejoramiento para la Enseñanza de la Ingeniería. http://portales.educacion.gov.ar/spu/ calidad-universitaria/proyectos-de-mejoramiento/promei-i-y-ii/. Último acceso octubre 2014.

[101] Ord1129. (2014). Ordenanza de la Universidad Tecnológica Nacional N 1129 "Cursado Intensivo". Secretaría Académica UTN-FRBA http://academica.frba.utn.edu.ar/ordenanzas/1129 cursado_intensivo.pdf. Último acceso octubre 2014.

[102] DISI. (2014). Departamento de Ingeniería en Sistemas de Información. Universidad Tecnológica Nacional - Facultad Regional Buenos Aires. http://sistemas.frba.utn.edu.ar Último acceso octubre 2014.

[103] Raus, N. A., Lujan, F. N., Deroche, A., Vegega, C., Pytel, P., \& Pollo-Cattaneo, M. F. (2013) Aplicación del Proceso de Ponderación de Reglas de Pertenencia a Grupos en Evaluaciones Finales en Carreras de Grado. Memorias del 1er Congreso Nacional de Ingeniería Informática / Sistemas de Información. ISSN 2347-0372.

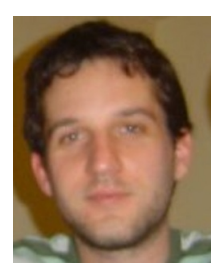

Pablo Cigliuti. Es Ingeniero en Sistemas de Información por la Universidad Tecnológica Nacional (Facultad Regional Buenos Aires), y Candidato a Magister en Tecnología Informática Aplicada a la Educación por la Facultad de Informática de la Universidad Nacional de La Plata. Es Profesor Adjunto en el Departamento de Ingeniería de Sistemas de Información de la Facultad Regional Buenos Aires de la Universidad Tecnológica Nacional. Es Investigador Tesista de Maestría en el Grupo de Investigación en Sistemas de Información del Departamento de Desarrollo Productivo y Tecnológico de la Universidad Nacional de Lanús. Su área de investigación es Explotación de Información aplicada a Educación. 